\title{
ESTRUTURA E REATIVIDADE EM MICELAS
}

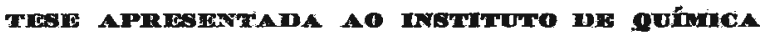

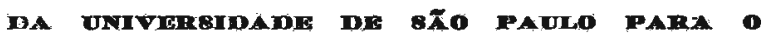

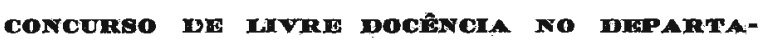
MIRNTO DE BROQUÉLICA. 
DEDICATÓRIA E AGRADECIMENTOS

A los idos, los perdidos, sobretodo aquelios que restaron y los encontrados que son pocos,

$$
\text { pero sabrosos! }
$$


A todos os que fazem o meu dia a dia conti nuar sendo uma aventura e aqueles que acreditam que o calor de uma relação não diminui a criatividade e, portanto, são capazes de distinguir frieza de competência.

Este trabalho foi realizado com o apoio de: Fundação de Amparo à Pesquisa do Estado de são Paulo (FAPESP) (BIOQ/FAPESP, 76/401);

Conselho Nacional de Desenvolvimento Cientifico e TecnológiCo (CNPq) (7186/75);

UNESCO (RLA 78/024,15) e

OEA (Projeto Multinacional de Bioquimica). 


\section{SIMBOLOS E ABREVIATURAS}

$\alpha$

grau de dissociação da micela

$a_{n} \quad$ desdobramento hiperfino isotrópico

AMA $\quad S$-acetil- $\beta$-mercaptoetilamina

$\mathrm{C}_{\mathrm{T}} \quad$ concentraçãQ total de detergente

$C_{D} \quad$ concentração de detergente micelizado

CMC concentração micelar crîtica

COA Coenzima A

CSL o derivado $\mathrm{N}$-oxil-4,4' dimetiloxazolidina de coles tan-3-ona

CTAB brometo de hexadecil trimetilamônio

DNFB 2,4-dinitrofluorobenzeno

DTNB ácido 5,5'-ditiobis (4-nitrobenzóico)

E - coeficiente de absorção molar

eq. $\quad$ equação

esr ressonância de spin eletrônica

GSH glutationa

$k_{\Psi} \quad$ constante de velocidade observada (ou observável)

$\mathrm{k}^{\mathrm{O}} \quad$ constante de velocidade na fase aquosa

$k_{2} \quad$ constante de velocidade de segunda ordem 


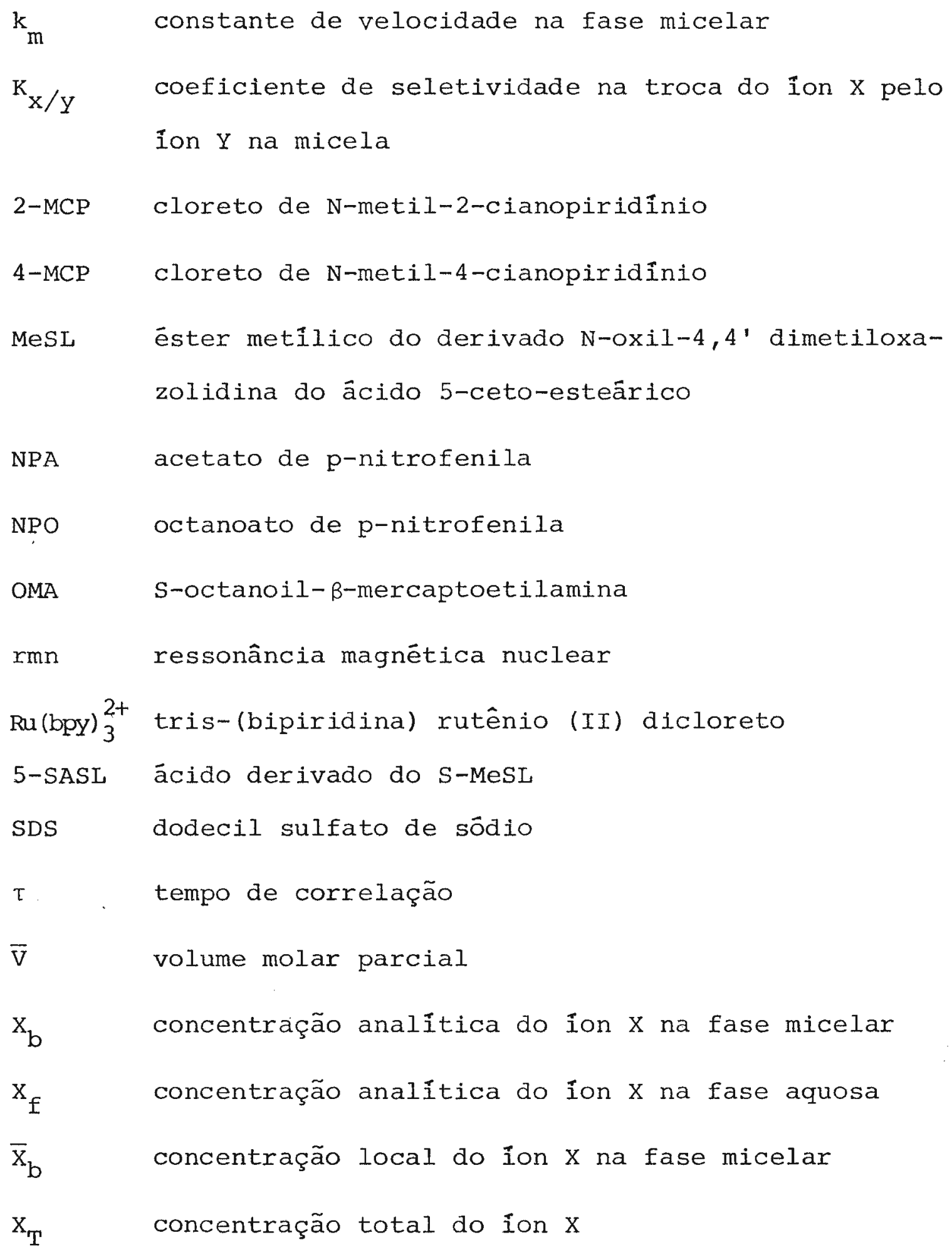


1. Preâmbulo $\ldots \ldots \ldots \ldots \ldots \ldots \ldots \ldots \ldots \ldots \ldots \ldots \ldots \ldots$

2. Introdução $\ldots \ldots \ldots \ldots \ldots \ldots \ldots \ldots \ldots \ldots \ldots \ldots \ldots \ldots \ldots \ldots$

2.1. Efeito de micelas nas reações de 2,4-dinitrô fluorobenzeno com tiofenōxido e fenôxido. ..... 3

2.2. Efeito de detergentes na transferência intra molecular de acila (S para $N$ ) em $S$-acil-B-mer captoetilaminas. $\quad \ldots \ldots \ldots \ldots \ldots \ldots \ldots \ldots$

2.3. Efeito de brometo de hexadeciltrimetilamônio na tiólise de acetato de p-nitrofenila. ...... 7

2.4. Troca iônica em soluções micelares. Sistemas tamponados. ..................... 9

2.5. Estudos de ressonância paramagnētica eletrôní ca da estrutura e propriedades dinâmicas de agregados de detergentes. .............12

3. Parte Experimental .................... 15

3.1. Materiais ........................ 15

3.2. Métodos $\ldots \ldots \ldots \ldots \ldots \ldots \ldots \ldots \ldots \ldots \ldots \ldots \ldots$

3,2.1. Mētodos analîticos ............ 16

3.2.2, Cinética .................... 17

3.2.2.1. Hidrólise ............. 17

3.2.2.2. Reações de fenóxido e tiofenó xido com DNFB. ........... 17 
$3,2,2,3$, Transferência intramolecu lar de acila ........... 18

3,2.2.4. Tiôlise de NPA ........... 18

3.2.3. Determinação do grau de dissociação .. 19 $3.2,3.1$, Fenol .................. 19

3.2.3.2. Determinação do $\mathrm{pK}_{\mathrm{ap}}$ dos tiofenóis

3.2.4. Determinação das constantes de distrí buição dos tiofenóis entre as fases a

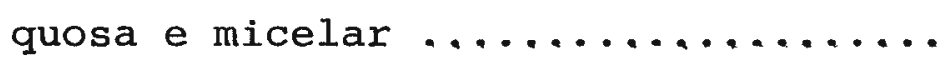

3.2.5. Experimentos de ressonância paramagnể tica eletrônica.................. 23

3.2.6. Medidas de fluorescência e determinação da relação de produtos na hidrólí se de cianopiridínios ........... 24

3.2.7. Espectro diferencial ........... 25

4. Resultados .......................... 27

4.1. Reações de DNFB em micelas ............... 27

4.2. Reações de S-acil-ß-mercaptoetilaminas ..... 36

4.3. Tiölise de NPA ..................... 48

4.4. Sistemas micelares tamponados ........... 56

4.5. Análise de micelas usando sondas de spin.... 60

5. Discussão ,........................ 77

5.1. Reações de DNFB em micelas .............. 77 
5.2. Reações de $s-a c i l-\beta$-mercaptoetilaminas ........ 84

5.3, Tiólise de NPA ...................... 90

5.4, Sistemas micelares tamponados ............. 93

5.5. Análise de micelas usando sondas de spin ...... 102

6. Conclusões $\ldots \ldots \ldots \ldots \ldots \ldots \ldots \ldots \ldots \ldots \ldots \ldots \ldots \ldots \ldots \ldots \ldots \ldots 12$

7.1. Resumo $\ldots \ldots \ldots \ldots \ldots \ldots \ldots \ldots \ldots \ldots \ldots \ldots \ldots \ldots \ldots \ldots \ldots 15$

7.2. Summary $\ldots \ldots \ldots \ldots \ldots \ldots \ldots \ldots \ldots \ldots \ldots \ldots \ldots \ldots \ldots$

8. Referências .......................... 121 
1. PREÂMBULO

Nesta Tese se apresentam alguns dos resultados de uma linha de pesquisa sobre micelas, modelo este que permite compreender e explicar a modificação biológica de reatividade quimica. O estabelecimento desta linha de inves tigação teria sido impossỉvel sem a participação de acadêmí cos e profissionais competentes que trabalham lou trabalharam) em nosso grupo. Por estrita ordem de aparição eles são: P.M. Monteiro; E.V. Delarosa; M. Lutfi; I.M. Cuccovia; E.H. Schröter; T. Bauch; E. Baumgarten-Rezende; M.J. Politi e R.V. Aleixo.

A evolução da nossa produção nesta ârea foi estimulada por colaboração estreita com a Prof. Dr. S. / Schreier e o Prof. Dr. F.H. Quina. Esta colaboração se man tēm atē hoje e, nesta altura jā nos acostumamos a considerar boa parte do trabalho como uma criação coletiva.

o modelo escolhido para estudar a modificação de reatividade foi o sistema de interfaces formadas a par tir da agregação, em solução aquosa, de compostos anfifili cos: micelas. A formação, estrutura e propriedades das mi celas, bem como a cinētica de reações em fase micelar fo ram analizadas em vārias revisões recentes (Cordes e Dunlap, 1969; Bunton, 1973, 1976; Fendler e Fendler, 1975; Mittal, 1977; Cordes, 1978, Chaimovich, 1979). Acredito, portanto, 
que uma introdução geral sobre propriedades de micelas e da cinētica de reações em fase micelar se faz desnecessā ria. Por consequência, a Introdução desta tese è diretamente pertinente aos assuntos a serem tratados na parte de Resultados e discutidos posteriormente. 
2. INTRODUÇÃO

2.1. Efeito de micelas nas reações de 2,4-dinitrofluoroben zeno com os ânions fenôxido e tiofenōxido ${ }^{1}$.

o 2,4-dinitrofluorobenzeno (DNFB) è um reagen te importante para a modificação de aminoācidos, e o seguin te estudo é uma extensão de trabalhos anteriores sobre o efeito de micelas no deslocamento do ín fluoreto por nu cleófilos contendo oxigênio ou nitrogênio (Herries e col. , 1964; Bunton e Robinson, 1969, 1970).

o ataque nucleofílico de ions tiolato ou fenolato sobre halonitrobenzenos na ausência de micelas foi es tudado extensivamente (Bunnet e Merrit, 1957; Bunnet, 1958; Ross, 1963; Miller, 1968).

Os compostos aromáticos, especialmente aqueles que possuem substituintes que aumentam a densidade eletrôni ca do anel, interagem fortemente com ions tetra-alquilamô nio (Ericksson e Gilberg, 1966; Fendler e Patterson, 1971 ; Bunton e col., 1973; Bunton e Minch, 1974) e as micelas ca tiônicas aceleram o ataque nucleofílico por ânions.Esperáva mos, portanto, que micelas de um surfactante catiônico, o brometo de hexadeciltrimetilamônio (CTAB), aumentassem a velocidade das reações de DNFB com ions fenóxido e tiofenôxi do.

1 Chaimovich e col., 1975. 


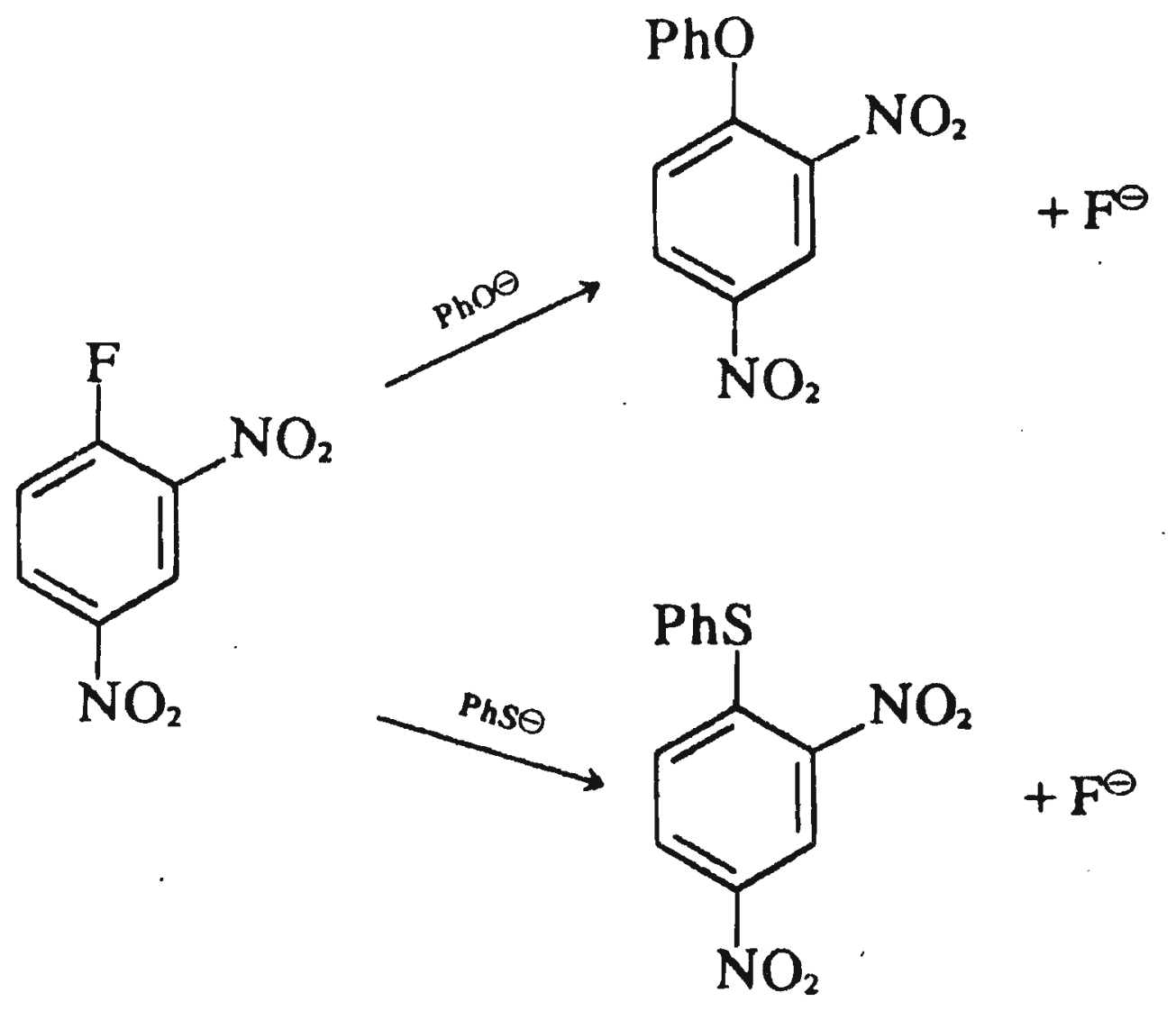

As reações de $n$-alquil mercaptanas com acetato de p-nitrofenila são fortemente aceleradas por micelas ca tiônicas e o aumento de velocidade cresce bruscamente com o 
aumento do número de carbonos no grupo n-alquila. Entretan to, neste sistema è difícil separar os efeitos das micelas sobre a ionização do tiol daqueles sobre a reatividade do ion tiolato (Tagaki e col., 1972). Em outro estudo de gran de interesse, Heitman (1968) mostrou que micelas funcionais, derivados de cisteína, são agentes desacilantes muito eficientes.

2.2. Efeito de detergentes na transferência intramolecular de acila $(S \rightarrow N)$ em $S-a c i l-\beta$-mercaptoetilaminas ${ }^{2}$.

A utilidade e as limitações do modelo micela / para a compreensão do mecanismo catalítico de enzimas tem sido discutido (Bunton, 1973; Cordes, 1973, 1978; Fendler e Fendler, 1975; Chaimovich, 1979). Desde que a distorção de uma parte do substrato tem se mostrado um fator importante em algumas reações catalisadas por enzimas (Jencks, 1969 , 1975) poder-se-ia esperar que o estudo de reações intra-moleculares em micelas pudesse servir como modelo desta dis torção.

Neste sentido estudamos o efeito de detergentes na transferência de acila intramolecular de S-para N-.. em mercaptoetilaminas, cujo mecanismo de reação é bem conhecido (Wieland e Horning, 1956; Martin e col., 1959; Martin e Parcell, 1961; Martin, Hedrick e Parcell, 1964; Martin e He 2 Cuccovia e col., 1977. 
drick, 1962; Barnett e Jencks, 1969). Nos primeiros trabaIhos de Martin e colaboradores (1959) demonstrou-se que a transferência de acila ocorre pela formação de um intermediário cíclico do tipo proposto para a reação de transferên cia de acila de $\mathrm{S}-$ para O- na sêrie $\mathrm{CH}_{3} \mathrm{COS}\left(\mathrm{CH}_{2}\right)_{\mathrm{n}} \mathrm{OH}$. Em pH superior a 6, a partição do intermediārio cíclico até / material de partida pode ser desprezada, resultando na for mação de amida como o único produto (Foye, Duvall e Mick les, 1962). Mais tarde foi proposto que o passo limitante da reação è uma transferência intramolecular de prōtons / (Barnett e Jencks, 1969).

A velocidade da transferência de acila de $\mathrm{S}$ para $\mathrm{N}$ em $\mathrm{S}$-acil- $\beta$-mercaptoetilamina é insensível a altas / concentrações de sal ou de solvente como o butanol ( Barnett e Jencks, 1969). Estes fatos facilitam a anālise de efeito de detergentes nesta reação complexa uma vez que / nem a alta força iônica efetiva da camada de stern (veja p. ex. Chaimovich, 1979), nem a baixa constante dielétrica / desta regiaõ (veja p. ex. Cordes, 1978) deveriam afetar sig nificativamente a velocidade da reação.

Os dados sobre o efeito de detergentes na ve locidade de transferência de acila $S$ a $N$ apresentados $\underline{\text { a }}$ qui demonstram uma significativa inibição por detergentes negativos, um efeito negligível em mịcelas não iônicas e uma pequena aceleração em ricelas positivas. 
2.3. Efeito de brometo de hexadeciltrimetilamônio na tióli se de acetato de $\mathrm{p}$-nitrofenila ${ }^{3}$.

Somente um nümero limitado de nucleófilos par ticipam, inequivocamente, na catālise enzimática covalente (Jencks, 1969). Entre estes, o grupo -SH da cisteína mos tra uma reatividade imprevisivelmente alta quando este se encontra no sítio ativo de enzimas "SH" como papaína ( Le wis, Johnson e Shafer, 1976), ficina (Metrione, Johnston e Seng, 1967), bromelina (Husain e Lowe, 1970) ou gliceraldeí do-3-fosfato desidrogenase (Byers, 1977). A reatividade nu cleofilica dos grupos $\mathrm{SH}$ em proteỉnas pode variar desde / aqueles que são extremamente reativos atê aqueles que são não-reativos ou "mascarados" (Friedman,1973; Jocelyn, 1972). Embora o mecanismo desta ativação não esteja esclarecido, existe um consenso geral que atribui esta ampla variedade de reatividade dos grupos $\mathrm{SH}$ a microambientes distintos em cada caso particular. Compostos de baixo peso molecular co mo coenzima $A(C O A)$ ou glutationa (GSH) que possuem um grupo $\mathrm{SH}$, e agem como coenzimas, apresentam também uma reatividade extremamente alta em uma sērie de reações enzimāticas (Friedman 1973; Jocelyn, 1972). Desde que a reatividade dos grupos SH do GSH e COA é previsỉvel (Shinkai e Kuni take, 1976) (em comparação com outras mercaptanas), o gru 3 Cuccovia e col., 1978 
po SH de GSH e COA deve ser "ativado" pela apoenzima, de forma similar aos grupos sH do sitio ativo.

Desde que as micelas servem como modelo do (possivel) papel das interfaces carregadas, e/ou neutras, na reatividade nucleofilica o estudo dos efeitos micelares sobre a reatividade de grupos SH tem relevância para se entender a questão das diferenças de reatividade encon tradas em sistemas biológicos. Existem jâ evidências que mostram que micelas podem afetar (e muito, em alguns casos) a velocidade de diferentes reações de grupos SH / (Shinkai e Kunitake, 1976; Heitman, 1968; Tagaki e col., 1972; Niehaus, 1974; Chaimovich e col., 1975). A velocidade de reação de $\mathrm{N}$-dodecanoil-dl-cisteina (DCS) com clo roacetamida, iodoacetamida e acetato de p-nitrofenila / (NPA) é aumentada 5-7, 60-100 e 100-200 vezes, respectivamente, quando se adiciona CTAB ao sistema (Heitman, / 1968). Por outro lado, a incorporação de DCS em micelas negativas conduz a um decréscimo na reatividade aparente do grupo SH (Heitman, 1968). A velocidade de reação de alquilmercaptanas com NPA è acelerada até $10^{4}$ vezes pela adição de detergentes do tipo brometo de alquil trime tilamônio (Tagaki e col., 1972). A formação de micelas mistas de tióis (como $\beta$-mercaptoetilamônio) e ācido / oleico tem sido proposta para explicar a isomerização / cis-trans de äcido oleico catalisada por tiois (Niehaus, 
1974). CTAB produz um aumento de velocidade de 1100 vezes na velocidade de reação de tiofenōxido com 2,4-dinitrofluo robenzeno (Chaimovich e col., 1975). A velocidade de tiólise de NPA por GSH e COA é acelerado por CTAB perto de 100 vezes (Shinkai e Kunitake, 1976).

o aumento de velocidade observado em muitas reações após a adição de micelas pode ser explicado, às vezes, por concentração dos reagentes na fase micelar e mudanças no pK aparente do nucleófilo sem ser necessārio postular uma mudança na reatividade intrínseca do nucleôfilo na fase micelar (Berezin, Martinek e Yatsimirski, / 1973). Antes de se atribuir o efeito observado na velocidade a mudanças de reatividade (veja Martinek e col., 1975, para uma análise pertinente) as velocidades devem ser cor rigidas tanto para concentração de substratos bem como pa ra compensar a possível distribuição diferente das formas iônicas do nucleófilo nas fases aquosa e micelar.

2.4. Troca iônica em soluções micelares: Sistemas tampona $\operatorname{dos}^{4}$.

A distribuição de ions $\mathrm{H}^{+}$ou ${ }^{-}$OH entre as fa ses aquosa e micelar é uma função sensivel das concentra*ções analỉticas de ácido ou base forte presentes no siste 4 Quina e col., 1979 
ma, da natureza e concentração total de detergente $\left(C_{T}\right)$ e do conteûdo iônico do meio (Bunton e Wolfe, 1974; Bunton, Rivera e Sepūlveda, 1978; Bunton, Romsted e Savel1i, 1979; Quina e Chaimovich, 1979; Chaimovich, 1979; Chaimovich e col., 1979). Foi possivel determinar experimentalmente a fração de $\mathrm{H}^{+}$ligada à fase micelar de sDS (Bunton, / Romsted e Savelli, 1979) e a fraçäo de - OH ligada à fase micelar de CTAB (Chaimovich e col., 1979) na ausência de tampão, em função de $C_{\mathrm{T}}$ e sal adicionado.

Apesar de se esperar que o uso de um tampão simplificasse o sistema, especialmente no estudo cinêtico de reações em fase micelar que envolvem $\mathrm{H}^{+} \mathrm{Ou}^{-} \mathrm{OH}^{-}$esta expectativa não correspondeu à realidade (veja p.ex. Cordes, 1978). Vārias questões fundamentais contribuem para a complexidade do sistema micelar tamponado:

(1) até que ponto os componentes do tampão / interagem com a fase micelar e até que ponto a presença / de micelas afeta o equilíbrio do tampão e a sua capacidade tamponante (veja p.ex. Bunton e Minch, 1974 para efeito de micelas no equilỉbrio tampão de ácidos carboxỉlicos);

(2) qual a relação entre o pH na fase aquosa e a concentração de ions ligados, $\overline{\mathrm{H}}_{\mathrm{b}}$ ou $\overline{\mathrm{OH}}_{b^{\prime}}$ na fase mi celar;

(3) as concentrações locais de $\mathrm{H}^{+}$ou ${ }^{-} \mathrm{OH}$ na fase micelar na presença de tampão em diversas condições 
se mantêm constantes?

Se os componentes do tampão não interagem com a fase micelar e a capacidade do tampão não é excedida, è evidente que o pH intermicelar se mantem constante sob con dições diversas (p.ex. quando muda $C_{T}$ ou a concentração sa lina). Mostramos recentemente que na presença de um sistema tamponante "adequado" e conhecidas as constantes de tro ca para $\mathrm{H}^{+}$ou ${ }^{-} \mathrm{OH}$ é possîvel calcular a dependência entre as concentrações locais de ions $\mathrm{H}^{+}$ou ${ }^{-} \mathrm{OH}$ ligados e trocá veis $\left(\mathrm{H}_{\mathrm{b}}\right.$ ou $\left.\mathrm{OH}_{\mathrm{b}}\right)$ e a $\mathrm{C}_{\mathrm{T}}$. Pudemos, assim, analizar o compor tamento cinético de reações que envolvem esses îns em soluções tamponadas de detergentes iônicos (Quina e Chaimo .. vich, 1979) (p.ex. - $\mathrm{OH}$ em CTAB).

Nesta parte do trabalho analizaremos uma sé rie de experimentos simples efetuados em soluções micelares de CTAB que demonstram, de forma inequivoca, que o tampona mento na fase aquosa não implica em tamponamento na superfície micelar. Em condições nas quais se pode demonstrar / diretamente que o tampão mantêm o pH intermicelar constante, a concentração local de íons -oH "ligados" na fase micelar $\left(\overline{\mathrm{OH}}_{\mathrm{b}}\right)$ varia com $\mathrm{C}_{\mathrm{T}}$ acima da CMC. 
2.5. Estudos de ressonância paramagnētica eletrônica da estrutura e propriedades dinâmicas de agregados de detergente ${ }^{5}$.

Em um grande nümero de trabalhos têm-se uti lizado a tēcnica de sondas de spin (e $s$ ) para investí gar as propriedades estruturais e dinâmicas das micelas (Waggoner, Griffith e Christensen, 1967; Waggoner,Kieth e Griffith, 1968; Ohnishi, Cyr e Fukushima, 1970; Fox , 1971; Oakes, 1971; Atherton e Strach, 1972; Nakagawa e Jizomoto, 1972; Brotherus e THrmala, 1973). Temos aplica do esta técnica para examinar vários aspectos da agregação de detergentes. Neste contexto investigamos (1) a concentração micelar crîtica (CMC); (2) a interação entre micelas e nucleöfilos reativos; (3) o mecanismo da forma ção de micelas e (4) o mecanismo de distribuição de solụ tos hidrofóbicos em micelas. (Ernandes, Schreier e Chaimovich, 1976; Ernandes, Chaimovich e Schreier, 1977). As micelas são excelentes modelos para se estudar os efeitos da microheterogeneidade sobre reações químicas (Chaimo vich, 1979 e referências ali citadas). Os problemas na interpretação dos dados surgem às vezes, do desconheci mento do grau de ligação do substrato à micela (Chaimo vich, 1979; Quina e Chaimovich, 1979). Temos examinado a ${ }^{5}$ Schreier e col., 1978 
interação entre um substrato (o Ion tiofenóxido) e um detergente (CTAB), com o propósito de detectar (possíveis) mudanças estruturais nas micelas de CTAB produzidas pela adição do ânion orgânico.

A existência de agregados prē-micelares foi descrita em vārios casos. Esta agregação se observa especialmente com sais biliares (Fontell, 1971) e sais de alcanoatos (Eagland e Franks, 1965; Danielson e Stenius, / 1971; Lindman e Brun, 1973; Gustavsson e Lindman, 1975). A formação de dỉmeros (Mukerjee, Mysels e Dulin, 1958) e agregados maiores (Lindman, Kamenka e Brun, 1974) foi su gerida para o SDS. Utilizando e s $r$ encontramos evidên cias diretas que mostram a existência de agregação prê-mí celar para o SDS abaixo da CMC (Ernandes, Chaimovich e Schreier, 1977).

A distribuição de solutos altamente hidrofóbicos é importante do ponto de vista das propriedades dí nâmicas das soluções micelares, do estudo das propriedades catalíticas das micelas e, tambēm, da solubilização de so lutos em soluções micelares. As implicações tanto teóricas como práticas da solubilização por detergentes foram analizadas por Elworthy, Florence e MC Farlane (1968). Nos últimos anos o nosso conhecimento sobre sitios de solubilização de substratos em detergentes aumentou de forma / considerável (Fendler e Fendler, 1975; Mittal, 1977). De 
ve-se mencionar, porêm, que o mecanismo de distribuição de substratos insolúveis em âgua tem recebido pouca atenção. Alguns estudos mecanísticos sobre a redistribuição de ãgua em solventes apolares na presença de mice las reversas foram publicados (Menger, Donohue e Williams, 1973; Eicke, Sheperd e Steinmann, 1976). Foi descrito o tempo de permanência de substratos de baixa solubilidade em āgua em sistemas micelares aquosos (Fendler e Fendler, 1975). Na última parte de nosso trabalho apresentamos re sultados que descrevem, preliminarmente, a distribuição mi celar de um substrato extremamente insolūvel em āgua.

As sondas de e s r utilizadas neste trabalho, apesar de não serem molēculas pequenas e esféricas, apresen tam tempos de correlação baixos ( da ordem de $4 \times 10^{-9}$ a té $3 \times 10^{-10}$ segundos ). Assim os espectros de e s.r fo ram analizados utilizando-se um formalismo de estreitamento (Kivelson, 1960; Freed e Frambel, 1963; Freed, 1972).Os espectros indicam, tambēm, que as sondas experimentam um grau de ordenamento baixo que não è mensurável diretamente nos espectros nestes siştemas. Assim, as contribuições de ordem e desdobramento hiperfino causado por prótons foram desprezadas nos cálculos de tempos de correlação. Discutiremos tambēm as contribuições do tempo de correlação rotacional das micelas nas linhas espectrais observadas. 
3. PARTE EXPERIMENTAL

3.1. Materiais

Brij. 58 (Sigma Chem. Co. Lote 8.0-1150) Acetato de p-nitrofenila (Sigma Chem. Co.), ácido 5,5' ditiobis(p-ní trobenzóico) (BDH, Biochemicals), CTAB (Merck, Darmstadt) foi recristalizado (x 3) de acetona-etanol, SDS ( $\mathrm{BDH}$, Poole) foi recristalizado em etanol.

Tiofenol (Eastman Kodak Co) foi destilado sob pressão reduzida. p-Metoxitiofenol (Aldrich Chem. Co) foi utilizado sem purificação. p-Metil e p-clorotiofenol (AIdrich Chem. Co) foram recristalizados de etanol-ägua. Acetato de tiofenila foi preparado a partir de tiofenol e anidrido acético e purificado por destilação sob pressão reduzida (p.e. $110^{\circ} \mathrm{C}, 13 \mathrm{~mm} \mathrm{Hg}$ ) (Böhme e Schran, 1949). S-Acetilmercaptoetilamina (AMA) foi sintetizada pelo mêtodo de Wie land e Bokelman (1952) (p.f. 137-138; lit. 137, wieland e Bokelman, 1952). S-octanoil-B-mercaptoetilamina (OMA) foi sintetizada de acordo com Foye, Duvale e Mickles (1962) a análise de $S$, e os espectros de IR, NMR e UV estão de acordo com a estrutura.

Cloreto de N-metil-2-cianopiridínio (2-MCP) / e N-metil-4-cianopiridínio (4-MCP) foram preparados a par tir dos iodetos correspondentes (Kosower e Patton, 1966) por tratamento com Ag Cl, em āgua acidulada (HCl), a tempe 
ratura ambiente. Após filtração e liofilização, os sais fo ram purificados por extração $\operatorname{com} \mathrm{CH}_{3} \mathrm{CN}$ (Aldrich, qualidade espectroscópica) e secados sob vâcuo. Os coeficientes de extinção molar coincidem com os publicados (Kosower e Pat ton, 1966) e a titulação de cloreto (Schales e Schales,1941) fornece o peso equivalente esperado. Uma amostra pura de octanoato de p-nitrofenila foi fornecida gentilmente pelo Prof.Dr. Omar A. El-Seoud (IQUSP).Tris-(bipiridina) rutê nio (II) dicloreto hexahidrato (Ru(bpy) ${ }_{3}^{2+}$ ) foi usado sem purificação (G. Frederick Smith) .

As sondas de spin: 2,2'-dimetil-N-oxil oxazolidina derivadas do: (1) ácido 5-ceto esteārico (5-SASL), (2) èster metỉlico do ácido 5-ceto esteārico (5-MeSL), (3) $5 \alpha$-androstan-17ß -ol-3-ona (ASL) e (4) colestan-3-ona / (CSL) foram obtidas da Syva, Palo Alto, Califórnia.

3.2. METODOS

3.2.1. Métodos analíticos

A concentração de CTAB foi determinada medindo brometo (Schales e Schales, 1941). A concentração de tióis livres foi determinada com DTNB usando o mêtodo des crito por Ellman (1959). 


\section{$3.2,2$. Cinêtica}

3.2.2.1, Hidrólise. A hidrólise alcalina de 4-MCP foi acom panhada medindo-se o aumento de absorbância (a $269 \mathrm{~nm}$ ) de vido a formação de produtos (Politi e col., 1978, Chaimo vich e col., 1979). A reação correspondente do 2-MCP foi acompanhada de forma semelhante medindo-se a absorbância a 297 nm devida a aparição da N-metil-2-piridona. A hidrólise alcalina de NPA e NPO foi acompanhada medindo-se a ab sorbância do Ion p-nitrofenóxido a $405 \mathrm{~nm}$.

3.2.2.2. Reações de fenóxido e tiofenôxido com DNFB. Todas as reações foram acompanhadas a $25^{\circ} \mathrm{C}$ usando um espectrofotômetro Cary 14 para as reações com fenóxido e um espectro fotômetro de fluxo (Durrum, stopped flow:) para as reações com tiofenóxido. A reação com tiofenóxido foi acompanhada a $350 \mathrm{~nm}$ em tampão borato $\left(1 \times 10^{-2} \mathrm{M}\right) \mathrm{pH} 9,27$. O tiofenol estā completamente ionizado neste pH (Pascal e Tarbell, / 1957; Danehy e Noel, 1960; Kreevoy e col., 1960). A concen tração de DNFB foi $1.25-5 \times 10^{-5} \mathrm{M}$ e a de tiofenol 2,5 -5 $\times 10^{-4} \mathrm{M}$. As constantes de velocidade são a média de 2 a 6 valores. Para as reações com fenóxido a concentração de fenol foi de $1.67-6,67 \times 10^{-4} \mathrm{M}$ e a de DNFB de aproximada mente $1.10^{-4} \mathrm{M}$ ( $\mathrm{pH} 10$, tampão borato). Na ausência de fenōxido ou tiofenóxido a reação de DNFB com hidróxido (pH 
9,27 ou $\mathrm{pH}$ 10) é lenta mesmo na presença de CTAB (Bunton e Robinson, 1969; Bunton e Robinson, 1970).

3.2.2.3. Transferência intramolecular de acila. A cinética desta reação foi acompanhada a $25^{\circ} \mathrm{C}$ (banho circulante Masterline) no compartimento termostatizado de um espectrofotômetro Gilford. A reação foi acompanhada a $229 \mathrm{~nm}$, e os coeficientes de extinção dos tioéstexes coincidem com os descritos (Martin, Hedrick e Parcell, 1964). Todas as reações foram iniciadas pela adição de 10 hL de uma solução / estoque $\left(-10^{-3} \mathrm{M}\right)$ recentemente preparada do tioester.

3.2.2.4. Tiólise de NPA. A tiólise de NPA foi acompanhada/ medindo-se a aparição de p-nitrofenōxido (405 nm) num espec trofotômetro Gilford a $30 \pm 0,2^{\circ} \mathrm{C}$ (banho circulante Masterline). A mistura de reação foi equilibrada a $30^{\circ} \mathrm{C}$ no compartimento de celas e a reação iniciada pela adição de 0,01 ml de uma solução estoque de NPA $\left(1-2 \times 10^{-3} \mathrm{M}\right)$ em $\mathrm{CH}_{3} \mathrm{CN} .0$ volume total de solvente orgânico nunca excedeu $0,8 \%(\mathrm{v} / \mathrm{V})$. Todas as soluçōes foram deaeradas e mantidas sob $\mathrm{N}_{2}$ ou Ar. As constantes de primeira ordem aparente $\left(k_{\Psi}\right)$, obtidas de gráficos de $\log \left(\mathrm{DO}_{\infty}-\mathrm{DO}_{t}\right)$ contra tempo eram lineares por (pelo menos) quatro meias vidas. As constantes de segunda ordem $\left(\mathrm{k}_{2}\right)$ foram obtidas de

$$
k_{2}=\frac{k_{\Psi}-k_{W}}{(\text { RSH })_{T}}
$$


onde $\mathrm{k}_{\mathrm{w}}$ é a constante de primeira ordem observada para a hidrólise espontânea de NPA nas mesmas condições (CTAB , $\mathrm{pH})$ na ausência de tiofenol. $(\mathrm{RSH})_{\mathrm{T}}$ representa a concentra ção total de tiofenol que, nas condições empregadas, está totalmente dissociado.

3.2.3. Determinação do grau de dissociação

3.2.3.1. Fenol. O fenol não se encontra totalmente ioniza do a pH 10 ( o pka do fenol em ägua a $25^{\circ}$ è aproximadamente 10). O surfactante poderia mudar a constante de disso ciação tanto do ácido bōrico (vide adiante) como a do fe nol, e, ao estimax a "catālise" micelax è necessário consi derar estas mudanças. Isto foi feito medindo-se o equili brio entre fenol e fenóxido, por espectrofotômetria, na presença e ausência de CTAB, usando-se tampão borato pH 10 antes da adição de CTAB. O CTAB tem pouco efeito sobre o pH de tampão borato $\left(10^{-2} \mathrm{M}\right)$ que decresce ligeiramente ao se adicionar $1,5 \times 10^{-2} \mathrm{M}$ CTAB (Bunton e Minch, 1974). As proporções relativas de fenol e fenōxido na solução de СТAB e tampão borato foram calculadas medindo-se as absorbâncias de fenol e fenóxido em CTAB e usando-se estes coe ficientes de extinção nos cálculos. 
3.2.3.2. Determinação do $\mathrm{pK}_{\mathrm{ap}}$ dos tiofenóis. o efeito do CTAB no $\mathrm{pK}$ aparente dos tiofenóis foi determinado a uma concen tração ūnica (saturante) de CTAB, Os dados espectrais obtidos para tiofenol e tiofenōxido na presença e ausência de CTAB foram analizados usando-se a equação:

$$
K=\frac{|\mathrm{H}|\left(1-\left(\mathrm{E}_{\mathrm{AH}} / \mathrm{E}_{\Psi}\right)\right)}{\left(\mathrm{E}_{\mathrm{A}}-/ \mathrm{E}_{\Psi}\right)-1}
$$

onde $\mathrm{E}_{\Psi}$ é o coeficiente de extinção observado (igual a absorbância/(RSH) ${ }_{T}$ ) em determinado $\mathrm{pH}$ e comprimento de onda, $E_{A H}$ e $E_{A}$ - são os coeficientes de extinção do tiofenol e tiofenóxido no mesmo comprimento de onda. A lei de Lambert-Beer ê obedecida sob as condições experimentais utilizadas (СтAB $4 \times 10^{-3} \mathrm{M}$, tiofenol c.a. $2 \times 10^{-5} \mathrm{M}$ ).

3.2,4. Determinação das constantes de distribuição de tiofenóis entre as fases micelar e aquosa.

Segundo o modelo de separação de fases (Berezin, Martinek e Yatsimirski, 1973) a constante de distribuição $\left(\mathrm{K}_{\mathrm{a}}\right)$ para ânion tiofenōxido pode ser definida como

$$
\mathrm{k}_{\mathrm{a}} \simeq \frac{\mathrm{c}_{\mathrm{m}}}{\mathrm{c}_{\mathrm{w}}} \overline{\mathrm{v}}
$$

onde $C_{m}$ e $C_{w}$ são as concentraçöes do ânion nas fases mice- 
lar e aquosas respectivamente e $\bar{v} \hat{e}$ o volume molar parcial do detergente micelizado. Usando-se este modelo e assumindo-se que o volume da fase micelar é pequeno em comparação com o volume total da solução pode-se demonstrar que

$$
A_{T}=C_{m} C_{D} \bar{V}+C_{W}
$$

onde $C_{D^{\prime}}$ a concentração de detergente micelizado, è igual a concentração total de detergente $\left(C_{T}\right)$ menos a $C M C$, e $A_{T}$ é a concentração total de tiofenóxido.

Das equações 3 e 4 pode-se demonstrar que

$$
E_{\Psi}=\frac{K_{a} C_{D}}{\left(1+K_{a} C_{D}\right)} E_{m}+\left(1-\frac{K_{a} C_{D}}{1+K_{a} C_{D}}\right) E_{w}
$$

onde $\mathrm{E}_{\mathrm{m}}$ e $\mathrm{E}_{\mathrm{w}}$ são coeficientes de extinção do tiofenóxido / nas fases micelar e aquosa, respectivamente. Rearranjando a eq. 5 obtēm-se uma forma linearizada que permite a determinação de $\mathrm{K}_{\mathrm{a}}$

$$
\frac{1}{E_{\Psi}-E_{w}}=\frac{1}{K_{a}\left(E_{m}-E_{w}\right)} \times \frac{1}{C_{D}}+\frac{1}{\left(E_{m}-E_{w}\right)}
$$

Resultados típicos mostrando o efeito do CTAB no espectro de tiofenóxidos e gráficos da eq. 6 são apresentạ dos na figura 1 . 

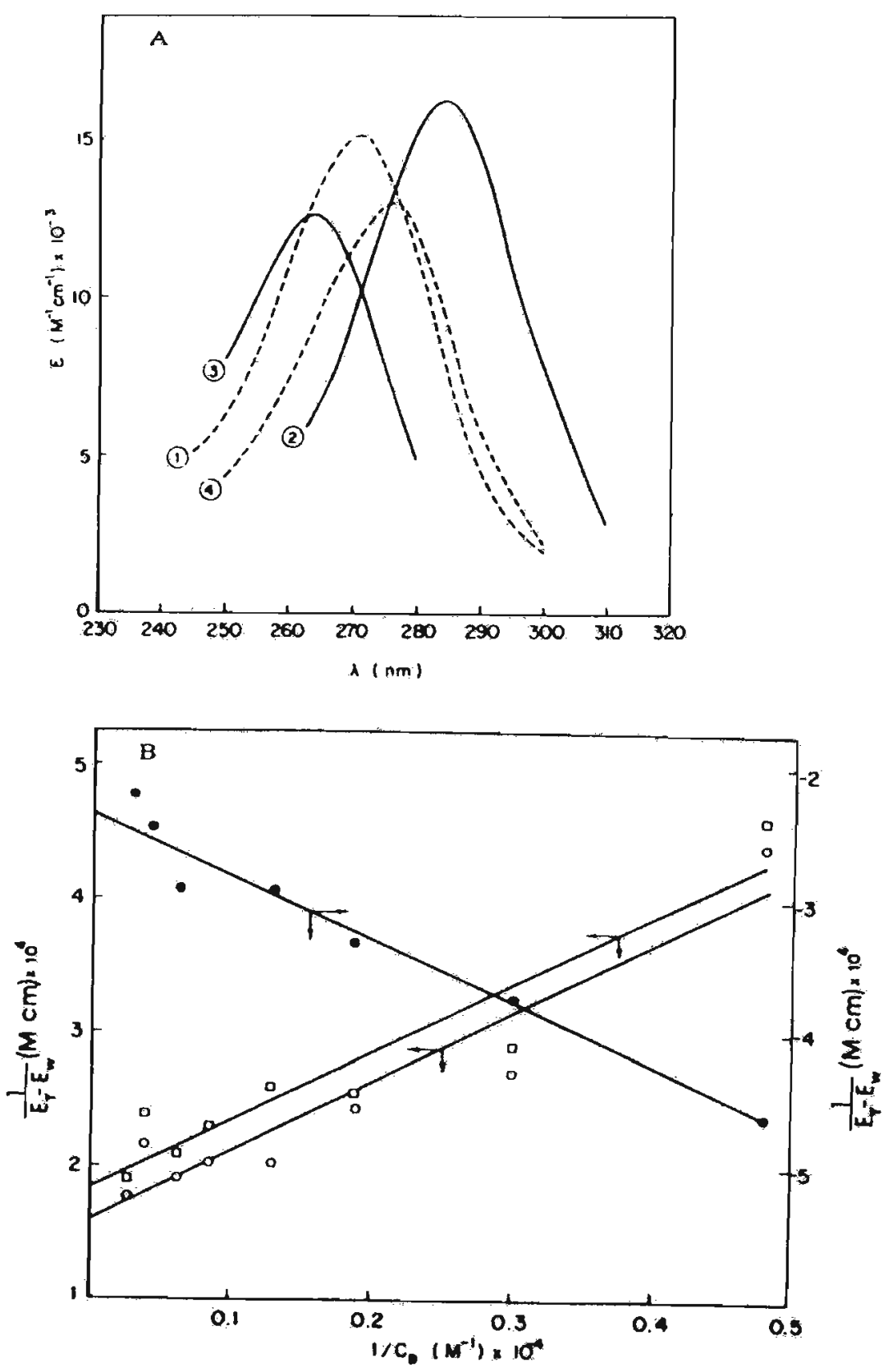

Figura 1. Efeito de $C T A B$ no espectro de ânions derivados de tiofenóis. Tođos os espectros fó ram obtidos em tampão borato $2 \times 10^{-2} \mathrm{M} \mathrm{pH} 8,5$. $A$ : (1) p-clorotiofenol; (2) p-clorotiofenol con $4 \times 10^{-3} \mathrm{M} \mathrm{CTAB;} \mathrm{(3)} \mathrm{p-metiltiofenol;} \mathrm{(4)} \mathrm{p}$-metil tiofenol com $4 \times 10^{-3} \mathrm{M}$ CTAB. B: Determinação de $\mathrm{K}_{\mathrm{a}}$ de tiofenóxido de acordo com a eq. 6 : (0) $250 \mathrm{~nm} ;$ (O) $285 \mathrm{~nm}$; (a) $275 \mathrm{~nm}$. 
As constantes de distribuição das formas pro tonadas dos tiofenöis foram calculadas, como descrito por Yatsimirski, Martinek e Berezin (1971), a partix do efeito do CTAB no pK dos tiofenóis.

3.2.5. Experimentos de Ressonância paramagnética eletrônica

As amostras foram preparadas evaporando-se / uma solução clorofórmica da sonda num tubo de ensaio sob uma corrente de $\mathrm{N}_{2}$ e retirando-se o solvente restante sob / vácuo. Neste tubo se adiciona a quantidade desejada de CTAB em água ou tampão borato $\left(1 \times 10^{-2} \mathrm{M}\right.$ pi 9,0$)$. A mistura foi agitada por (aproximadamente) $5 \mathrm{~min}$ (quando a sonda usada / era 5-SASL, 5-MeSL ou ASL). As soluções assim obtidas foram usadas como estoque obtendo-se as concentraçôes menores por diluição.

A solução estoque de CSI/SDS foi preparada / de forma semelhante, mas estendendo-se o periodo de agita ção (lenta, tubo fechado) por 24 hs. A solução estoque CSL/ /CTAB foi preparada adicionando-se 3,00 ml de uma solução / de CTAB em àgua degaseada ao tubo contendo o filme de CSI. Esta solução foi submetida a ultrasson (Virsonic, Modejo 150 Cell Disrupter, potência "60", microsonda) usando pulsos de 10 segundos por períados de 250 ou 500 segundos. As soluções assim obtidas denominam-se $S-250$ e S-500, respectivamente. 
A concentração de CSL em solução aquosa foi determinada apōs extração da sonda com clorofórmio. As so luções aquosas contendo CSL foram extraỉdas com clorofór mio até não apresentarem sinal de e s r. (3 vezes). Os ex tratos clorofórmicos foram reunidos, concentrados sob $\mathrm{N}_{2}$ e, finalmente o volume foi ajustado com clorofórmio. A concen tração de CSL na solução clorofórmica foi determinada medin do-se a altura da linha central do espectro de e s $r$, usan do uma curva de calibração adequada.

A concentração de CTAB retida nos experimen tos de filtração foi determinada por condutimetria (Beckman Instruments) após extração dos filtros com āgua (50 ${ }^{\circ} \mathrm{C}$ ) atể condutância constante.

A filtração foi realizada utilizando-se fil tros Millipore (13 mm) e seringas com um adaptador "Swinnex". Os espectros de e s $r$ foram obtidos em ce las planas para solução aquosa (James Scalon, Solvang,Calif.) usando-se um espectrômetro Varian E-4 a temperatura ambien te $\left(22 \pm 2^{\circ} \mathrm{C}\right)$.

3.2.6. Medidas de fluorescência e determinação de relação / de produtos na hidrólise de cianopiridinios.

Medidas de emissão foram realizadas num espectrofluorímetro Hitachi-Perkin Elmer MPF-4 operando-se na 
forma proporcional. Aliquotas $(3,00 \mathrm{ml})$ de soluções conten do $\mathrm{Ru}(\mathrm{bpy})_{3} \mathrm{Cl}_{2} \cdot 6 \mathrm{H}_{2} \mathrm{O}\left(3,5 \times 10^{-5} \mathrm{M}\right), \mathrm{KBr}(0,10 \mathrm{M})$ e CTAB $(0-0,04 \mathrm{M})$ equilibradas em ar a $30^{\circ} \mathrm{C}$, foram excitadas a 450 $\mathrm{nm}$ e os espectros foram registrados. Alíquotas sucessivas de solução estoque concentrada de 2-MCP $(0,192 \mathrm{M})$ ou 4-MCP $(0,154 \mathrm{M})$ foram adicionadas e os espectros foram registra dos após cada adição. A concentração das soluções estoque foi verificada por absorbância e a adição total não foi/ maior que $40 \mu \mathrm{L}$. Os dados de emissão foram lançados num gráfico de ster-Volmer para obter a constante de supressão de Stern-Volmer (Demas e Addington,1976; Quina, 1977). Tan to para 2-MCP como para 4-MCP as relações de produtos de hidrólise (piridona/amida) foram determinadas por absorbân cia (Politi e col., 1978) ou por determinação de cianeto / (Sparlin, Hinze e Armstrong, 1977) utilizando-se curvas de calibração correspondentes às condições usadas neste traba 1ho.

3.2.7. Espectro Diferencial

Os espectros foram obtidos num espectrofotômetro Cary 14 usando celas calibradas. Os espectros diferenciais (Figura 2) sugerem que existe uma intera ção entre m-dinitrobenzeno e tiofenóxido em micelas de CTAB. 


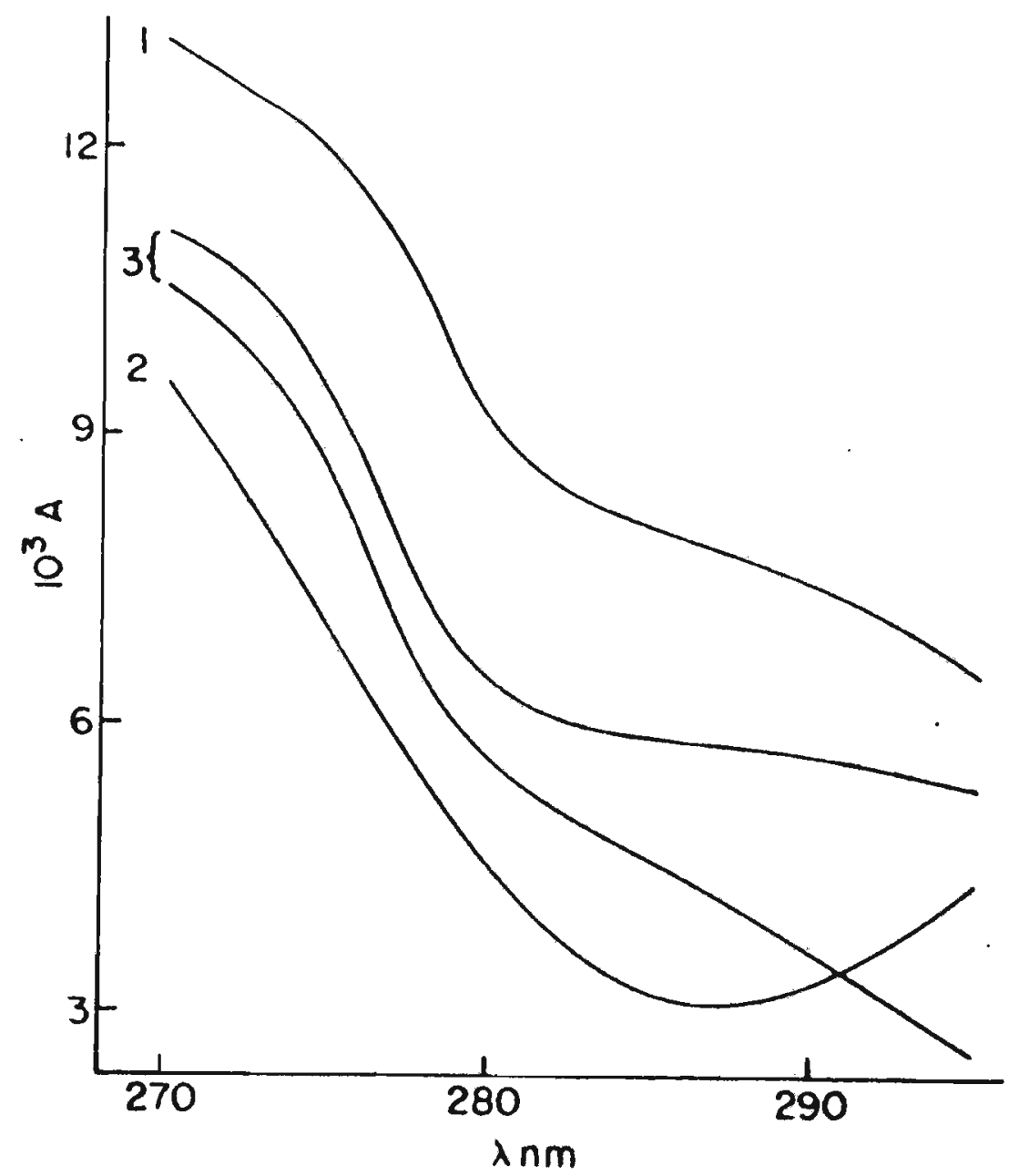

Figura 2. Espectro diferencial de $6,7 \times 10^{-5} \mathrm{M}$ m-dinitrobenzeno e $6,7 \times 10^{-5} \mathrm{M}$ tiofenóxido na presença de CTAB $(0,33 \mathrm{M})$ e tampão borato $(0,017 \mathrm{M})$. $1,2,3$, representam 3 espectros tirados nas mes mas condições. 3 foi determinado duas vezes pa ra mostrar o erro na determinação. 


\section{RESULTADOS}

4.1. Reações de DNFB em micelás

Reação com o ion fenōxido. Os efeitos micela res na reação do ion tiofenóxido com DNFB são relativamente simples. Contudo, o aumento de velocidade obtido por adição de micelas de CTAB é bem maior nesta reação do que em ou tras reações bimoleculares em água. A constante de velociaa de de segunda ordem $\mathrm{k}_{2}$ aumenta, chega a um patamar e não apresenta um máximo (Figura 3) enquanto,para outras reações bimoleculares catalizadas por micelas, pode-se observar sem pre um māximo (Fendler e Fendler, 1975; Cordes e Gitler, 1973; Bunton, 1973; Bunton e Wolfe, 1973). A constante de velocidade de segunda ordem $\left(\mathrm{k}_{2}=260 \mathrm{M}^{-1} \mathrm{~s}^{-1}\right)$ obtida para reações na ausência de micelas é uma mēdia de seis experi mentos em que a concentração de tiofenóxido variou entre / 0,25 e $0,5 \times 10^{-3} \mathrm{M}$ e a concentração de DNFB entre 0,0125 e $0,05 \times 10^{-3} \mathrm{M}$. Na região do patamar o valor da constante de segunda ordem na presença de micelas $\left(\mathrm{k}_{2}^{\mathrm{m}} \Psi\right)$ e $2,8 \times 10^{5} \mathrm{M}^{-1} \mathrm{~s}^{-1}$ para $5 \times 10^{-5} \mathrm{M} \mathrm{DNF}$, de tal forma que o aumento da velocida de é da ordem de 1100 .

Micelas não-iônicas de Brij 58 aceleram a reação mas o efeito é relativamente pequeno (Tabela 1). Uma explicação eletrostática simples da catálise micelar prediz que micelas não-iônicas não deveriam ter efeito nesta reação. 


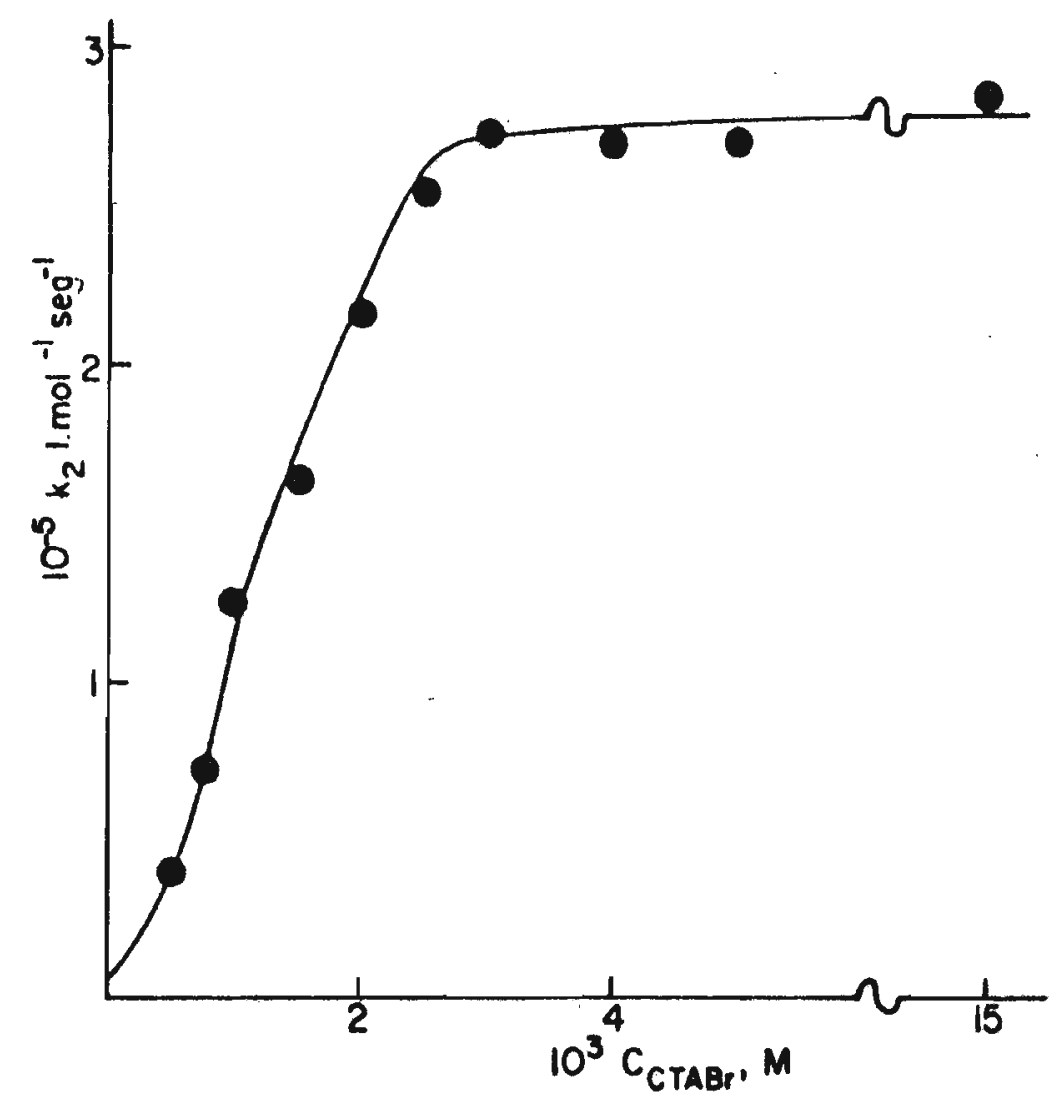

Figura 3. Reação do ĩon tiofenóxido com 2,4 dinitró fluorobenzeno na presença de CTAB a $25^{\circ} \mathrm{C}$.

TABELA 1. Efeito do Brij 58 na reação de DNFB e tiofenóxido ${ }^{a}$.

\begin{tabular}{ccc}
\hline$C_{D}\left(\mathrm{M} \times 10^{3}\right)$ & $\mathrm{k}_{2}\left(\mathrm{M}^{-1} \mathrm{seg}^{-1}\right)$ \\
\hline- & 260 \\
0,06 & 386 \\
0,80 & 1320 \\
3,34 & $3940^{\mathrm{b}}$ \\
15,0 & 9340
\end{tabular}

(a) A $25^{\circ}, \mathrm{pH} 9,27,10^{-2} \mathrm{M}$ tampão borato e $5 \times 10^{-4} \mathrm{M}$ tiofenol; $2,5 \times 10^{-5}$ M DNFB.

(b) $5 \times 10^{-5}$ DNEB. 
Porēm, existem outros casos em que a explicação simples fa Iha e a velocidade de reação muda (Bunton e Robinson, 1969; Fendler, Fendler e Liechti, 1970; Cordes e Gitler, 1973;Bun ton, 1973; Bunton e Robinson, 1969; Buist e col., 1970) pro vavelmente porque os reagentes, relativamente hidrofóbicos, (DNFB e tiofenóxido) se concentram nas micelas não iônicas de Brij. A relação entre a constante de velocidade e a concentração de detergente não apresenta a forma sigmoidal ca racteristica de catálise micelar.

Efeito de CTAB na ionização do fenol. A fim de poder calcular o grau de dissociação do fenol na presença de CTAB sob as condições cinéticas, examinamos o espec tro UV do fenol e do fenóxido em СтАв na ausência e na pre sença de CTAB usando tampão com $\mathrm{pH}$ nominal 10,0.

O leitor deve, neste ponto, considerar que os dados apresentados mais adiante na secção Resultados 3.4 modificam bastante tanto o desenho experimental, como a in - terpretação possĩvel destes dados (veja tambēm Chaimovich, 1979).

A ionização do fenol aumenta com a adição de até $5 \times 10^{-3} \mathrm{M}$ de CTAB (Tabela 2), concordando com outras ob servações sobre efeito de micelas na ionização de ācidos / não carregados (Bunton e Minch, 1957; Tong e Glessman, 1957; Hiskey e Downey, 1954),

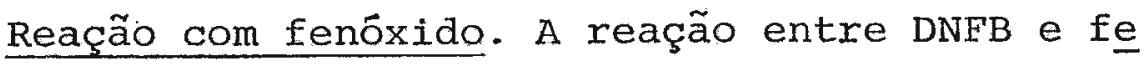
nol em tampão borato pH 10 é catalisada eficientemente por 
TABELA 2. Efeito do CTAB na ionização do fenola

$$
\text { СтAв }\left(M \times 10^{3}\right) \quad C_{\text {fenöxido }} / C_{\text {fenol }}+C_{\text {fenöxidc }}
$$

\begin{tabular}{ll}
- & 0,48 \\
1,0 & 0,49 \\
2,0 & 0,55 \\
2,0 & 0,57 \\
3,0 & 0,63 \\
4,0 & 0,66 \\
5,0 & 0,70 \\
6,0 & 0,71 \\
7,0 & 0,71 \\
7,0 & $0,74^{\mathrm{b}}$ \\
8,0 & $0,70^{\mathrm{b}}$ \\
9,0 & 0,74 \\
9,0 & 0,72 \\
50,0 & 0,74 \\
\hline
\end{tabular}

(a) A $25^{\circ} \mathrm{C}$ sob condições cinēticas com $6,67 \times 10^{-4} \mathrm{M}$ fenol

(b) $3,33 \times 10^{-4} \mathrm{M}$ fenol.

micelas de CTAB (Fig. 4). Os símbolos vazios representam a cons tante de segunda ordem aparente calculada dividindo-se a constante observada, $k_{\Psi}$, pela concentração analitica de fenol. Os 
sîmbolos cheios representam a constante calculada em termos da concentração de fenôxido estimada espectrofotometricamen te. A Tabela 2 mostra o efeito do СТAB sobre o equilíbrio / fenol-fenóxido. Deve-se notar que este desenho experimental não diferencia entre solutos nas fases aquosa e micelar. A constante de segunda ordem mäxima, a $4 \times 10^{-3} \mathrm{M}$ CTAB, é 158 $M^{-1} s^{-1}$ baseada na concentração de fenóxido $e, 107 \mathrm{M}^{-1} \mathrm{~s}^{-1}$ baseada na concentração total de fenol. A diferença entre / estes valores demonstra a importância de se levar em conta - efeito de micelas sobre equilíbrios do tipo ácido-base ou qualquer tipo de equilíbrio onde participem os reagentes.

A constante de segunda ordem para a reação / do fenol com DNFB em āgua, ê $0,68 \mathrm{M}^{-1} \mathrm{~s}^{-1}$, calculada em termos de concentração de fenóxido,e $0,33 \mathrm{M}^{-1} \mathrm{~s}^{-1}$ calculada em termos de concentração analítica de fenol $\left(1,33 \times 10^{-3} \mathrm{M}\right.$ fe nol, $6,67 \times 10^{-4} \mathrm{M}$ DNFB). Assim, o aumento de velocidade / produzido pelo CTAB é de 230 ou 315 vezes, segundo a forma na qual se efetua este cálculo. A forma da curva que rela ciona $\mathrm{k}_{2}$ com CTAB (Fig.4) mostra o mäximo característico de outras reações bimoleculares na presença de micelas.

o efeito de SDS foi analizado em forma quali tativa obtendo-se o esperado retardamento da velocidade em micelas negativas.

Efeito de micelas no espectro de UV dos ions fenōxido e tiofenóxido. A adição de pequenas quantidades de 


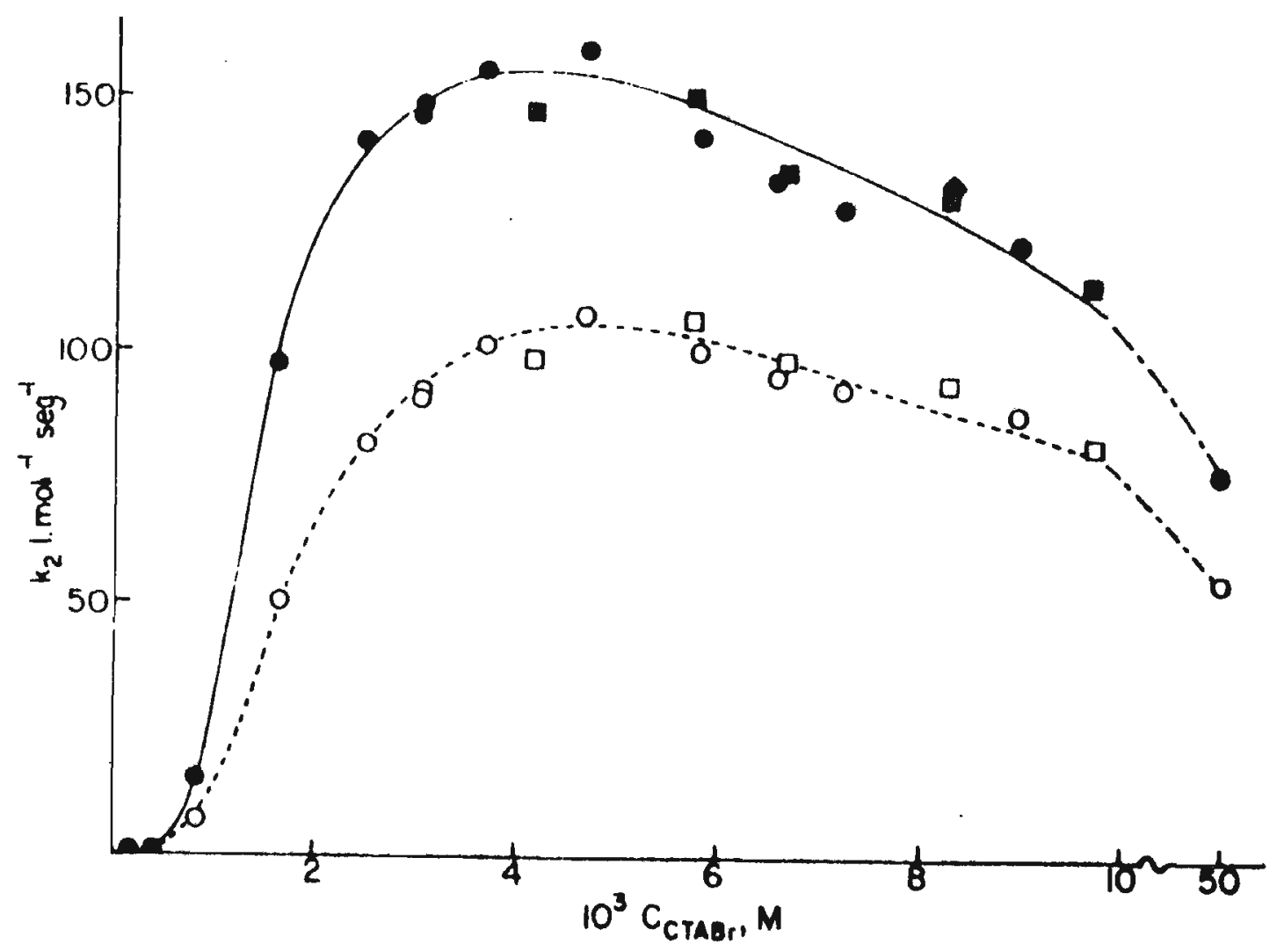

Figura 4. Reação de fenóxido com 2,4 dinitrofluoroben zeno na presença de CTAB. Os símbolos cheios represen tam os valores de $\mathrm{k}_{2}$ corrigidos pela dissociação do fenol. $\diamond \bullet 1,67 \times 10^{-4} ; \square \square 3,33 \times 10^{-4} ; \circ \bullet 6,67 \times 10^{-4}$ M fenol.

CTAB não muda substancialmente o espectro de tiofenōxido.Po rém, pode-se observar uma mudança marcante quando a concentração de surfactante è suficientemente grande para incorpo rar totalmente o substrato na micela. Os espectros são mostrados na Figura 5 e os coeficientes de extinção, bem como 


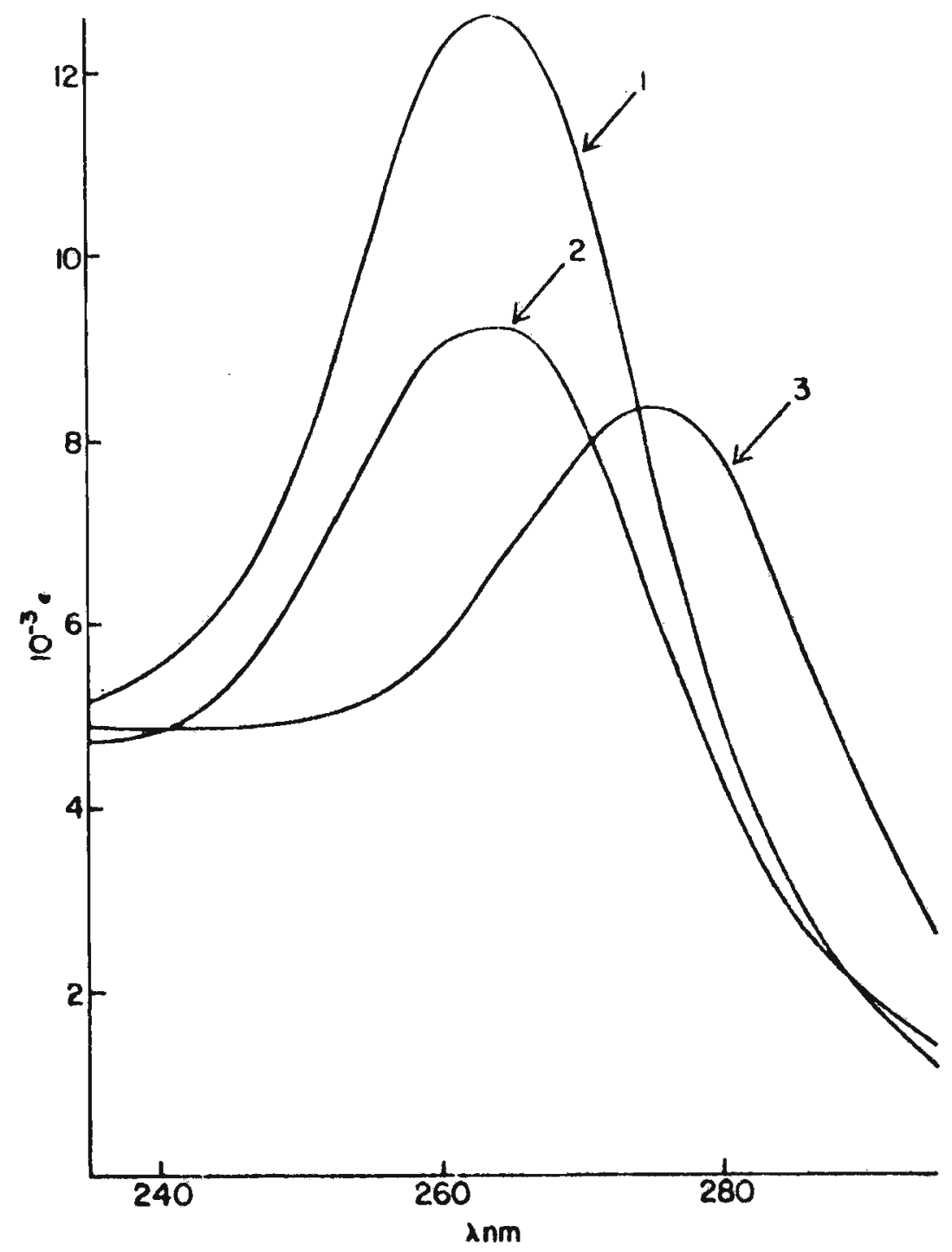

Figura 5. Efeito do CTAB no espectro UV de 0,125 x $10^{-3} \mathrm{M}$ tiofenôxido. (1) na ausência de CTAB; (2) com $0,75 \times 10^{-3} \mathrm{M} \mathrm{CTAB;} \mathrm{(3)} \mathrm{com} 3 \times 10^{-3} \mathrm{M} \mathrm{CTAB.}$ 
os $\lambda_{\max }$, na Tabela 3 . Os resultados da Tabela 3 mostram que pequena quantidade de СТАB é suficiente para incorporar o tiofenóxido e este fato é confirmado medindo-se as āreas sob os picos de absorção para soluções de CTAB e tiofenóxido / (Fig. 6). Estas āreas foram estimadas de duas formas usandose grāficos que relacionam absorbância contra frequência. Na primeira medimos a área desde $V_{\max }$ até a frequência mais / baixa $\left(31.300 \mathrm{~cm}^{-1}, 320 \mathrm{~nm}\right)$ e na segunda desde $43.500 \mathrm{~cm}^{-1}$ $(230 \mathrm{~nm})$ até o máximo. A variação destas duas āreas e a soma (em unidades arbitrārias) em função da concentração de CTAB são apresentadas na Figura 6. Apesar da arbitrariedade na estimativa das áreas os resultados mostram o efeito mar cante do CTAB sobre o espectro do tiofenóxido. Pode-se obser var também que a área espectral é aproximadamente constante acima de $1,5 \times 10^{-3} \mathrm{M}$ CTAB, confirmando que, a maiores concen trações de detergente o tiofenóxido está totalmente incorporado e interage fortemente com os grupos iônicos das micelas. Evidência adicional que mostra a forte intera ção de tiofenōxido com CTAB provēm da magnitude do decréscimo da CMC do CTAB quando se adiciona tiofenóxido. A CMC do CTAB em āgua é de $9 \times 10^{-4} M$ (Fendler e Fendler, 1975). A adi ção de $4 \times 10^{-5} \mathrm{M}$ tiofenóxido a pH $10\left(10^{-2} \mathrm{M}\right.$ de tampão bora to) produz uma diminuição da CMC até $0,8 \times 10^{-4} \mathrm{M}\left(25^{\circ} \mathrm{C}\right)$ e a pH $9.1\left(30^{\circ} \mathrm{C}\right)$ a CMC diminui até $1 \times 10^{-4} \mathrm{M}$. A micelização foi estimada medindo-se a mudança de absorbância do íon tiofenô- 


\begin{tabular}{ccccc}
\hline $\begin{array}{l}\text { TABELA 3. Espectro ultravioleta do ion tiofenóxido na } \\
\text { presença de CTAB }\end{array}$ & & & \\
\hline CTAB $\left(\operatorname{MxI0} 0^{3}\right)$ & $\lambda_{\max }$ & $E_{\max }$ & $E_{262}$ & $E_{274}$ \\
\hline- & 263 & 12.600 & 12.600 & 8.750 \\
0,75 & 264 & 9.250 & 9.230 & 6.450 \\
1,50 & 271 & 7.570 & 7.000 & 7.500 \\
2,00 & 272 & 7.670 & 6.740 & 7.600 \\
3,00 & 274 & 8.320 & 6.420 & 8.320 \\
\hline
\end{tabular}

(a) com $1,25 \times 10^{-4} \mathrm{M}$ tiofenol, $\lambda \mathrm{em} \mathrm{nm}$.

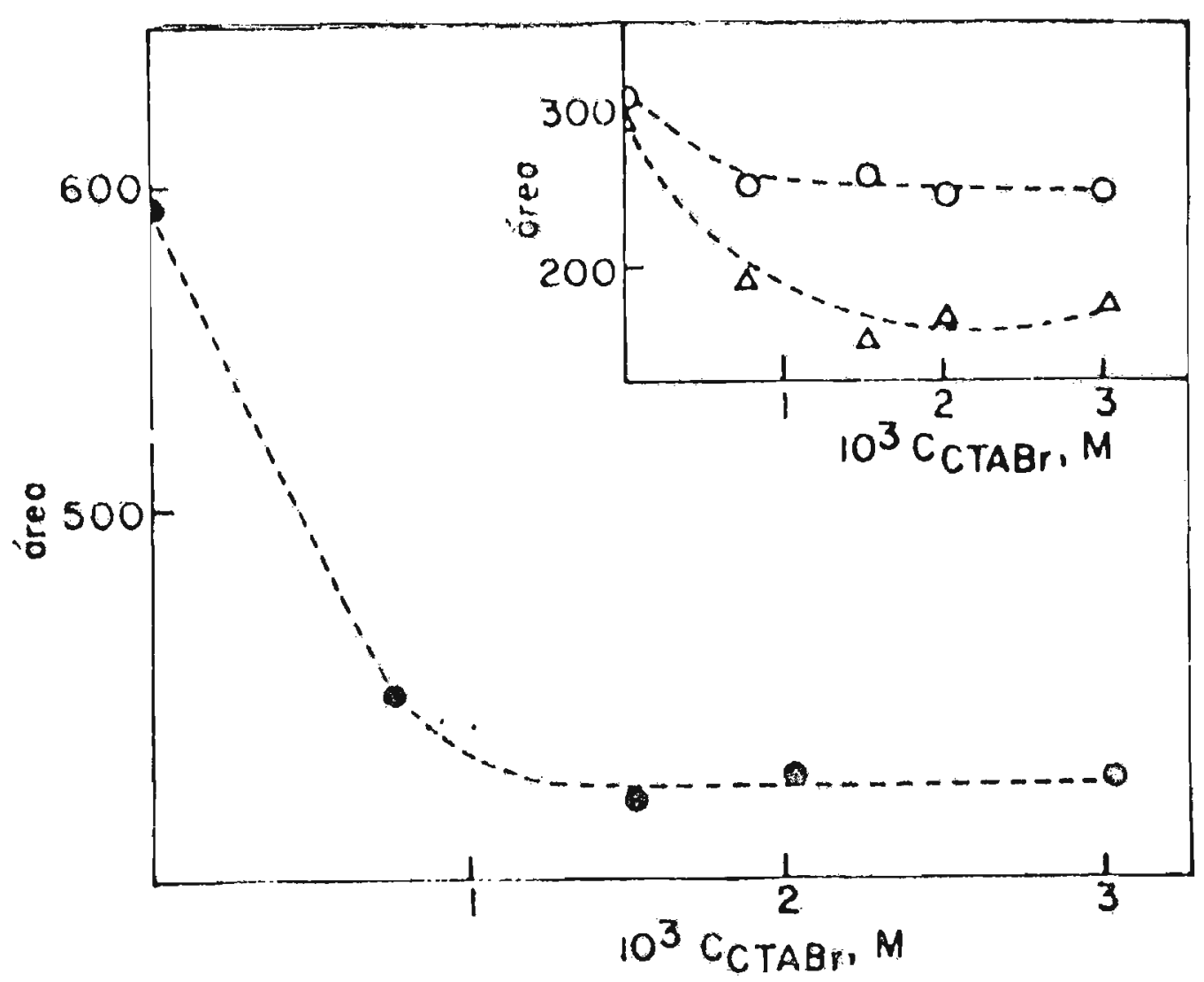

Figura 6. Efeito do CTAB nas áreas dos picos de absorção do tiofenóxido (unidades arbiträrias); 0 , de $V_{\max }$ a $43.500 \mathrm{~cm}^{-1} ; \Delta, V_{\max }$ a $31.300 \mathrm{~cm}^{-1}$, área total. 
xido a $275 \mathrm{~nm}$.

Os efeitos da CTAB no espectro de UV de fenol e do ion fenóxido são muito menores daqueles causados pelo / mesmo detergente no espectro do tiofenōxido. Existem, porem, efeitos batocrômicos (Figura 7) que são, como se poderia esperar, maiores no fenóxido que no fenol, seguramente pelo / maior grau de interação do ion com o detergente. Porém, o efeito na absorbância é sempre menor que no tiofenóxido. Tanto o $\lambda_{\max }$ quanto o $E_{\max }$ do fenol e fenóxido mudam quando estes se incorporam em micelas de CTAB. As diferenças entre fenóxido e tiofenóxido são compreensíveis, uma vez que as ligações de hidrogênio ao enxofre são mais fracas que ao oxigênio. Por tanto, o tiofenóxido deveria interagir mais fortemente do que o fenóxido com uma micela catiônica.

4.2. Reações de $s$-acil- $\beta$-mercaptoetilaminas

o detergente catiônico, СТAB, cataliza a trans ferência do grupo acila de $S$ para $N$ na $s$-octanoil-B-mercapto etilamina (OMA) (Figura 8), e se observa que a constante de / velocidade para esta reação aumenta bruscamente quando a concentração de $\operatorname{CTAB}$ é superior a $3 \times 10^{-4} \mathrm{M}$. A CMC do CTAB em á gua é $9 \times 10^{-4} \mathrm{M}$ (Fendler e Fendler, 1975) mas é sabido que / tanto a adição de sais como a adição de alguns eletrólitos an fifilicos podem diminuir a CMC deste detergente (Bunton, 1973; 


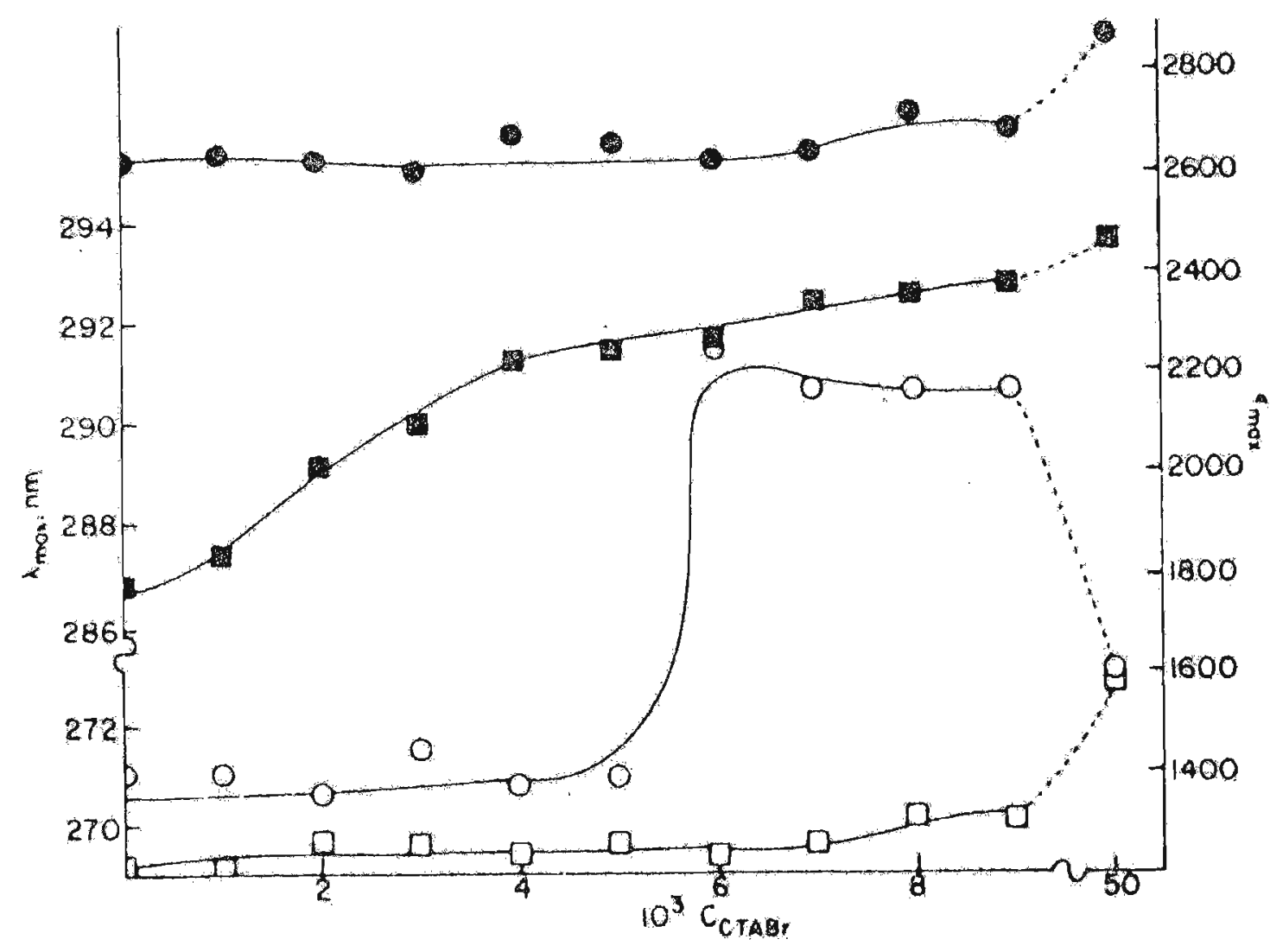

Figura 7. Efeito do CTAB em $\lambda_{\max }\left(\square\right.$ ) e $E_{\text {max }}$ $(0)$ ) de fenol (poritos vazios) e fenoxido (pon tos cheios).

Fendler e Fendler, 1975). Utilizando-se o valor de $3 \times 10^{-4} \mathrm{M}$ como CMC efetiva nas nossas condiçöes cinëticas, pode-se cál cular a aceleração mäxima e o coeficiente de partição do l substrato entre a ägua e a pseudofase micelar (Berezin, Martinek e latsimirski, 1973). Utilizando o modelo de separação de fase na sua forma mais simples (veja, por exemplo, Bere zin, Martinek e Yatsimirski, 1973; Quina e Chaimovich, 1979 


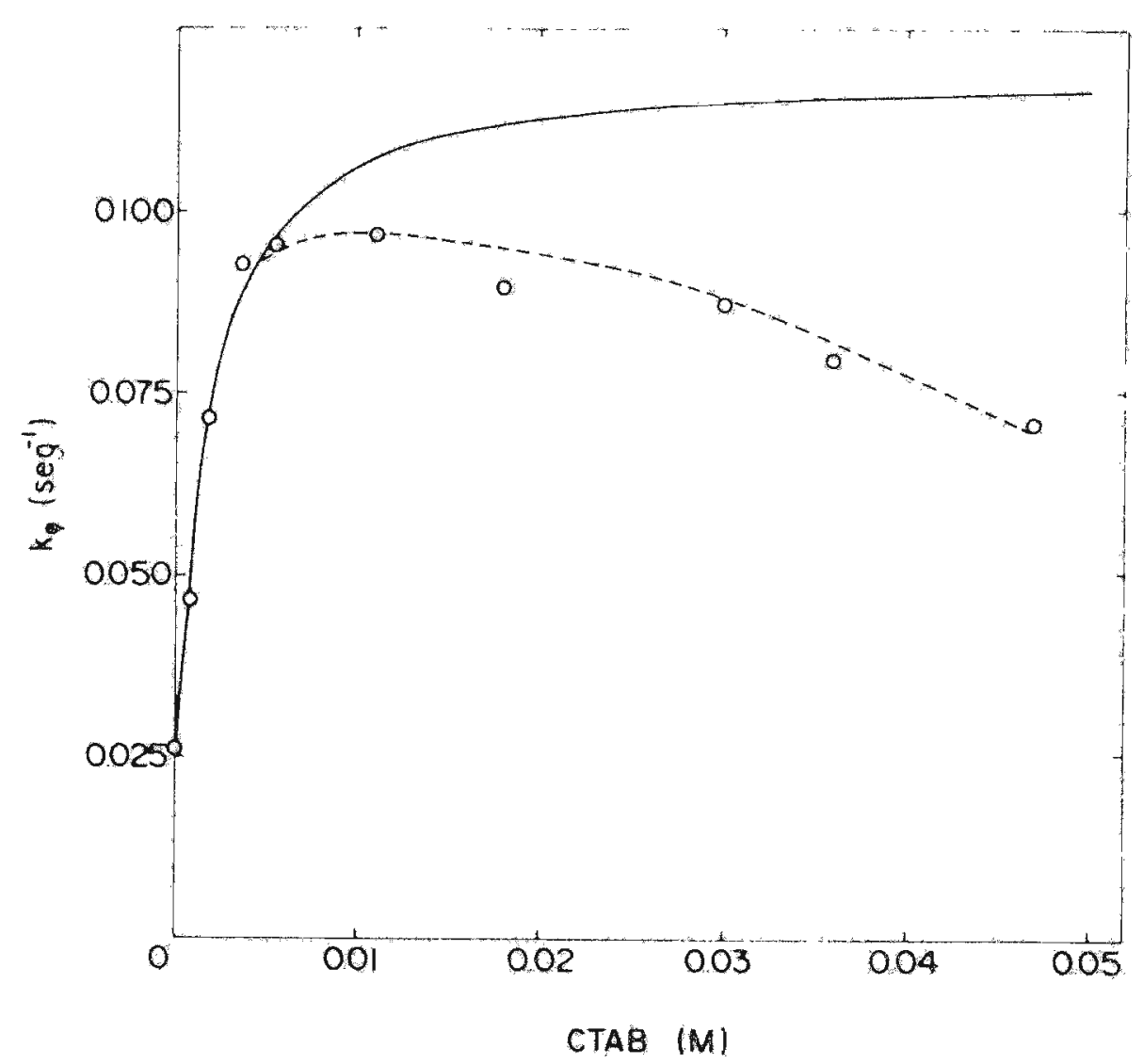

Figura 8. Catälise da reação de transferência de acila $(S \rightarrow N)$ em S-octanoil-B-mercaptoetilamina / por CTAB. A linha sólida foi calculada rveja tex to).

e Chaimovich, 1979) uma reação unimolecular pode ser analiza da utilizando-se a equaçäo:

$$
k_{\mathrm{Y}}=\frac{k_{\mathrm{m}} \mathrm{K}\left(\mathrm{C}_{\mathrm{T}}-\mathrm{CMC}\right)+\mathrm{k}^{\mathrm{O}}}{\mathrm{K}\left(\mathrm{C}_{\mathrm{T}}-\mathrm{CMC}\right)+1}
$$

onde $k_{\Psi} \vec{e}$ a constante de primeira ordem observada, $C_{T} \quad \bar{e}$ a 
concentração total de detergente, $k^{\circ}$ é a constante observa da na ausência de detergente, $k_{m}$ é a constante de velocidade na fase micelar e $K$ a constante de distribuição do substrato. $k_{m}$ e $k$ foram calculadas por iteração a partir de um valor inicial de $k_{m}$ igual a $k_{\Psi}$ mäxima (Figura 8). Somente / os dados cinéticos obtidos atë $5,5 \times 10^{-3} \mathrm{M}$ de cTAB foram $\underline{u}$ tilizados nestes cálculos. Em pH 6,8 (tampão fosfato de sôdio $0,01 \mathrm{M}) \mathrm{k}^{0} \mathrm{e} 0,026 \mathrm{~s}^{-1}$, a $\mathrm{k}_{\mathrm{m}}$ calculada sob as mesmas con dições é $0,12 \mathrm{~s}^{-1}$, de tal modo que a aceleração causada por CTAB è 4,6 vezes.

Com o intuito de descartar a possibilidade / de que a agregação do substrato modificasse de alguma ma neira o valor da constante de velocidade da reação não cata lizada, a concentração de OMA foi variada entre $2,8 \times 10^{-5}$ e 4,2 $2 \times 10^{-4} \mathrm{M}$. Entre estes limites, $\mathrm{k}^{\circ}$ é constante. Como / se pode observar na Figura 8 os valores de $k_{\psi}$ obtidos a con centração alta de detergente se desviam significativamente da curva teórica indicando, claramente, que o modelo descri to pela equaçäo 7 explica os dados obtidos de modo apenas/ parcial.

o efeito inibitório de detergentes negativos como o dodecil sulfato de södio (SDS) neste sistema é muito maior que o (pequeno) efeito catalitico observado com CrAB (Figura 9).

Vários modelos foram considerados para acomo 


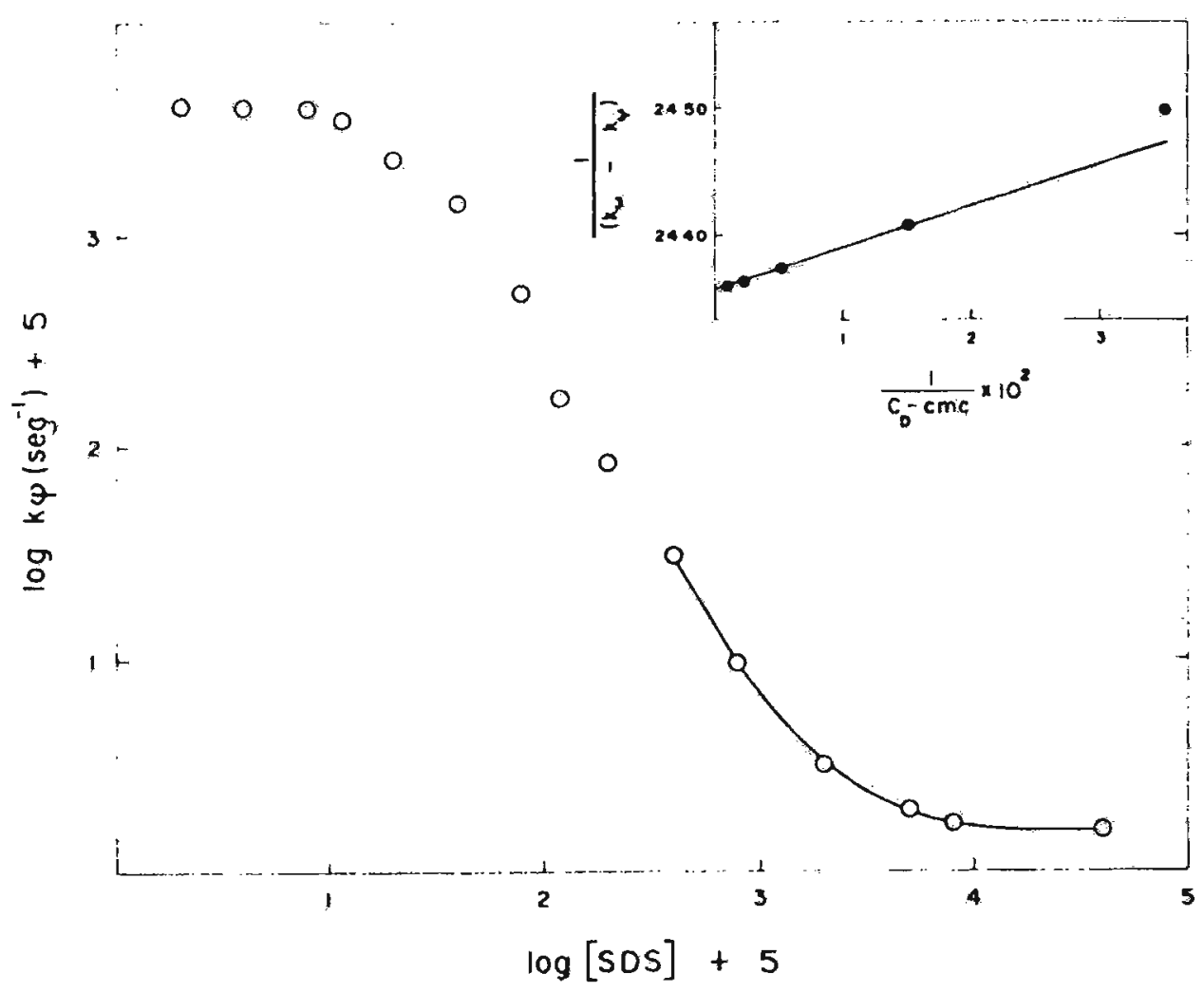

Figura 9. Efeito de SDS na reação de transferência de acila $(S \rightarrow N)$ em S-octanoil-B-mercaptoetilamina. A linha sólida foi calculada, o gráfico inscrito / mostra a mesma região de concentração de SDS lançado de acordo com a equação 8 (veja texto). A concentração inicial de OMA ē $2 \times 10^{-4} \mathrm{M}$.

dar todos os dados experimentais que são mostrados na Figura 9. Estes modelos se bașearam na suposição da formação de agregados, contendo substrato e SDS em proporções defini das, em toda a faixa de concentração de SDS (esquema I). 


\section{ESQUEMA I}

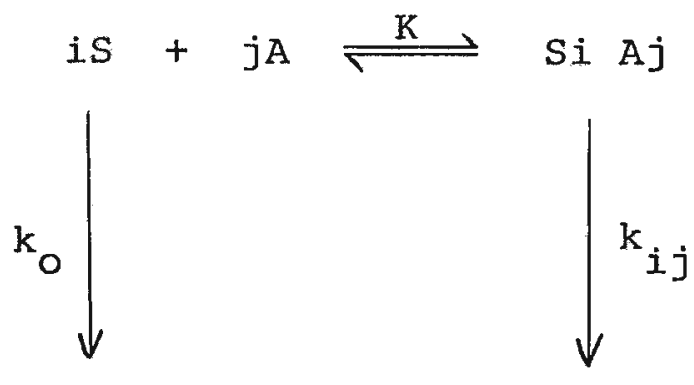

o tratamento usado não poderia, de fato, se ajustar aos dados cinéticos.Sem tentar agora uma anâlise / quantitativa, podemos esquematizar os equilibrios que devem ser considerados na análise:

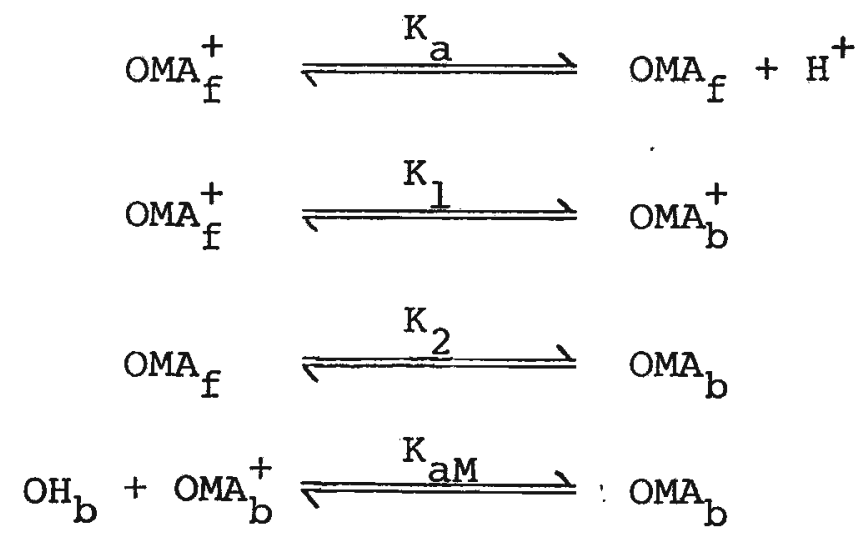

onde $\mathrm{OMA}_{\mathrm{f}}^{+}, \mathrm{OMA}_{\mathrm{b}}^{+}$, $\mathrm{OMA}_{\mathrm{f}}$ e $\mathrm{OMA}_{\mathrm{b}}$ representam as espēcies pro tonadas nas fases aquosa e micelar, respectivamente. Uma / descrição da anālise deste sistema pode ser encontrada em Quina e Chaimovich (1979) e Chaimovich (1979). No esquema I, i representa os moles de OMA no agregado substrato-detergente; $\underline{j}$ o número de moles de detergente no agrega- 
do, $\mathrm{K}$ a constante de equilíbrio e $\mathrm{k}_{\mathrm{ij}}$ a constante de veloci dade para a transferência intramolecular de acila de $\mathrm{s}$ para $\mathrm{N}$ num agregado contendo i moles de OMA e j moles de SDS. E te modelo foi utilizado com sucesso em outros sistemas de aminólise (Bruice, Katzhendler e Fedor, 1968). Porēm, este método não forneceu resultados internamente consistentes / neste caso. A inaplicabilidade deste modelo é, provavelmente um reflexo da existência de equilíbrios múltiplos entre - SDS e o substrato que resultam num conjunto de agregados,com $i$ e $j$ variāveis (esquema $I) ~ e$, consequentemente, $k_{i j}$ diferen tes. A relação $i / j$ deveria variar com a concentração de detergente. Desde que a inibição por SDS se observa facilmente até em proporções OMA/SDS maiores que 1, (Figura 9) i po de ser maior que j nos agregados em concentrações baixas de SDS.

Os pontos experimentais obtidos a SDS/OMA > 10, onde o agregado pode ser visto como uma micela tipica de SDS, foram ajustados utilizando-se o modelo de distribuição já comentado quando da análise do efeito de CTAB na mesma / reação (linha cheia na Figura 9). Na inserção utiliza-se ou tra forma da equação 7 :

$$
\frac{1}{k^{\circ}-k_{\Psi}}=\frac{1}{k^{0}-k_{m}}+\frac{1}{\left(k^{\circ}-k_{m}\right) k} \times \frac{1}{\left(C_{T}-C M C\right)}
$$


o procedimento iterativo resulta num valor de $\mathrm{K}=8,2 \mathrm{x} 10^{4}$. Constantes de distribuição desta ordem de magnitude já foram observadas em aminólises intermoleculares usando uma micela / funcional e um éster com carga oposta como substrato (Bruice, Katzhendler e Fedor, 1968). $\mathrm{k}_{\mathrm{m}}$ foi calculada e forneceu um valor de $1,5 \times 10^{-5} \mathrm{~s}^{-1}$ com uma CMC de $1,2 \times 10^{-3} \mathrm{M}$.

A velocidade da reação de transferência intra molecular de $S$ para $N$ é ligeiramente inibida pela adição de um detergente não-iônico (Brij 35) (Tabela 4).

TABELA 4. Efeito de Brij 35 sobre a velocidade de transfe rência de acila $(\mathrm{S} \rightarrow \mathrm{N})$ em $\mathrm{S}$-octanoil-B-mercapto etilamina ${ }^{a}$.

\begin{tabular}{cc}
\hline Brij $35\left(M \times 10^{4}\right)$ & $k_{\Psi}\left(s^{-1} \times 10^{2}\right)$ \\
- & 4,4 \\
2,7 & 4,3 \\
5,5 & 4,4 \\
11,0 & 3,7 \\
22,0 & 4,0 \\
55,0 & 2,5 \\
\hline
\end{tabular}

(a) $25^{\circ} \mathrm{C}$ em $4,0 \times 10^{-2} \mathrm{M}$ na fosfato, pH 6,80. Concentração inicial de AMA $2,54 \times 10^{-4} \mathrm{M}$.

Com o intuito de estimar as contribuições re lativas das partes hidroföbicas e eletrostáticas nos efeitos dos detergentes sobre esta reação, estudamos a transferência 
intramolecular de acila de $S$ para $N$ em $S$-acetil-B-mercaptoe tilamina ( $A M A$ ). A velocidade da reação, utilizando AMA como substrato, năo ê afetada pela adição de CTAB atē 0,1M. Este (falta de) efeito poderia ser esperado com base nos resulta dos anteriores de aminólise de ésteres carregados (Bruice, Katzhendler e Fedor, 1968) e indica que o AMA não se incorpora, de forma significativa, na fase micelar do CTAB. O SDS inibe a reação de transferência intramolecular em AMA / (Figura 10). Os resultados de inibição podem ser ajustados a um modelo de distribuição simples utilizando a equação 7. Os parâmetros calculados foram ainda analizados variando-se o pH entre 6,4 e 7,8 (Tabela 5).

TABELA 5. Efeito de SDS na velocidade de transferēncia de acila $(S \rightarrow N)$ em $S$-acetil- $\beta$-mercaptoetilamina ${ }^{a}$.

\begin{tabular}{lccc}
\hline $\mathrm{pH}$ & $\mathrm{k}_{\mathrm{o}}\left(\mathrm{s}^{-1}\right)$ & $\mathrm{k}_{\mathrm{m}}\left(\mathrm{s}^{-1}\right)$ & $\mathrm{k}$ \\
\hline 6,4 & 0,054 & $4,0 \times 10^{-4}$ & 322 \\
6,8 & 0,122 & $1,52 \times 10^{-3}$ & 375 \\
7,14 & 0,234 & $2,0 \times 10^{-3}$ & 279 \\
7,8 & 0,722 & $7 \times 10^{-3}$ & 202 \\
\hline
\end{tabular}

(a) $25^{\circ}, 2 \times 10^{-2} \mathrm{M}$ Na fosfato. Concentração inicial de subs trato $2 \times 10^{-4} \mathrm{M}$. Veja o texto para a descrição do cálculo de $k_{m}$ (constante de velocidade na fase micelar) e $k$ (constante de distribuição do substrato). ko representa o valor da cons tante de velocidade na fase aquosa.

A inibição máxima $\left(\mathrm{k}_{\mathrm{o}} / \mathrm{k}_{\mathrm{m}}\right)$ causada por sDs ê da ordem de 100 vezes em todos os pHs estudados. O aumento 


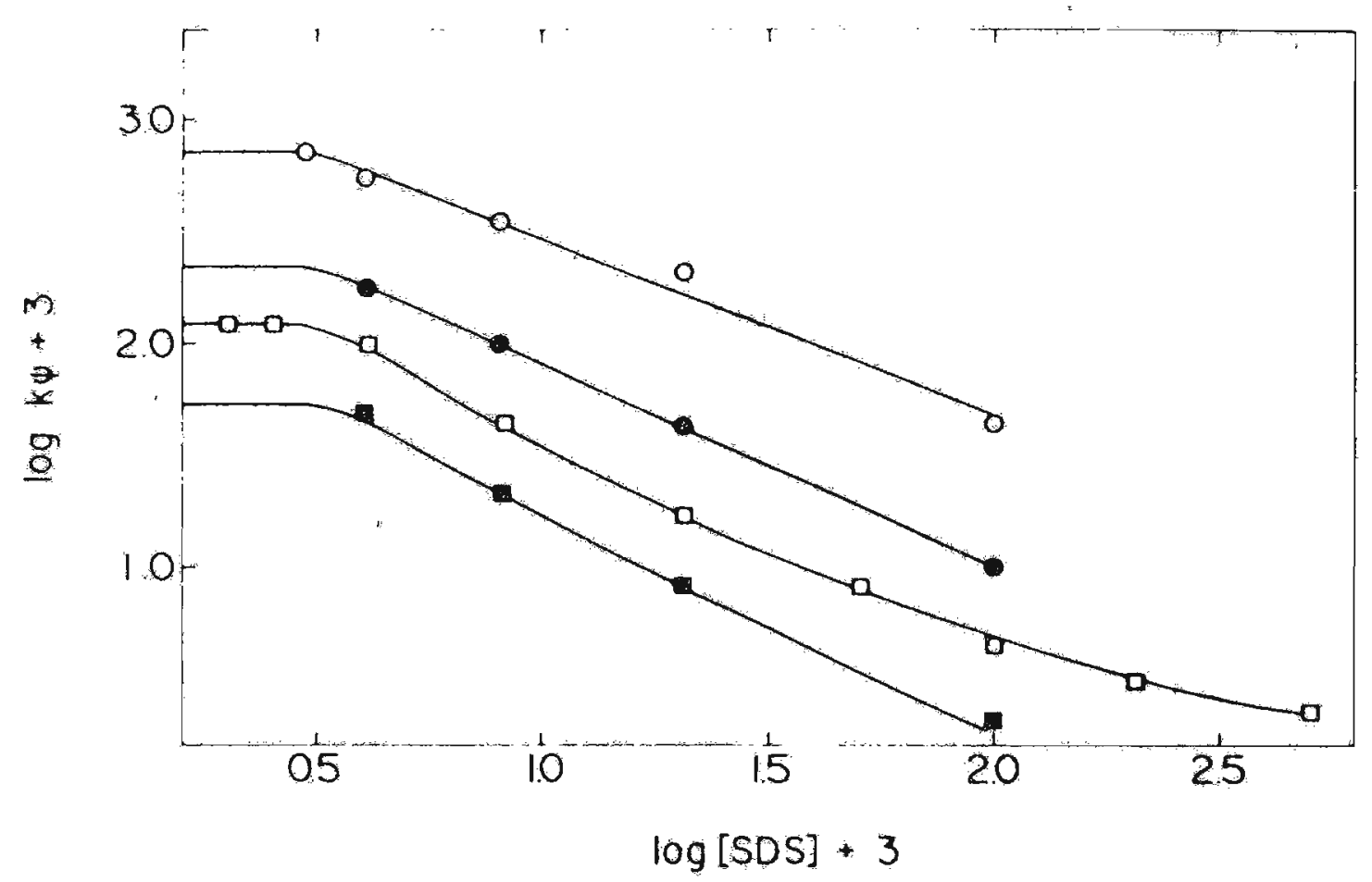

Figura 10, Efeito de SDS na reação de transferência de acila $(S \rightarrow N)$ em $S$-acetil- $\beta$-mercaptoetilamina. As Ixnhas foram calculadas de acordo com a eq.7.

( $\mathrm{pH} 6,4 ;(\square) \mathrm{pH} 6,8 ;(0) \mathrm{pH} 7,14 ;(0) \mathrm{pH} 7,8$. Todos os tampōes continham $0,02 \mathrm{M} \mathrm{NaH}_{2} \mathrm{PO}_{4}$ ajustado ao $\mathrm{pH}$ desejado com NaOH.

observado da velocidade com pH está de acordo coin os efeitos de pH, jâ publicados, nesta xeação (Barnett e Jencks, / 1969). O efeito de $\mathrm{pH}$ sobre $\mathrm{k}_{\mathrm{m}}$ e $\mathrm{k}$ (Figura/ 10 e Tabela 5) indica que a forma protonada de AMA se liga 
melhor a SDS, fato este esperado para um sistema onde a li gação ē, predominantemente, iônica.

Desde que o efeito de SDS na velocidade de transferência em OMA pode ser atribuído (como limite) a um simples efeito na constante de dissociação do amônio (veja adiante), efetuamos uma pesquisa restrita, por ressonância nuclear magnētica (RNM), dos complexos OMA/SDS a fim de tentar distinguir outros efeitos que não envolvessem a ação do SDS no pK do grupo amônio terminal. Para este fim prepa raram-se uma série de soluções aquosas de OMA contendo con centrações crescentes de SDS. Calculou-se que nestas condi ções (pH 5,0 $\pm 0,2 ;$ numa diluição de $1: 100)$ as medidas de rmn poderiam ser efetuadas antes que ocorresse qualquer mu dança significativa na concentração de OMA. A largura a meia altura do sinal da ponte metilênica aumenta (Tabela 6) para logo diminuir até alcançar um patamar onde o valor da largura observado è significativamente maior no complexo./ OMA/SDS que no OMA livre. Esta variação na largura das linhas concorda com a proposição, formulada anteriormente, que existiria um contínuo de complexos de OMA/SDS, em proporções molares variáveis. Uma investigação detalhada destes complexos foi dificultada pela baixa solubilidade dos mesmos nestas concentrações de OMA. Deve-se notar ainda, que - triplete do $\mathrm{C}_{2}\left(\mathrm{H}_{2}\right)$ da cadeia do resíduo octanoila se alarga de tal forma que se torna de difícil resolução nas mais 
TABELA 6. Alargamento do sinal de ressonância magnética nuclear de ${ }^{1} \mathrm{H}$ dos prötons da ponte metilênica de $\mathrm{CH}_{3}\left(\mathrm{CH}_{2}\right)_{6} \mathrm{COS}\left(\mathrm{CH}_{2}\right)_{2} \mathrm{NH}_{3} \mathrm{Cl}$ (OMA) produzido por $\operatorname{sDs}^{\mathrm{a}}$.

\begin{tabular}{ccc}
\hline OMA (M) & SDS (M) & $\begin{array}{c}\text { Largura da } 1 \text { i- } \\
\text { nha }(\mathrm{Hz})\end{array}$ \\
\hline 0,025 & - & 1,6 \\
$"$ & 0,125 & 2,6 \\
$"$ & 0,188 & 2,0 \\
$"$ & 0,250 & 2,0 \\
0 & 0,375 & 2,0 \\
$" 050$ & 0,500 & 2,0 \\
$"$ & - & 1,7 \\
$"$ & 0,220 & 5,6 \\
& 0,325 & 3,6 \\
& 0,375 & 3,6 \\
\hline
\end{tabular}

(a) Veja Resultados e Parte Experimental para detalhes. A in certeza na determinação da largura da linha é 0,1 Hz.

baixas concentrações de SDS. Estes resultados constituem indicação de uma diminuição da liberdade conformacional do OMA quando este se incorpora num agregado contendo SDS. 
4.3. Tiólise de INPA

Mostramos anteriormente que O CTAB tem um pro fundo efeito no espectro UV do Ion tiofenóxido (Chaimovich e col., 1975). Estas mudanças espectrais foram usadas para cal cular tanto as constantes de distribuição como os $\mathrm{pK}_{\mathrm{ap}}$ dos tiofenóis nas fases aquosa e micelar. (veja Parte Experimental 3.2.3.2. e 3.2.4.). Os dados espectrais mais relevantes se apresentam na Tabela 7 .

A Tabela 8 resume os resultados do efeito do crial sobre o pkap dos tiofenóis substituíảos e as constantes de distribuição correspondentes entre as fases aquosa e mice lar, tanto para as formas protonadas como para as não protonadas. De uma inspecção dos valores dos $\mathrm{pK}_{\mathrm{ap}}$ è evidente que todos os tiofenóis estão completamente dissociados nas condi ções cinēticas $(\mathrm{pH}>7.8)$, especialmente na presença de CTAB. Assim, as constantes de segunda ordem calculadas para a tiōlise do NPA representam a reação entre os ânions tiofenóxido e O NPA.

A adição de CTAB produz um aumento de aproximadamente 50 vezes na velocidade de tiólise do NPA por tiofe nóxido (Figuras 11 e 12, Tabela 9). Os produtos destas reações são, em todos os casos, p-nitrofenóxido e os acetatos de tio fenila correspondentes. Com base nos dados conhecidos sobre a velocidade de hidrólise de tioēsteres (Jencks, 1969; Shin- 


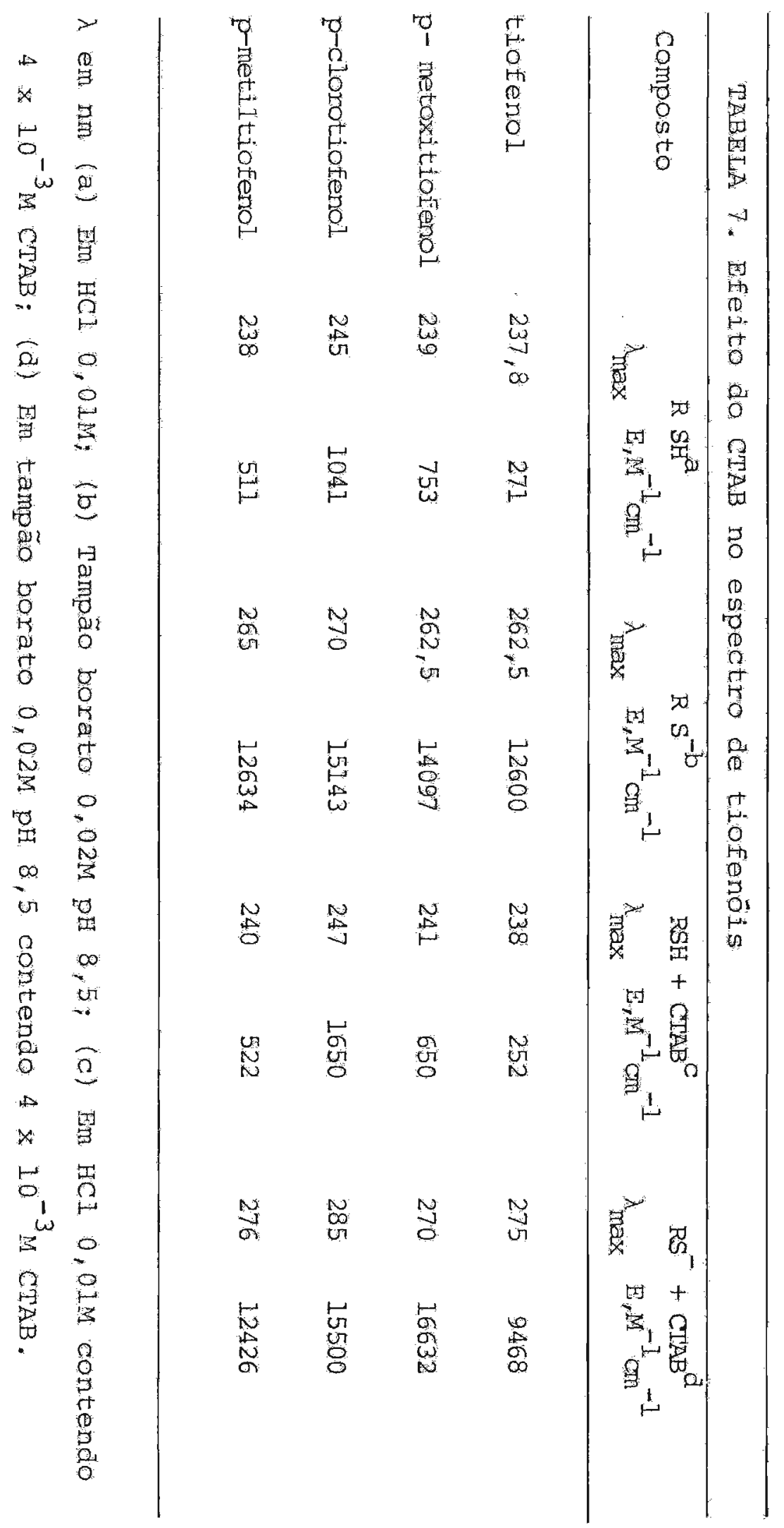


TABELA 8. Constantes de distribuição de tiofenóis entre a água e CTAB e efeito de CTAB no $\mathrm{pK}$ aparente de tiofenóis.

\begin{tabular}{|c|c|c|c|c|}
\hline Composto & $\begin{array}{l}\mathrm{K}_{\mathrm{a}}(\mathrm{SH})^{\mathrm{a}} \\
\times 10^{-3}\end{array}$ & $\mathrm{~K}_{\mathrm{a}} \times 10^{-3 \mathrm{~b}}$ & $\mathrm{pk}^{\mathrm{C}}$ & $\mathrm{pK}_{\mathrm{m}}^{\mathrm{d}}$ \\
\hline relorojuofenol & 1 & $20 \pm 5$ & 6,5 & 5,3 \\
\hline tiofenol & 1 & $4,7 \pm 0,8$ & 6,8 & 6,2 \\
\hline pretittiofenol & 1 & $8,2 \pm 0,5$ & 7,1 & 6,3 \\
\hline p-metoxitiofenol & 0,93 & $2,7 \pm 0,4$ & 7,0 & 6,6 \\
\hline
\end{tabular}

(a) Calculado segundo Yatsimirski, Martinek e Berezin (1971);

(b) Calculado a partix da equação 6 ; (ver 3.2.4.)

(c) pK em āgua (veja Chuchani e Frohlich, 1971);

(d) $\mathrm{pK}_{\text {aparente }}$ na presença de CTAB $4 \times 10^{-3} \mathrm{M}$, calculado $\underline{\mathrm{u}}$ sando a equação 2 . (ver 3.2 .3 .2$. 


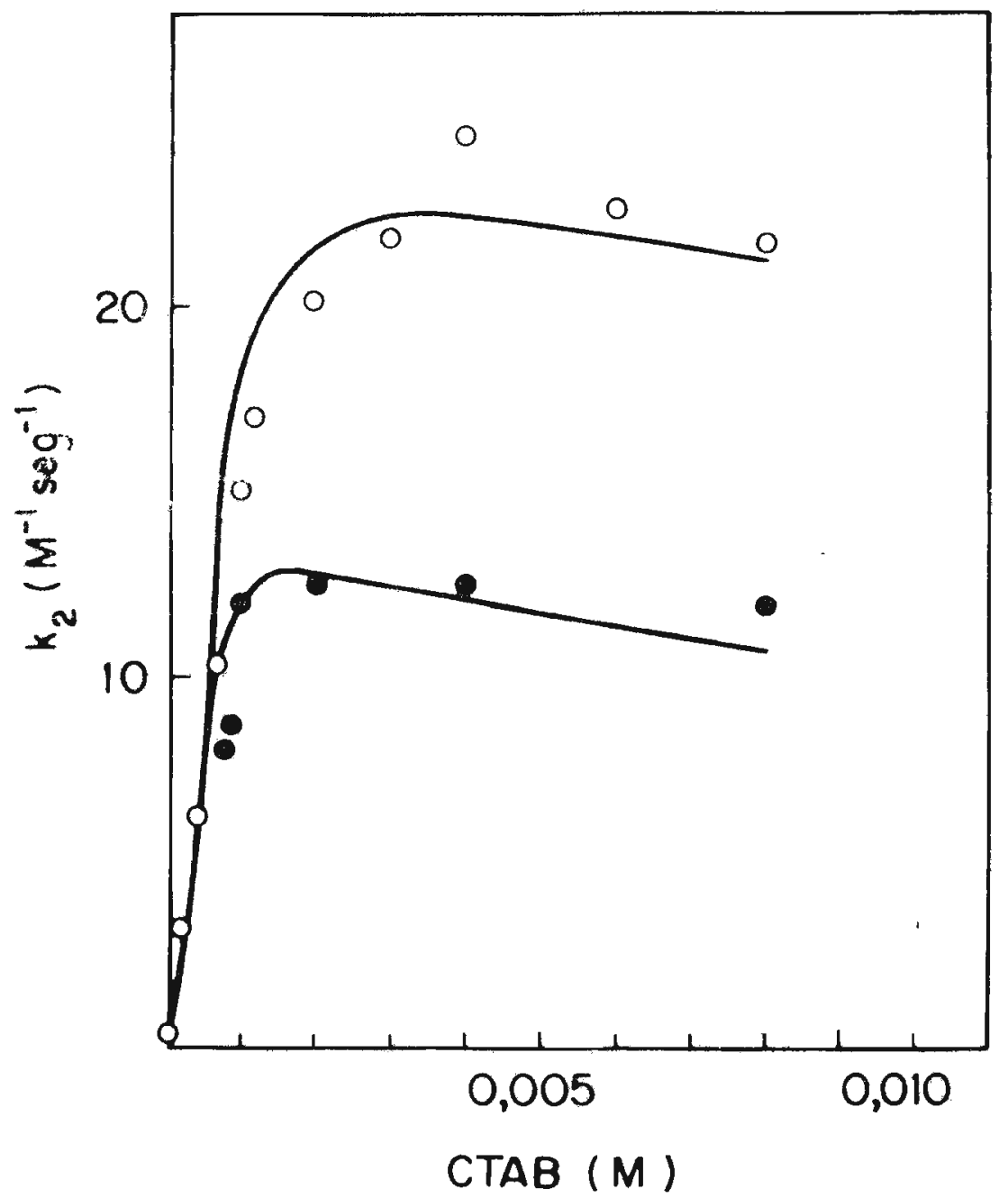

Figura 11. Efeito de CTAB na tiólise de NPA (•)p-cloro tiofenol em $\left(2 \times 10^{-2} \mathrm{M}\right)$ tampão borato $\mathrm{pH} 8.5$; (0) tiofenol em tampão borato $\left(4,5 \times 10^{-2} \mathrm{M}\right) \mathrm{pH} 7.8$. As curvas foram calculadas usando a eq.9 (veja o texto). A concentração de NPA utilizada foi, em geral, $5 \times 10^{-6} \mathrm{M}$ e a dos tiofenóis $5 \times 10^{-5} \mathrm{M}$. 


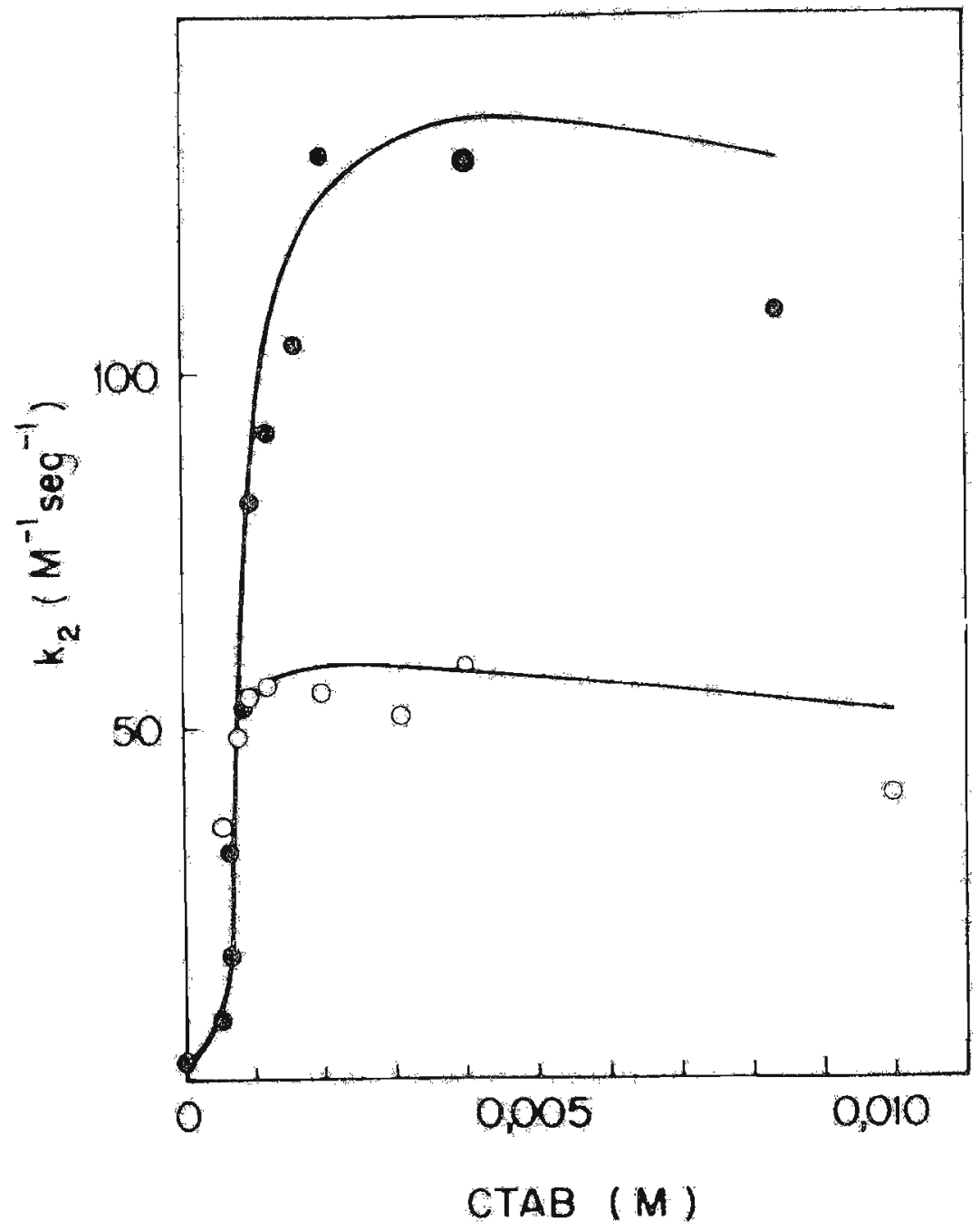

Figura 12. Efeito de CTAB na tiolise de NPA: (0)p-metil tiofenol; (0) p-metoxitiofenol. As reaçôes foram feitas en tampão borato $\left(2 \times 10^{-2} \mathrm{M}\right) \mathrm{pH} 8.5 ;$ as curvas foram $/$ calculadas usando a eq. 9 (veja o texto). A concentra cão de NPA foi geralmente $5 \times 10^{-6} M$ e a dos tiofenois $5 \times 10^{-5} \mathrm{M}$. 
TABELA 9. Efeito de CTAB na tiôlise de UPA por tiofenōxí dos.

\begin{tabular}{|c|c|c|c|c|}
\hline Composto & $k_{2 w^{\prime}}, M^{-1} s^{-1 a}$ & $\mathrm{k}_{2 \max } \mathrm{M}^{-1} \mathrm{~s}^{-1 \mathrm{~b}}$ & $k_{2 M^{\prime}}{ }^{-1} s^{-1 C}$ & $\mathrm{~K}_{\mathrm{a}} \mathrm{M}^{-1 \mathrm{a}}$ \\
\hline $\begin{array}{l}\text { p-clorotiofe } \\
\text { nôxido }\end{array}$ & 0.30 & 12,7 & 0,19 & 15000 \\
\hline tiofenöxido & 0,36 & 25,0 & 0,39 & 3900 \\
\hline $\begin{array}{l}\text { p-metiltiofe } \\
\text { nóxido }\end{array}$ & 1,08 & 59,4 & 0,91 & 2300 \\
\hline $\begin{array}{l}\text { p-metoxitiofe } \\
\text { nóxido }\end{array}$ & 2,29 & 130 & 2,18 & 2300 \\
\hline
\end{tabular}

(a) Constante de segunda ordem na fase aquasa;

(b) Constante de segunda ordem máxima observada na presença de CTAB (veja Figuras 11 e 12);

(c) Valor calculado para a constante de segunda ordem na fa se micelar (eq. 9, veja o texto);

(d) Valor de melhor ajuste para a constante de distribuiğa leq. 9, veja o texto).

kai e Kunitake, 1976; Connors e Bender, 1961; Noda, Kuby e Lardy, 1953) pode-se antecipar que os tioésteres resultantes devem ser estáveis sob nossas conẩições de reação. Evidências conclusivas dessa estabilidade foram obtidas demonstrando-se uma correspondência quantitativa entre o decrêscimo da $/$. concentraçäo de SH livre e a produção de p-nitrofenôxido, tan 
to na ausência como na presença $4 \times 10^{-3} \mathrm{M}$ de CTAB e tambēm a estabilidade do acetato de tiofenila sob todas as condi ções descritas neste trabalho.

As constantes de segunda ordem aumentam brus camente a concentrações de CTAB maiores a $5 \times 10^{-4} \mathrm{M}$. Medidas condutimētricas independentes confirmaram que, sob nossas/ condições cinēticas, a CMC do CTAB è, de fato, diminuída de $9 \times 10^{-4} \mathrm{M}$ (Fendler e Fendlex, 1975) para $5 \times 10^{-4} \mathrm{M}$,

o efeito do CTAB na velocidade de tiólise foi analizado quantitativamente utilizando-se um modelo de sepa ração de fases (Berezin, Martinek e Yatsimirski, 1973) (eq . 9).

$$
\mathrm{k}_{2 \Psi}=\frac{\left(\mathrm{k}_{2 \mathrm{~m}} / \overline{\mathrm{V}}\right) \mathrm{K}_{\mathrm{a}} \mathrm{K}_{\mathrm{b}} \mathrm{C}_{\mathrm{D}}+\mathrm{k}_{2}^{\mathrm{o}}}{\left(1+\mathrm{k}_{\mathrm{a}} \mathrm{C}_{\mathrm{D}}\right)\left(1+\mathrm{K}_{\mathrm{b}} \mathrm{C}_{\mathrm{D}}\right)}
$$

onde $k_{2 \Psi} \vec{e}$ a constante de segunda ordem observada, $k_{2 m}$ e $k_{2}^{0}$ são as constantes de segunda ordem nas fases micelar e aquo sa, respectivamente, e $k_{a}$ e $K_{b}$ são as constantes de distribuição de tiofenóxido e NPA, respectivamente.

A equação 9 se ajustou aos dados experimentais da seguinte forma: Tomando $\mathrm{K}_{\mathrm{b}}=27 \mathrm{M}^{-1}$ (wartinek e col., 1975), $\mathrm{CMC}=5 \times 10^{-4} \mathrm{M}$ (vide acima) $\mathrm{V} \overrightarrow{\mathrm{V}}=0,37 \mathrm{M}^{-1}$ (Martinek. e col., 1975) e usando os dados experimentais para $k_{2}^{0}$ (Ta bela 9) os melhores valores para $k_{a}$ e $k_{2 m}$ foram ajustados por iteração sucessiva, O valor inicial de $\mathrm{K}_{\mathrm{a}}$ foi obtido / a partir dos resultados apresentados na Tabela 8, Uma esti 
mativa inicial de $\mathrm{k}_{2 \mathrm{~m}}$ pode ser obtida examinando o aumento máximo de velocidade. Da equação 9 pode sex demonstrado que (Berezin, Martinek e Yatsimirski, 1973):

$$
\frac{k_{2 \max }}{k_{2}^{o}}=\frac{k_{2 m}}{k_{2}^{o} \bar{v}} \times \frac{k_{a} k_{b}}{\left(k_{a}^{1 / 2}+k_{b}^{1 / 2}\right)^{2}}
$$

onde $k_{2 \max } \bar{e}$ a constante de segunda ordem mäxima obtida pela adição de detergente. Quando $\mathrm{K}_{\mathrm{a}}>\mathrm{K}_{\mathrm{b}}$ a equação 8 reduz a :

$$
\operatorname{Lim}_{\mathrm{K}_{\mathrm{a}}>\mathrm{K}_{\mathrm{b}}} \frac{\mathrm{k}_{2 \max }}{\mathrm{k}_{2}^{\circ}}=\frac{\mathrm{k}_{2 \mathrm{~m}}}{\mathrm{k}_{2}^{\circ}} \times \frac{\mathrm{K}_{\mathrm{b}}}{\overline{\mathrm{V}}}
$$

$\operatorname{para} \mathrm{K}_{\mathrm{b}}=27 \mathrm{M}^{-1}$ e $\overline{\mathrm{V}}=0,37 \mathrm{M}^{-1}$

$$
\operatorname{Lim}_{\mathrm{k}>\mathrm{K}_{\mathrm{b}}} \frac{\mathrm{k}_{2 \max }}{\mathrm{k}_{2}^{\circ}}=\frac{\mathrm{k}_{2 \mathrm{~m}}}{\mathrm{k}_{2}^{\circ}} \times 77
$$

o que prediz um aumento de velocidade de 77 se $\mathrm{k}_{2 \mathrm{~m}} \equiv \mathrm{k}_{2}^{\circ}$. Desde que os aumentos de velocidade encontrados não são maio res que 50, um valor inicial de $k_{2 m}=k_{2}^{0}$ é plenamente justificado. Os valores de $\mathrm{k}_{2 \mathrm{~m}}$ e $\mathrm{K}_{\mathrm{a}}$ com os quais a equação 9 se ajusta melhor aos dados experimentais são apresentados na Ta bela 9. Deve-se notar que os valores de $\mathrm{K}_{\mathrm{a}}$ assim obtidos são iguais aos determinados pelos dados de absorção dentro dos erros experimentais (comparar Tabela 8 com Tabela 9). As cons 
tantes de segunda ordem nas fases micelar $\left(\mathrm{K}_{2 \mathrm{~m}}\right)$ e aquosa $\left(k_{2}^{0}\right)$ são essencialmente iguais fcom exceçăo do p-clorotio fenóxido).

4.4. Sistemas micelares tamponados.

Temos empregado Ions $N$-alquil-4-Gianopiridi nio como substrato para estudar o efeito de micelas ná dis tribuição de produtos (Politi e col., 1978) e quantificar a ligaça de ${ }^{-} \mathrm{OH}$ a micelas de CrAB (Chaimovich et al, 1979). Estes estudos tem aproveitado o fato de que estes ions su primem a emissão de sondas tais como ku (bpy) ${ }_{3}^{2+}$ e que, por serem ions positivos, são excluĩdos de micelas de mesma / carga (Quina, 1977). Estes Ions piridinicos sofrem hidrôli se alcalina para fornecer o N-alquil-4-carbamidopirítínio (A) e a N-alquil-A-piridona (P) correspondente numa propor ção (P/A) que depende do meio e do pH (Kosowex e Patton, 1966; Politi e col., 1978). Deve-se notar ainda que os ions piridínicos mencionados são, por sua vez, completamente excluídos da fase micelar de CTAB quando o grupo alquila ê me tila (Quina, 1977; Chaimovich e col., 1979). Seria lógico/ esperar, por analogia, que o N-meti1-2-cianopiridinio (2-NCP) fosse tambēn excluido da fase micelar. Esta exclusão foi demonstrada pelo fato de que as constantes de stern-Volmer $\left(\mathrm{K}_{\mathrm{SV}}\right)$ para a supressão da emissäo do Ru (bpy) ${ }_{3}^{2+}$ por 4-MCP 
$\left(1040 \pm 20 \mathrm{M}^{-1}\right)$ e $2-\mathrm{MCP}\left(870 \pm 10 \mathrm{M}^{-1}\right)$ são independentes da concentração de CTAB $(0-0,04 \mathrm{M})$, dentro de erro experimental na presença de $0,10 \mathrm{M} \mathrm{KBr}$.

Em contraste com os nossos resultados anterio res obtidos na ausência de tampâo (Chaimovich e col. 1979), - CTAB não afeta a constante de velocidade observada ( $\left.k_{\Psi}(M C P)\right)$ para a hidrólise alcalina de 4-MCP ou 2-MCP na presença de 0,02 M tampão borato (Figura 13). Por outro lado, nas mesmas condiçöes, as constantes de velocidade observadas ( $k_{\psi}$ (NPO)) para a hidrólise alcalina de NPO, um substrato que deveria / ser incorporado eficientemente na fase micelar, diminuem brus camente com o aumento da coneentração de CTAB acima de $I x$ $10^{-3} \mathrm{M}$ (figura 13B). O valor da constante de asșociação de NPo, $K=1.5 \times 10^{4} \mathrm{M}$, foi calculada por extrapolação de dados de literatura obtidos para homólogos de cadeia nais curta; / (Gitler e Ochoa Solano, 1968; Yatsimirski, Martinek e Berezin, 1971). Finalmente, o perfil einético para a hidrólise alcalina de NPA, um substrato que se particiona entre a fase aquosa e a fase micelar, mostra um mäximo com uma diminuição gra dual de $k_{\Psi}$ a concentração alta de CTAB (Figura 14). Deve -se notar que hidrólise alcalina de NPA na presença de detergen. tes é, possivelmente, um dos sistemas mais estudados no campo da catálise micelar (Romsted e Cordes, 1968; Behme e col., 1965; Meyer, 1972; Chevion, Katzhendler e Sarel, 1972). Po 


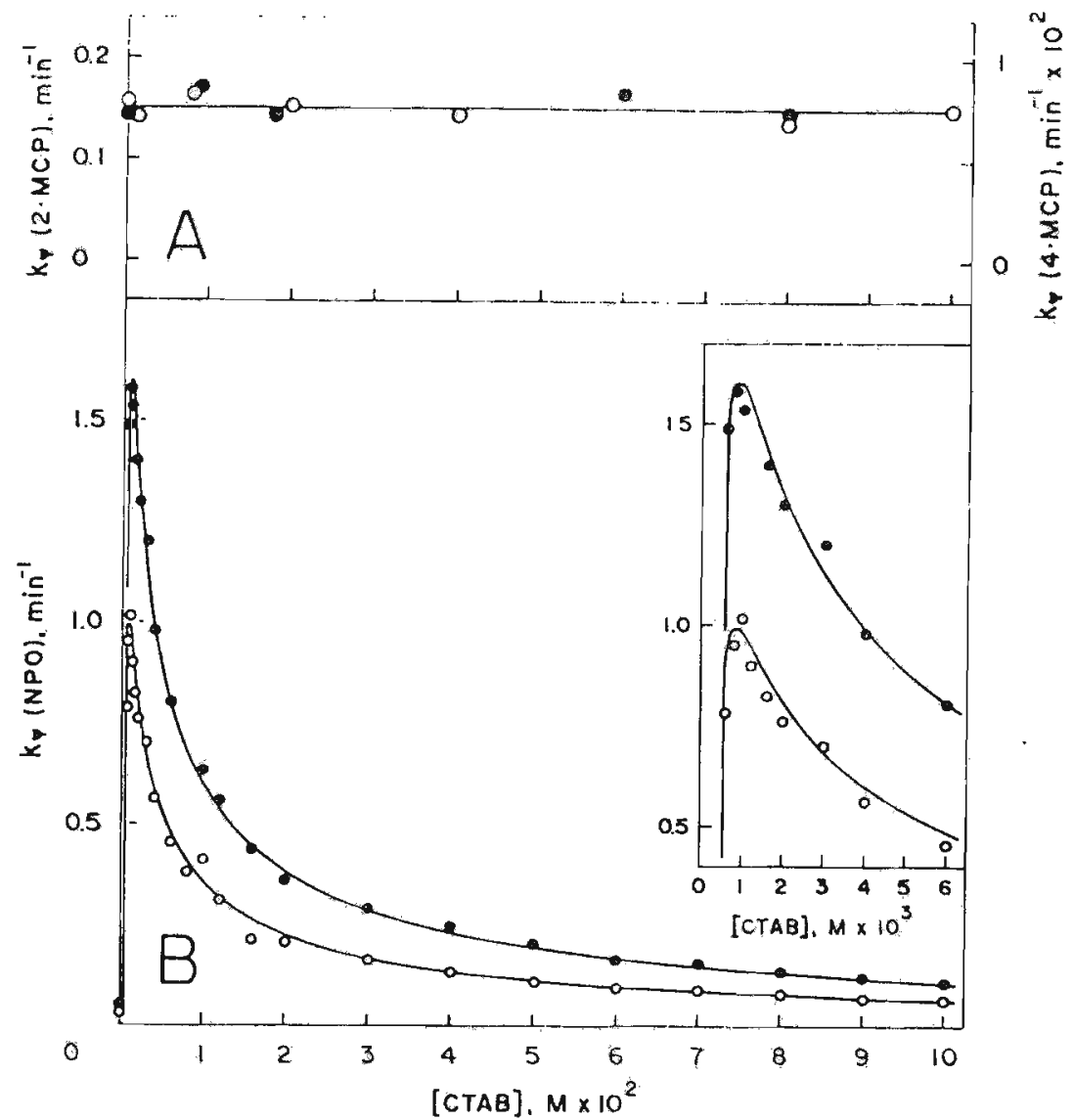

Figura 13. Efeito do CTAB na constante de velo cidade observada para a hidrólise alcalina na presença de tampão borato 0,020M.
A. 2-MCP a pH 9,50 (ن) e
4-MCP a pH 9,80 (0)

B. NPO a pH 9.50 (O) e a pH 9,80 (O) . Os dados ob tidos a CTAB baixo são mostrados em escala / expandida. As curvas foram calculadas (Veja texto) 


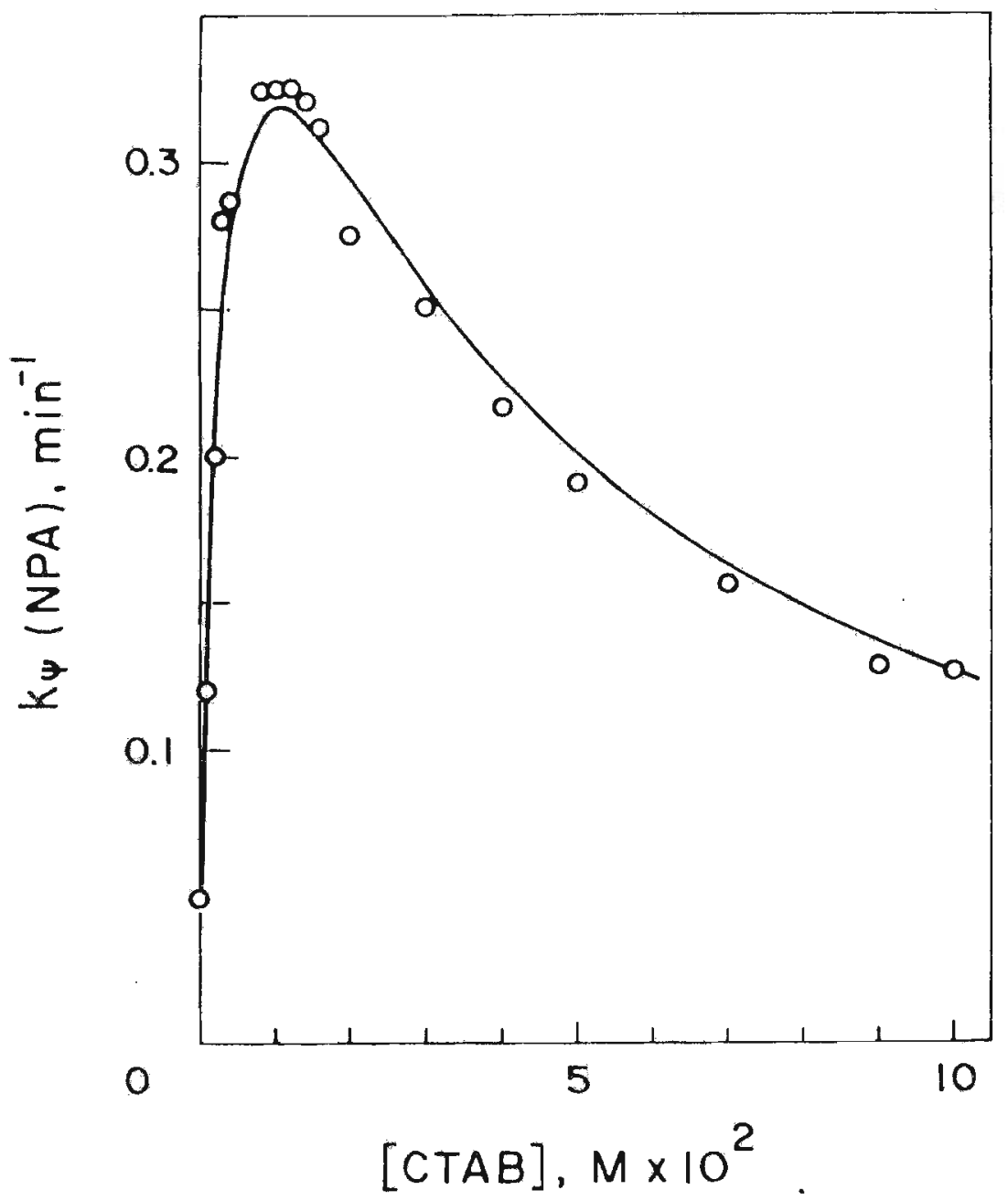

Figura 14. Efeito do CTAB na constante de veloci dade observada para a hidrólise alcalina de NPA a pH 9.50, tampão borato 0,020M. A curva é calcu lađa segundo a descrição do texto. 
rém, apesar da popularidade deste sistema, a análise quan titativa somente começou a ser feita recentemente (Funasaki, 1979, Chaimovich, 1979).

4.5. Anālise de micelas usando sondas de spin.

A. Anälise espectral

Vários fatores determinam a forma e a largu ra das bandas observadas em e s $r$ (a) o(s) tempo(s) de cor relação rotacional (anisotrópico) da sonda de spin; (b) o tempo de correlação rotacional do agregado; (c) o grau de ordem da sonda no agregado; (d) desdobramentos hiperfinos não resolvidos devidos aos prótons e (e) interaçôes spin-spin intermoleculares. Uma anālise computacional sofisticada poderia, eventualmente, avaliar a contribuição de cạ da um destes fatores nos espectros observados. Desde que os sistemas com os quais temos trabalhado são complexos e não estão completamente definidos e jā que informações $x^{-m}$ levantes sobre propriedades estruturais e dinâmicas podem ser obtidas atravēs de uma anālise espectral mais simples, - Eormalismo de estreitamento rotacional foi utilizado em toda a análise espectral. A rigor este formalismo só pode ser aplicado a moléculas esféricas. Entretanto, os espec tros obtidos, sobretudo no caso de micelas e sondas relati. 
vamente soluveis, mostram que as sondas estão se movendo em forma rāpida e quase isotrôpica. Assim, os resultados foram analizados utilizando-se as expressões propostas por Cannon e col. (1975) para calcular os tempos de correlação.

$$
\begin{aligned}
& \tau_{1}=6,5 \times 10^{-10} \mathrm{w}_{0}\left[\left(\frac{h_{0}}{h_{-1}}\right)^{1 / 2}+\left(\frac{h_{0}}{h_{+1}}\right)^{1 / 2}-2\right] \mathrm{s} \\
& \tau_{2}=5,9 \times 10^{-10} \mathrm{w}_{0}\left[\left(\frac{h_{0}}{h_{-1}}\right)^{1 / 2}-\left(\frac{h_{0}}{h_{+1}}\right)^{1 / 2}\right] \mathrm{s}
\end{aligned}
$$

onde $\tau_{1}\left(\tau_{2}\right)$ é o tempo de correlação, $W_{0}$ é a largura da ban da central e $h_{0}, h_{-1}, h_{+1}$ são as alturas das linhas central, campo baixo e campo alto respectivamente.

B. A concentração micelar crîtica e o efeito de substrato na estrutura da micela: interação entre o tiofenōxido e o СТAB.

A figura 15 mostra o espectro de uma sonda de spin anfifílica em tampão (a) e em CTAB em concentração abai xo (b) e acima (c) da $\operatorname{CMC}\left(9,2 \times 10^{-4} \mathrm{M}\right.$ a $25^{\circ} \mathrm{C}$, Fendler e Fen dler, 1975). As restrições impostas ao movimento da sonda pe la incorporação à estrutura micelar são bem evidentes. Parte desta restrição pode ser devida a uma interação eletrostātica entre a sonda e a superfície carregada positivamente.Abai xo da CMC dever-se-ia esperar somente o espectro da sonda em 


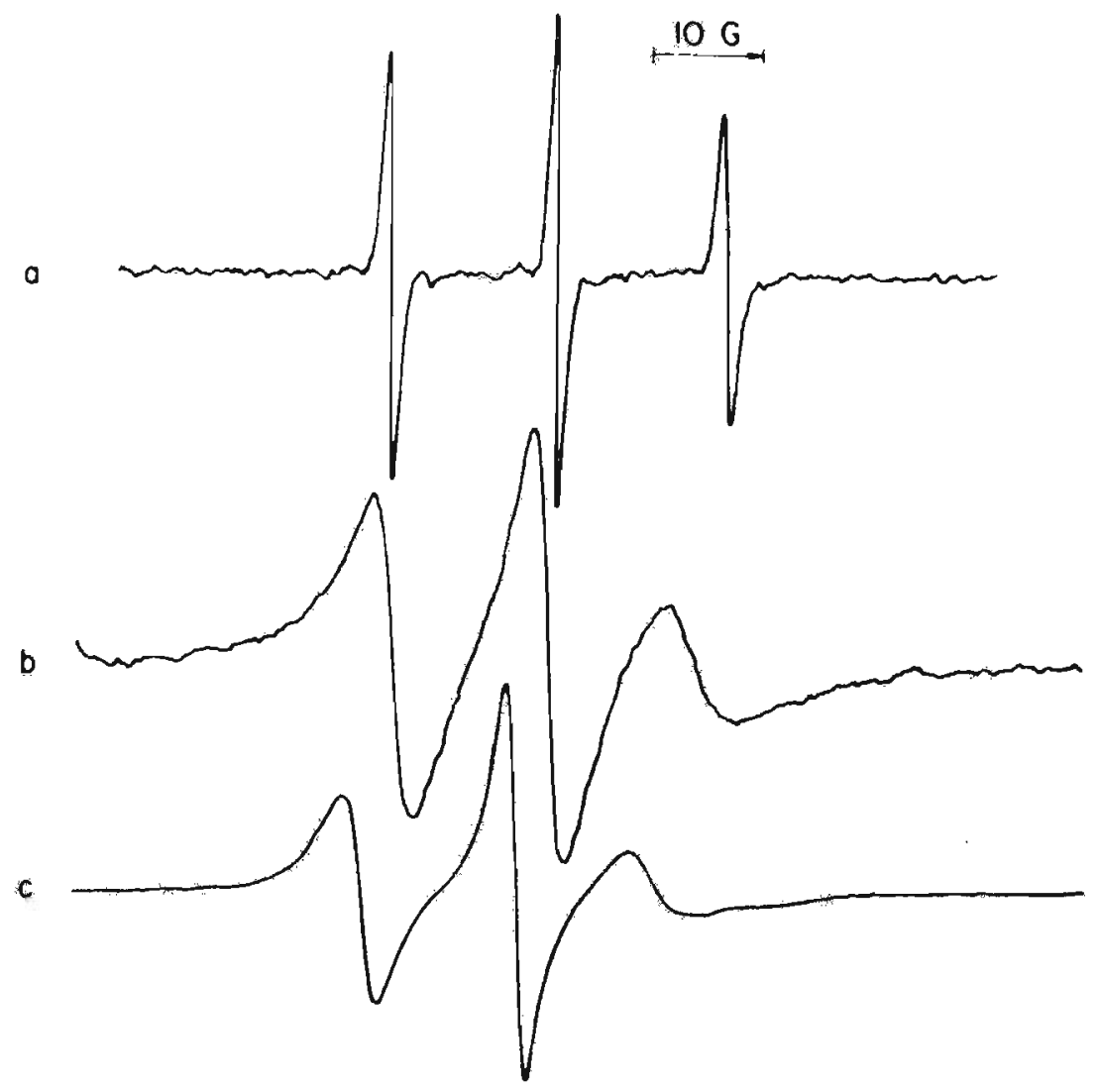

Figura 15. Espectro de e s $x$ do 5-SASL.

(a) em tampão; (b) em $6 \times 10^{-4} \mathrm{M}$ CTAB e

(c) em $5.73 \times 10^{-3} \mathrm{M}$ CTAB. 
āgua, mas pelo contrário, observa-se um maior grau de imo bilização quando comparado com o espectro da mesma sonda em micelas. Este ponto será discutido mais adiante.

Quando a sonda utilizada é o 5-MesL lo metil éster da sonda anterior) os espectros são similares, mas duas diferenças significativas podem ser apontadas: (1) a sonda não è suficientemente solüvel em água para apresen tar um espectro nas nossas condições; (2) o tempo de correlação calculado em detergente é significativamente menor. A Figura 16 mostra a variação dos valores de $\tau_{1}$ em função. da concentração de CTAB para 5-SASL e 5-MeSL. O tempo de corre lação rotacional $\left(\tau_{1}\right)$ aumenta discretamente acima da CMC, en quanto que na CMC, se observa uma variação brusca do ' ${ }_{1}$ ' es pecialmente quando a sonda utilizada é 5-SASL. A possibilidade de relacionar o comportamento espectral da sonda e uma propriedade física do detergente è, então, clara e, a partir destes dados, calculamos: uma CMC do CTAB de $8,75 \pm$ $0,25 \times 10^{-4} \mathrm{M}$, em excelente concordancia com os dados da literatura (Fendler e Fendler, 1975).

$A$ adição do íon tiofenóxido a micelas de CTAB foi examinada sob duas condições experimentais: (1) variando-se a concentração de detergente e mantendo-se a concentra ção de tiofenōxido constante $\left(1 \times 10^{-4}\right),(2)$ mantendo-se 0 detergente constante $\left(3 \times 10^{-3} \mathrm{M}\right)$ e variando-se a concentração de tiofenóxido. o primeiro tipo de experimentos permi - 


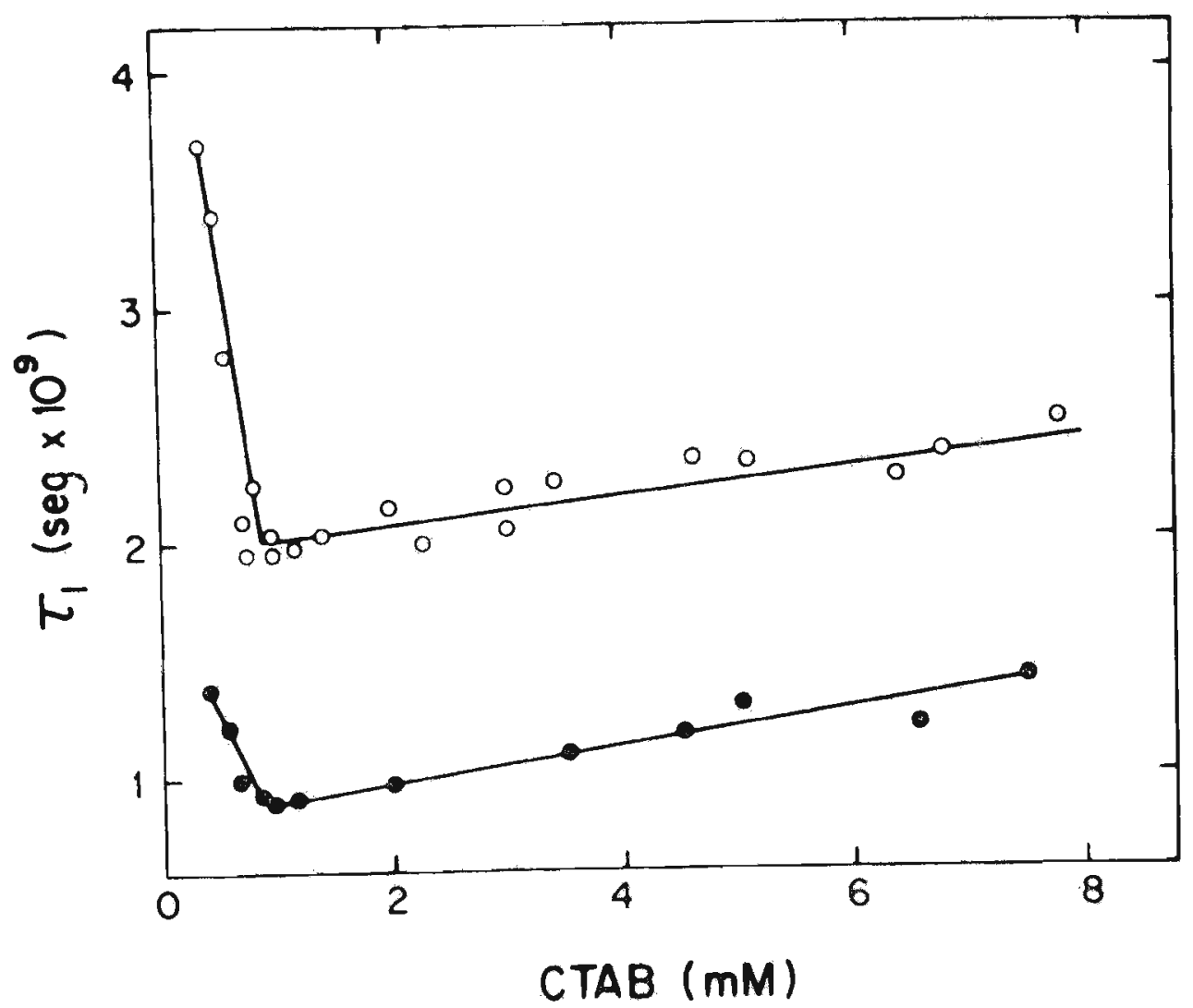

Figura 16. T $\tau_{1}$ para 5-SASL (O) e 5-MeSL (0) em função da concentração de СТAB.

tiu observar uma diminuição da CMC (até $5 \times 10^{-4} \mathrm{M}$ ) e um valor mëdio de $\tau_{1}$ de $2,3 \pm 0,04 \times 10^{-9}$ s na ausência e 2,052 $0,03 \times 10^{-9} \mathrm{~s}$ na presença de tiofenóxido, sempre acima da CMC do CTAB. O segundo protocolo mostrou que a adição de tio fenóxido causa um decréscimo no valor de $\tau_{1}$ que atinge um minimo $\left(1,7 \times 10^{-9} \mathrm{~s}\right)$ quando a relação CTAB/tiofenōxido é de $6 \pm 1$. Aumentando-se a concentração de tiofenóxido $\circ \tau_{1}$ au- 
menta, chegando a um patamar onde o valor de $\tau_{\perp}$ é 2,5 x $10^{-9} \mathrm{~s}$. Observou-se também que, quando a sonda usada é 5-MeSL, o desdobramento hiperfino do espectro da sonda di minui em função do aumento da concentração de tiofenóxido de 14,56 até $14,04 \mathrm{G},\left(6 \times 10^{-3} \mathrm{M}\right.$ tiofenóxido) indicando / que a sonda está inserida numa região de menor polaridade em alta concentração do tiofenóxido.

c. Agregação de detergentes abaixo da concentração micelar crítica.

A figura 17 mostra o espectro que resulta / da incorporação de 5-SASL em várias concentrações de SDS. Apesar da solubilidade mensurāvel do 5-SASL em āgua (Figu ra 17a) não se observa nenhum componente do tipo "fase aquo sa" no espectro desta sonda em SDS acima da CMC (Figura / 17c). Abaixo da CMC, porēm, dois componentes são clara mente distinguíveis (Figura $17 \mathrm{~b}$ e 17d). O valor publicado para a CMC do $\operatorname{SDS}\left(7,6-8,6 \times 10^{-3} \mathrm{M}\right.$, Williams, Phillips e Mysels, 1955) coincide com o valor por nós determinado/ usando o método de e $\mathrm{s} r\left(8,5-9,0 \times 10^{-3} \mathrm{M}\right)$. E claro,por outro lado, que abaixo da CMC podem se distinguir clara mente dois tipos de sinal (Figura 17b). Experimentos de controle realizados extraindo-se a sonda coin soluções de SDS ou diluindo-se soluções que contém sonda e detergen- 


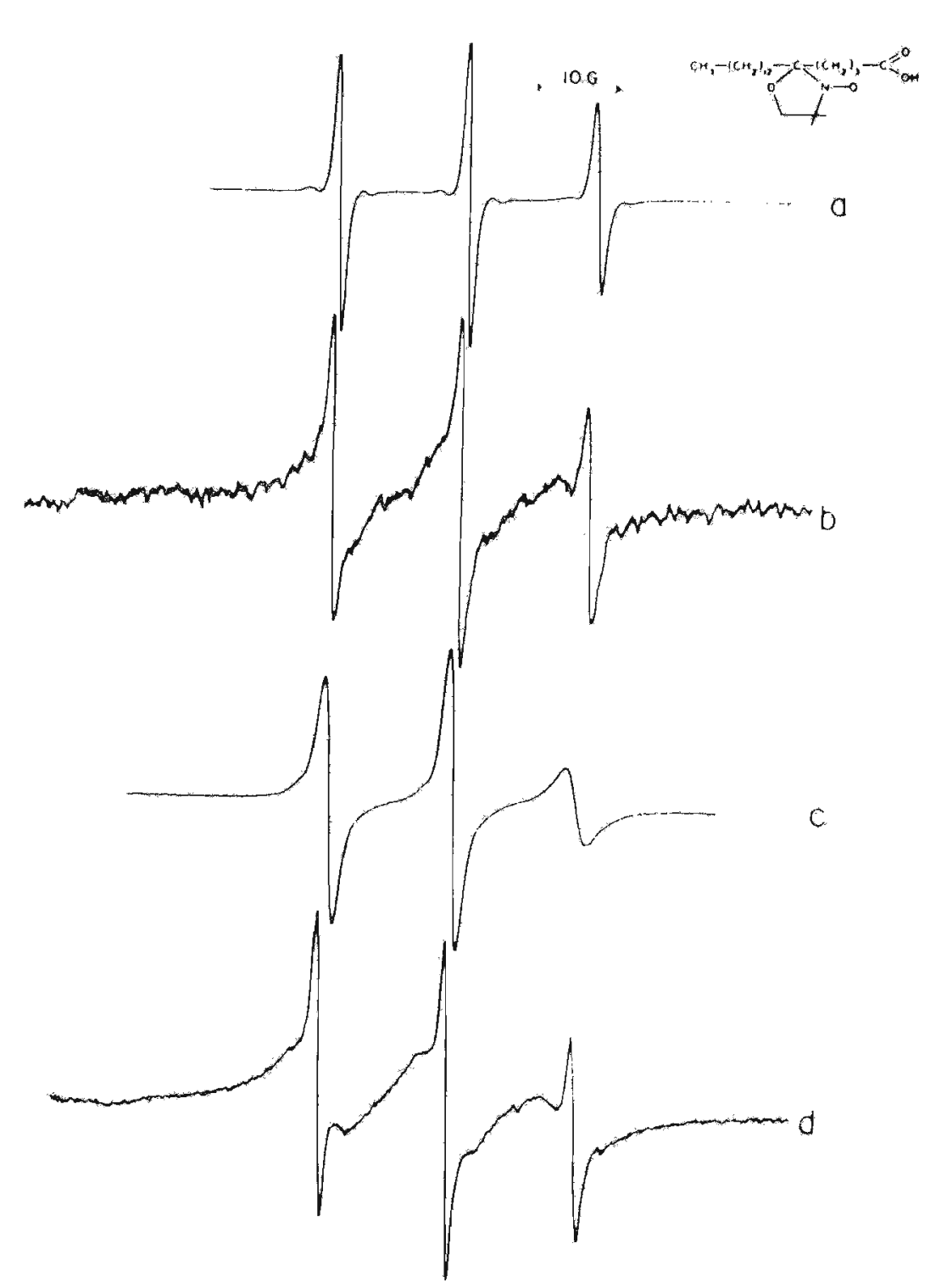

66

Figura 17. Espectro de e s r de 5-SASL em várias concentrações de SDS: (a) 0 ; (b) $5 \times 10^{-3} \mathrm{M}$; (c) $10^{-2} \mathrm{M} e$ (d) $4 \times 10^{-3} \mathrm{M}$.

te (figura 17 d) mostram que os sinais observados abaixo da CMC do SDS não representam um artefato de diluição. Experi mentos semelhantes com outra sonda solüvel (ASI) mostraram resultados anālogos apesar da diferença estrutural entre / ASL e SASL.

Os resultados obtidos ao se utilizar sondas insolūveis em āguá (5-MesL e CSL) são algo diferentes. Al 
gumas características espectrais são apresentadas na Figura 18 para 5-MeSL. O espectro de 5-MeSI em SDS acima da CMC / mostra que o movimento desta sonda é menos restrito que o obtido para 5-SASL nas mesmas condições (Figura 18c). Estes resultados são apresentados na Tabela 10 .
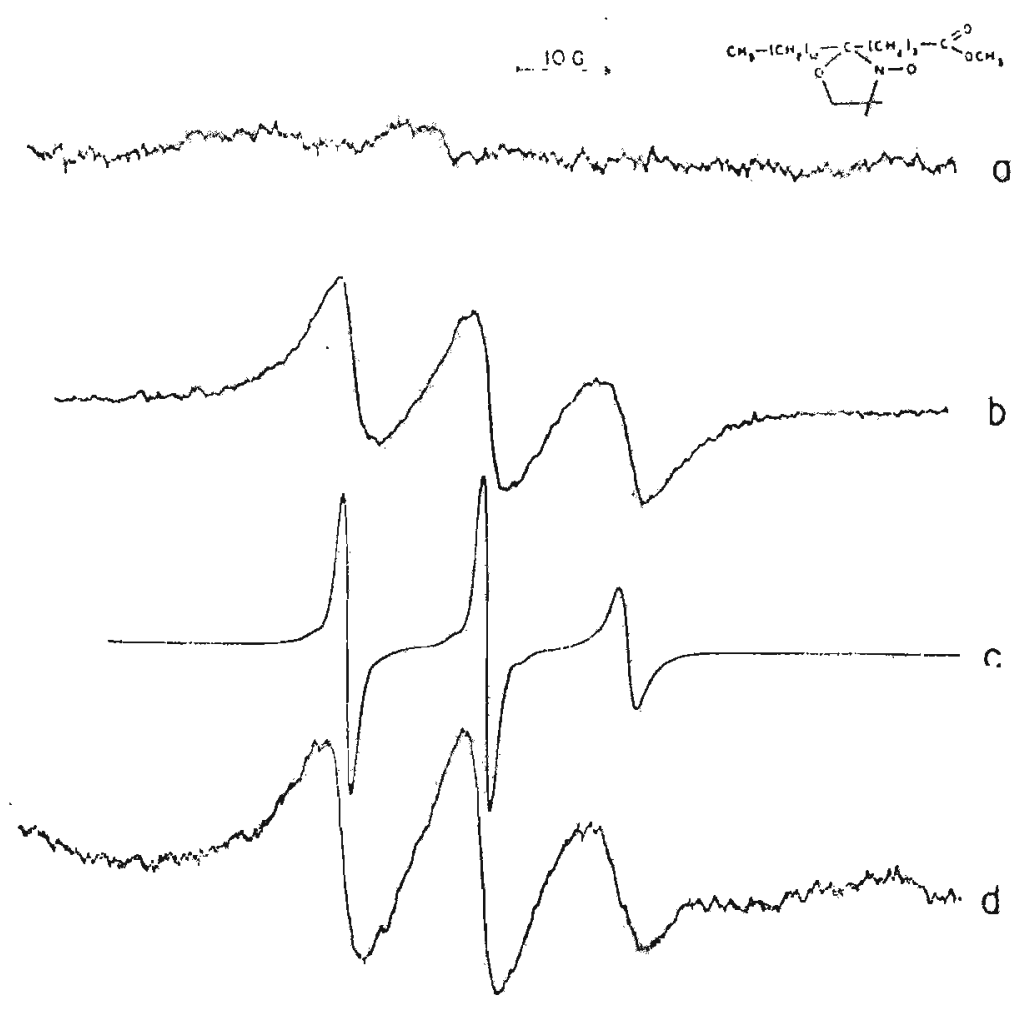

Figura 18. Espectro de e $s \mathrm{r}$ de 5-MesL em vārias concentraçöes de $\operatorname{SDS}$ (a) $0 ;$ (b) $6 \times 10^{-3} \mathrm{M} ;$ (c) $1.10^{-2} \mathrm{M}$ e (d) $5 \times 10^{-3} \mathrm{M}$. 


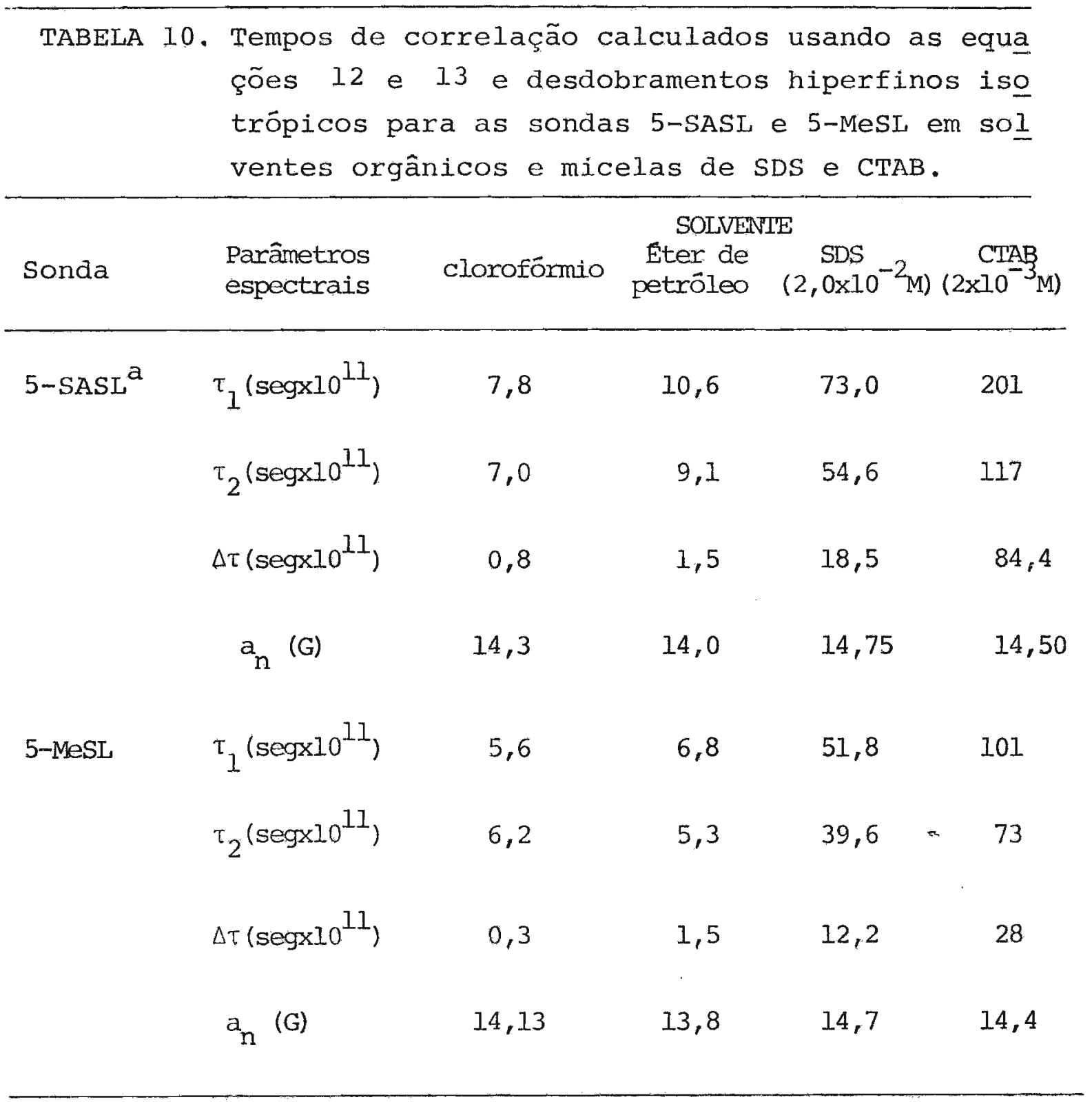

(a) O a para esta sonda em ägua é 15,2 G.

Os espectros das sondas insolūveis em āgua / (Figura 18â) não apresentam dois componentes quando os espec tros são obtidos abaixo da CMC do detergente (comparar 18 b e e $\underline{\mathrm{d}} \operatorname{com} 17 \underline{\mathrm{b}} \mathrm{e} \underline{\mathrm{d}}$ ) . As linhas aparecem alargadas devido, se 
guramente, a interação spin-spin (Figura 18므 e $\underline{a}$ ). Desde que a relação detergente/sonda é idêntica acima e abaixo da CMC, devemos concluir que abaixo da CMC, toda a sonda está contida em agregados de detergente onde a fração de detergente ê menor que aquela existente acima da CMC. Existe, portanto, um aumento 1íquido da relação sonda/detergente nos agregados o que dá origem à interação intermolecular observada. Um expe-rimento controle foi realizado solubilizando-se um filme de sonda com uma solução de SDS abaixo da CMC. O espectro re sultante (Figura 18d) é idêntico ao observado quando a solução contendo sonda e SDS è diluída até uma concentração se melhante de SDS (Figura 18b).

D. Distribuição de solutos insolüveis em agregados de deter gente.

o sistema aqui utilizado consiste em CTAB e CSL em água. O espectro de e s $\mathrm{r}$ de CSL em $1 \times 10^{-2} \mathrm{M}$ CTAB após sonicação (solução s250 Parte Experimental 3.2.5.) con siste de uma única Iinha alargada por troca (Figura 19a). A forma deste espectro muda quando o tempo de sonicação aumenta ou quando a solução é mantida a $50^{\circ} \mathrm{C}$ (Fig. 19b).

Quando um filme de CSL è sonicado em ãgua o espectro obtido na "solução" resultante è similar ao mostrado (Fig. 19a). porëm de menor intensidade. A forma do espec- 


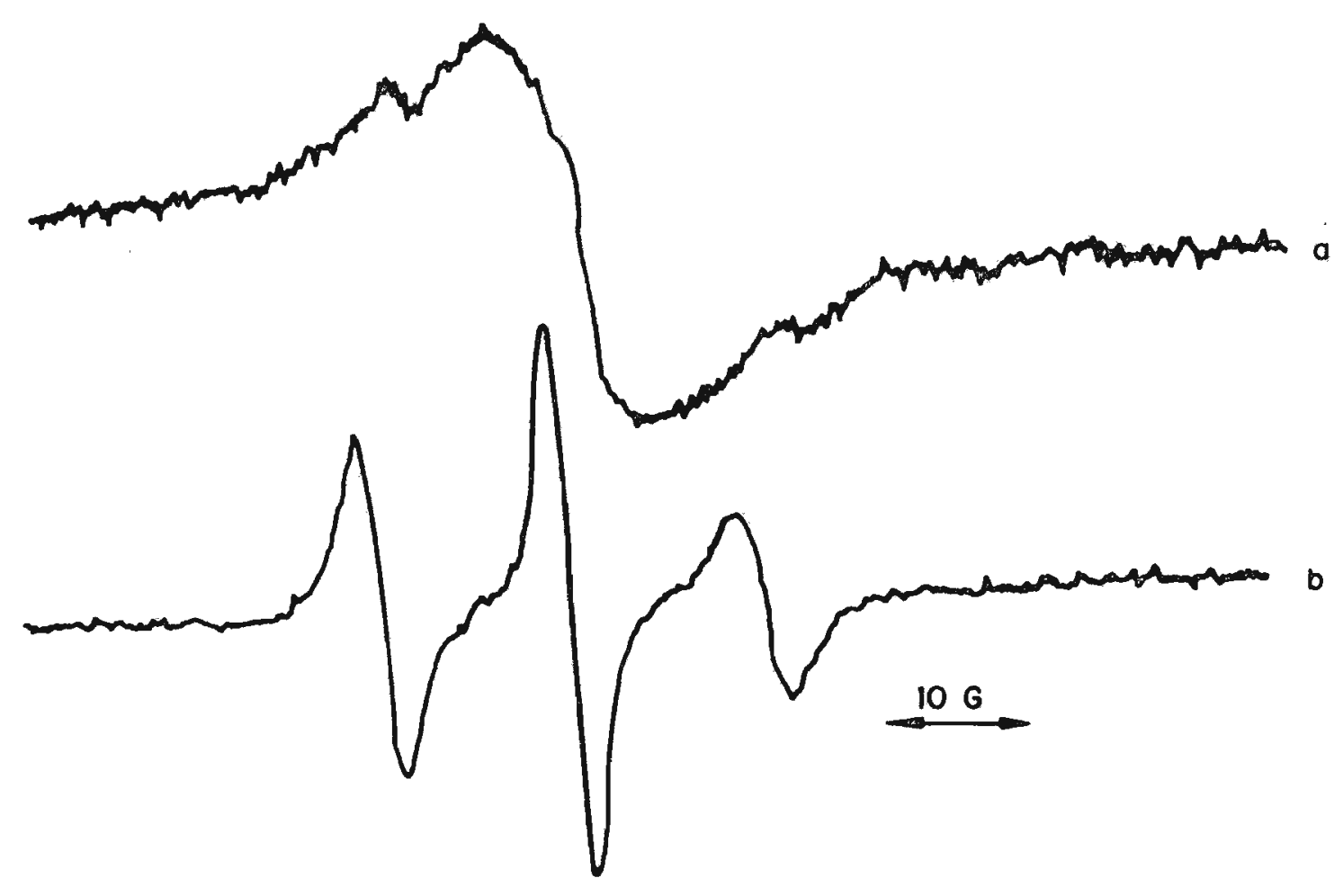

Figura 19. Espectro de e s $\mathrm{r}$ de CSL. (a) $6,7 \mathrm{x}$ $10^{-5} \mathrm{M}$ CSL em $10^{-2} \mathrm{M}$ CTAB após $250 \mathrm{seg}$ de sonicaÇão; (b) $2 \times 10^{-5} \mathrm{M}$ CSL em $10^{-2} \mathrm{M}$ CTAB apōs fil tração por $2200 \AA$ e mantido a $50^{\circ} \mathrm{C}$ por $30 \mathrm{~min}$.

tro não muda com o aumento do tempo de sonicação, desaparece quando a solução é filtrada (2200 凡) e diminui de intensidade com o tempo. Estes resultados sugerem que a sonicação de CSL em ãgua produz uma dispersão de CSL que, como seria de se esperar, é retirada por filtração e sedimenta lentamente causando uma perda do sinal de e s r 
A sonicação de CSL com CTAB abaixo da CMC ( $1 \times 10^{-4} \mathrm{M}$ ) produz um espectro similar em forma e intensi dade àquele mostrado (Figura 19a). Contudo, neste caso, o espectro não muda, em forma ou intensidade, com o tempo e a espécie que produz o espectro de e s $r$ é completamente retida por filtração (2200 $)$ ).

O espectro de CSL em CTAB $10^{-2} \mathrm{M}$ obtido após sonicação e filtração (Millipore, 2200 \&) (solução $\$ 500$ / Parte Experimental 3.2.5.) apresenta mais de um componente (linha cheia da Figura 20). Um dos componentes é uma linha alargada, não resolvida, característica de um agregado onde existe um alto grau de interação spin-spin. Sob as condi Ções usadas (CSL: $\mathrm{CTAB}=0,01)$ e tomando-se 100 como 1imite superior do nümero de agregação de CTAB (Fendler e Fendler, 1975), o número médio de ocupação seria 1 CSL por mí cela. Tal distribuição não deveria resultar num espectro / como o observado e pode-se concluir, portanto, que o CSI não se distribui rapidamente na fase micelar do CTAB.

Os resultados apresentados acima, tomados /

em conjunto, indicam que este sistema poderia gerar infor mações ūteis sobre o mecanismo de solubilização por detergen tes. Este problema foi focalizado em duas formas diferentes: utilizando-se filtração e acompanhando-se a cinética de redistribuição do CSL em CTAB.

Quando a solução S500 (que contēm CSI em CTAB 


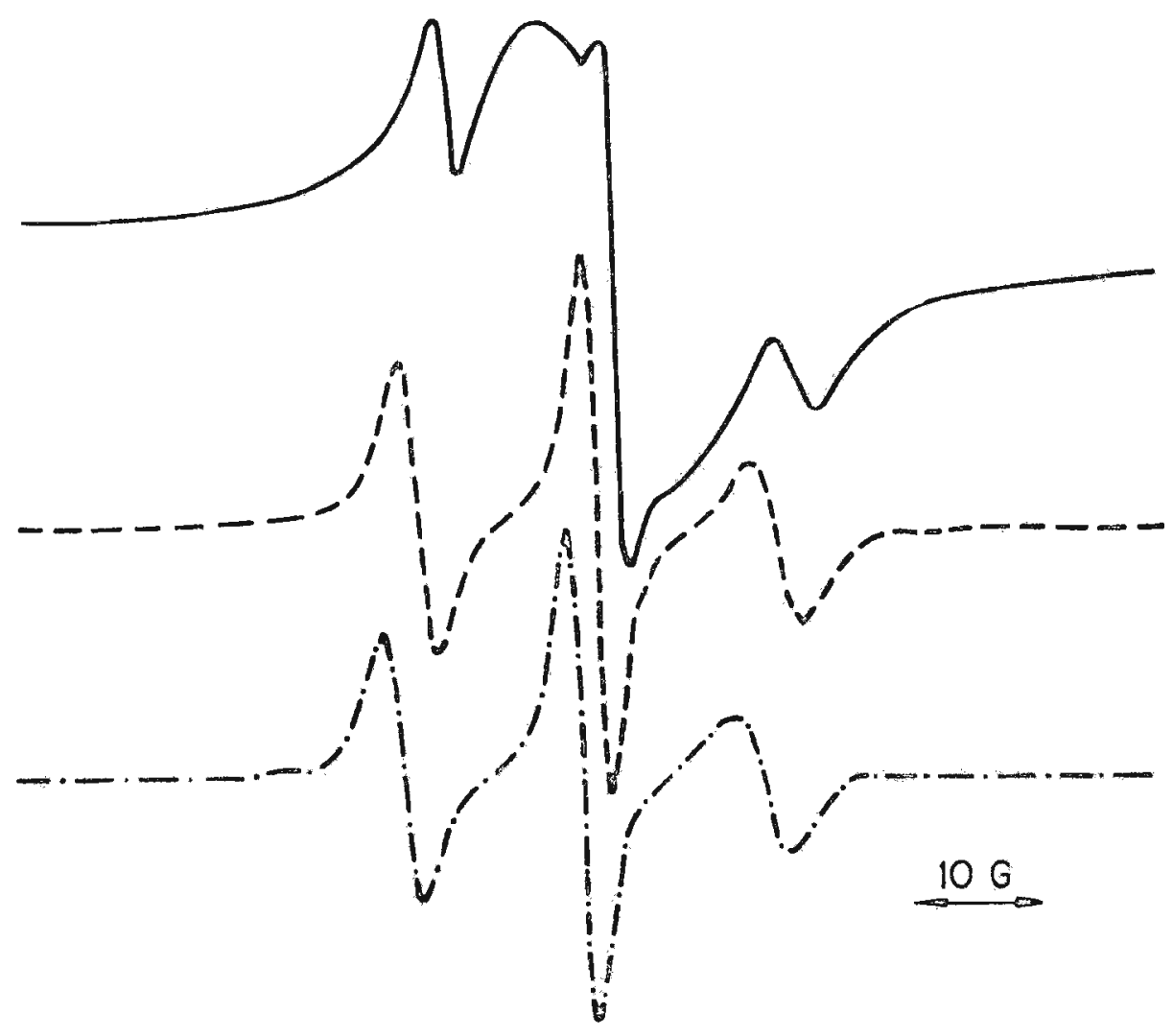

Figura 20. Espectro de e s r de CSL após filtração por Millipore de diversos tamanhos de poro (- - CSL em CTAB $\left(10^{-2} \mathrm{M}\right)$ após sonicação e filtração por $2200 \AA ;(----)$ solução acima após filtração por $1000 \AA ;(-.-.-$.$) , solução acima apōs filtração por$ $250 \AA$.

$\left.10^{-2} \mathrm{M}\right)$ é filtrada em Millipore de tamanho de poro decrescente - componente que mostra um espectro alargado (por interação spin-spin) è perdido gradualmente e se obtēm, finalmente, o espectro esperado para CSL monomërico em micelas de CTAB / 
(Figura 20), O valor da relação CSL: CTAB existente nos agre gados retidos nos filtros foi determinado medindo-se diretamente a quantidade de CTAB retida nos filtros e estimando-se a concentração de CSL por diferença. Estes experimentos permitem descrever, aproximadamente, as classes de agregados $i$ nicialmente presentes na solução 5500 . Na Tabela 11 pode-se observar que o conjunto dos agregados retidos por filtração

TABELA 11. Fração de sonda em diferentes agregados CTAB-CSL

\begin{tabular}{lcccc}
\hline \multicolumn{1}{c}{ Amostra } & CTAB M & CSL M & CTAB/CSI & o CSI \\
\hline Solução s500 & $10^{-2}$ & $2 \times 10^{-5}$ & 500 & $(100)$ \\
$\begin{array}{l}\text { Retido por } \\
\text { filtro de } 2200 \AA\end{array}$ & - & - & 3 & 60 \\
$\begin{array}{l}\text { Retido por } \\
\text { filtro de } 1000 \AA\end{array}$ & - & - & 100 & 10 \\
Filtrado & $10^{-2}$ & $6 \times 10^{-6}$ & 1700 & 30 \\
\hline
\end{tabular}

em $2200 \AA$ contēm $60 \%$ da concentração inicial de CSL e apresen tam uma relação CTAB: CSI relativamente baixa. Uma percentagem baixa do CSL é contida inicialmente em agregados que são reti dos por filtros de $1000 \AA$. A solução remanescente contēm qua se a totalidade de CTAB presente na solução inicial e $30 \%$ do CSL. A relação CTAB/CSL nesta população é bem maior que a ini cial. 
O espectro mostrado com linha cheia na Figura 21 corresponde à solução $\$ 500$ apōs filtração por um Millipore de 2200 A. Este espectro pode ser reproduzido pela adição de espectros caracteristicos das situações inicial e final / no processo de redistribuição (Figura 21.). Note que os valo

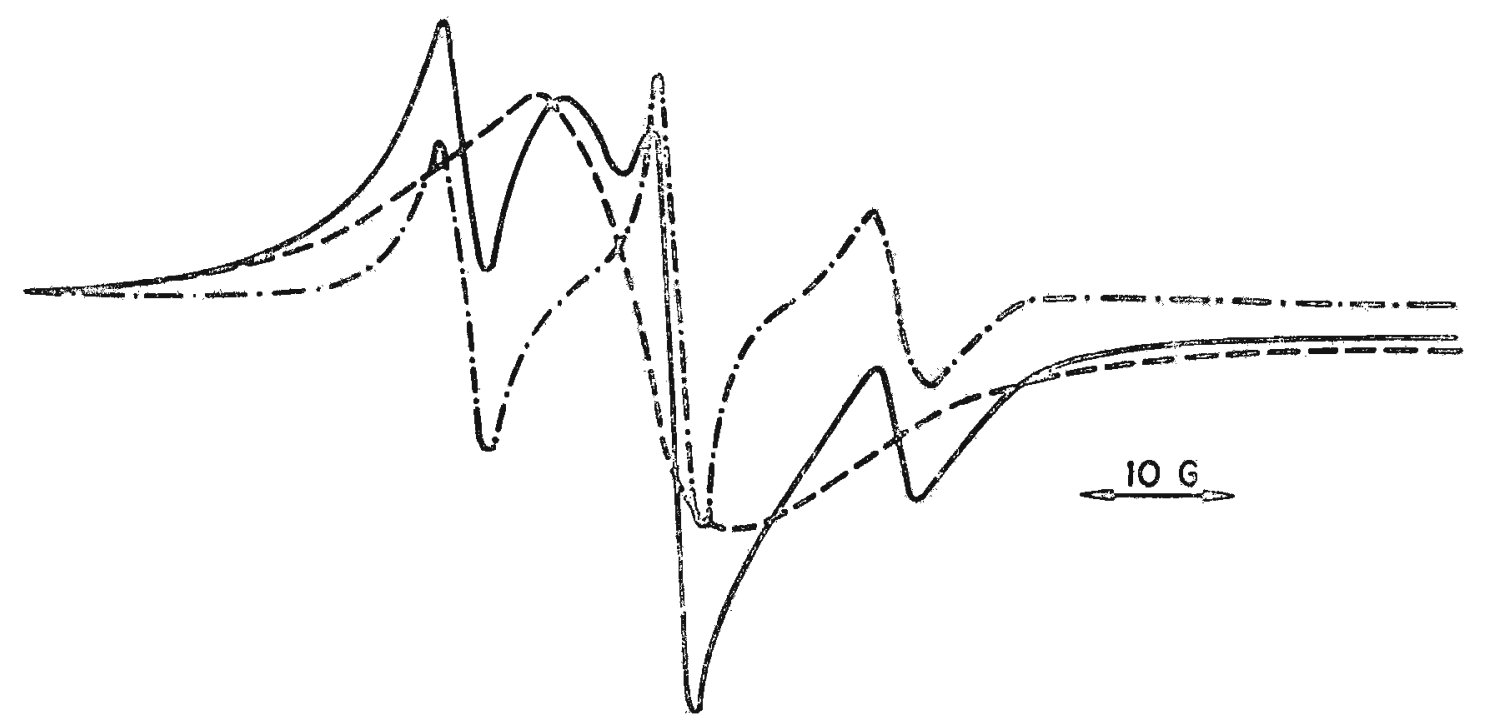

Figura 21. Espectro de e s r da solução s 250 (--) (veja Parte Experimental 3,2.5 e texto); e após incubação por 48 hs a $50^{\circ} \mathrm{C}(\ldots,-$,$) . A Iinha cheia corresponde$ ao espectro da solução 5500 (veja Parte Experimental 3.2.5. e texto) após filtração por $2200 \AA$, o mesmo espectro pode ser obtido somando os dois primeiros $(27: 1)$. 
res de $\mathrm{g}$ nos espectros são significativamente diferentes. A cinētica de redistribuição do CSL em CTAB foi estudada em função do tempo e da temperatura (Tabela 12). A situação fí nal mostrada pelos espectros de e s r é aquela corresponden te à esperada para CSI distribuido uniformemente em micelas de CTAB (Figura 22).

TABELA 12. Meia vida aparente $t_{1 / 2}$ para a redistribui ção de CSL em micelas de CTAB.

\begin{tabular}{|c|c|c|c|c|}
\hline $\begin{array}{c}\text { CSL } \\
\left(\mathrm{M} \times 10^{6}\right)\end{array}$ & $\begin{array}{c}\text { CTAB } \\
\left(M \times 10^{2}\right)\end{array}$ & AMOSTRA & $\begin{array}{c}t^{o} \\
\left({ }^{\circ} \mathrm{C}\right)\end{array}$ & $\begin{array}{l}t_{1 / 2} \\
(h r)\end{array}$ \\
\hline 8 & 1 & Filtrada por $1000 \AA$ & 50 & 7,8 \\
\hline 5,6 & 1 & Filtrada por $2200 \AA$ & 50 & 8,7 \\
\hline 6 & 1 & Filtrada por $2200 \AA$ & 50 & 7,8 \\
\hline 6 & 0,2 & Filtrada por $2200 \AA$ & 50 & 7,8 \\
\hline 6 & 1 & Filtrada por $2200 \AA$ & 25 & 90 \\
\hline
\end{tabular}




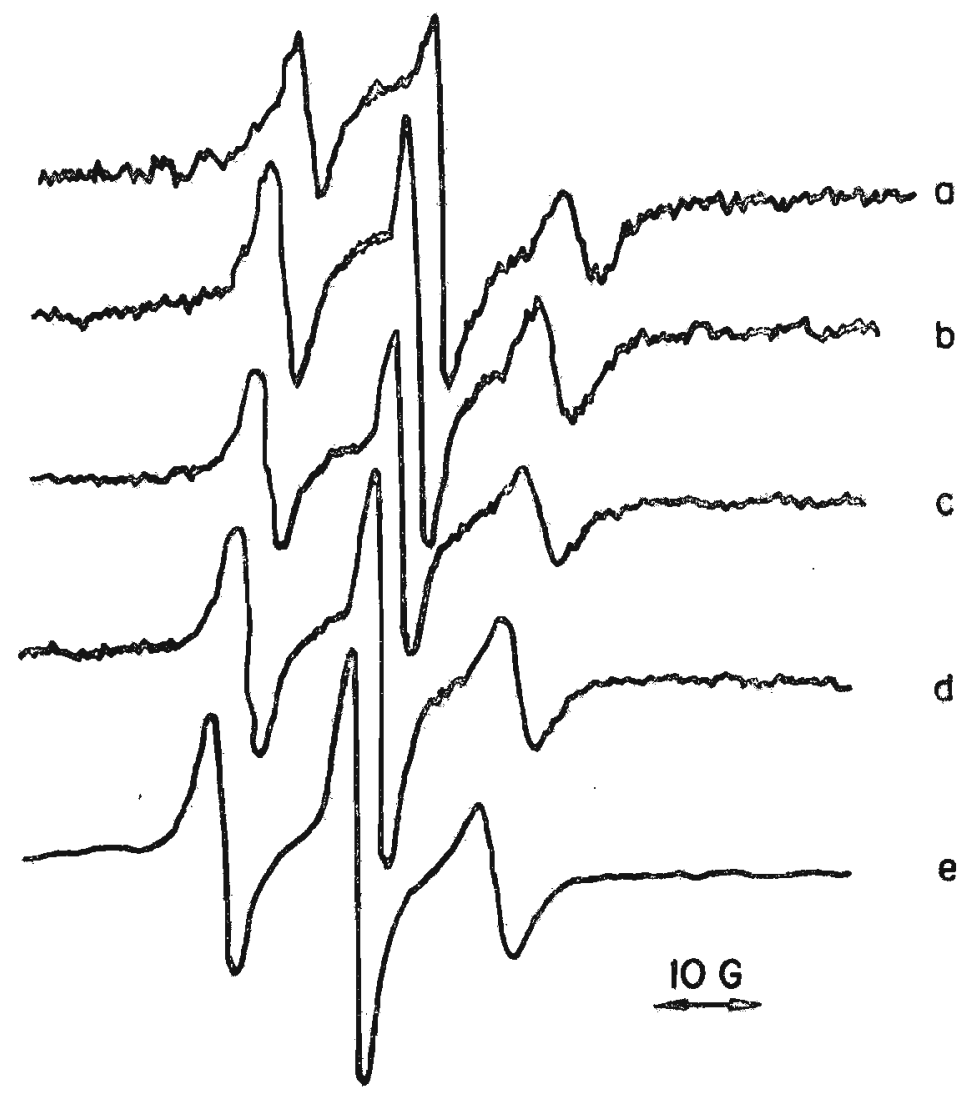

Figura 22. Espectros de e s r do CSL após filtra ção da solução 5250 por $2200 \AA$ e incubação a $50^{\overline{0}}$ por tempos diferentes. Os tempos de incubação e a sensibilidade usada para registrar o espectro são: (a) 0 min.; $2 \times 10^{4}$; (b) 60 min., $2 \times 10^{4} ;$ (c) 120 min., $1,25 \times 10^{4}$; (d) 240 min., $1 \times 10^{4}$ e (e) 480 $\min ., 3,2 \times 10^{3}$. 
"Agora estamos novamente no limite de nosso bom senso, exa
tamente onde os seres humanos perdem a razão".

Goethe

\section{DISCUSSÃO}

5.1. Reações do DNFB em micelas

Aumentos de velocidade relativos produzidos por CTAB. Em geral é difícil medir a constante de velocida de de segunda ordem da reação bimolecular que ocorre na su perfície micelar pois, embora seja fácil incorporar todo o substrato não-iônico, è bem mais difícil estimar o grau de partição do reagente hidrofílico iônico entre as fases aquo sa e micelar (Bunton e Wolfe, 1973) (Porēm, ver Quina e Chai movich, 1979). Os aumentos de velocidade relativos produzi dos por CТAB micelizado para várias reações de DNFB com nu cleófilos iônicos são apresentados na Tabela 13. Estes va lores foram calculadas no māximo das curvas que relacionam $\mathrm{k}_{\Psi}$ com CTAB . A catálise micelar aumenta de forma signifi cativa e a concentração de detergente no máximo de catálise decresce à medida que o nucleófilo é mais hidrofóbico. Este efeito jā fora descrito em outros sistemas catalizados por micelas (Berezin, Martinek e Yatsimirski, 1973, Gi tler e Ochoa-Solano,1968; Bunton, Robinson e Sepúlveda, 
TABELA 13. "Catálise" por CTAB de reações de ataque nucleo filico à $\operatorname{DNFB}^{\mathrm{a}}$.

\begin{tabular}{lc}
\hline Nucleófilo & $\mathrm{k}_{\text {rel }}$ \\
\hline$-\mathrm{OH}$ & $58^{\mathrm{b}}$ \\
$\mathrm{H}_{2} \mathrm{~N} \mathrm{CH}_{2} \mathrm{CO}_{2}^{-}$ & $30^{\mathrm{b}}$ \\
Anilina & $8^{\mathrm{b}}$ \\
Fenóxido & 230 \\
Tiofenöxido & 1100 \\
\hline
\end{tabular}

(a) A $25^{\circ} \mathrm{C}$ relativo à reação em āgua; (b) Bunton e Robinson $(1969,1970)$.

1969). Estas diferenças poderiam ter duas causas: (1) A incorporação dos nucleōfilos hidrofóbicos, como fenóxido e tiofenóxido, na fase micelar seria maior e, (2) ao mesmo / tempo, estes penetrariam mais profundamente na camada de stern, que constitui o sitio de reação. Os compostos aromäticos, em especial aqueles que possuem substituintes que doam elétrons, interagem fortemente com micelas. Reação com o íon tiofenöxido. As reações bi moleculares modificadas por micelas exibem, em geral, um má ximo definido com o aumento da concentração de detergente. 
Estes mäximos tem sido racionalizados em termos de efeitos salinos negativos causados pelo contra"ion do detergente (Cor des e Gitler, 1973) e a partiçẫo do reagente iônico entre a agua e a fase micelar (Bunton e Robinson, 1968). Este tultimo, que é na verdade um efeito de diluição, tem sido aplica do quantitativamente para analizar entre outras reaçöes a hidrôlise de acetais catalizada por SDS (Bunton e wolfe,1973).

A reação de DNFB com tiofenóxido ẻ uma exceção a norma. Aplícando-se o tratamento de diluição ao máximo de velocidade, assumiu-se que um reagente näo afetaria a incorporação do outro na micela. A observação de um patamar na reação đó tiofenóxido sugere que um reagente pode afetar a interação do outro com a micela, embora isso näo aconteça aparentemente com a fenöxido. Se o tiofenöxido e o DNFB for mam um complexo na micela, o perfil do gräfico $k_{4} /$ CTAB pode ria apresentar um patamar como o observado para as reaçöes unimoleculares catalizadas por micelas (Bunton e col, , 1967; Bunton e col., 1973; Bunton, Kamego e Minch, 1972). Alterna tivamente poder-se-ia assumir que um reagente altera a es trutura da micela de modo que a nova fase micelar incorpore - segundo substrato mais facilmente. A forte interação entre o tiofenöxido e o CTAB fazem esta hipótese atraente, e ë apoiada pela observação de um espectro diferencial entre o m-dinitrobenzeno e o tiofenóxido na presença de CTAB. A anạ Iise quantitativa, ifgorosa, destes dados não foi realizada 
até agora, Apresentamos, neste trabalho, um inîcio de anāli se que, usando o formalismo da teoria de troca iônica em so luções micelares (Quina e Chaimovich, 1979, Chaimovich,1979), oferece uma primeira interpretação do efeito de micelas na reação do tiofenol com DNEB.

Mostramos, recentemente (Quina e Chaimovich, 1979) que a expressão apropriada para a constante de veloci dade observada $\left(k_{\psi}\right)$ de uma reação entre um substrato não car regado, como DNEB, e um muleófilo cuja carga é oposta à da micela, como o tiofenóxido, numa solução micelar de CTAB ê

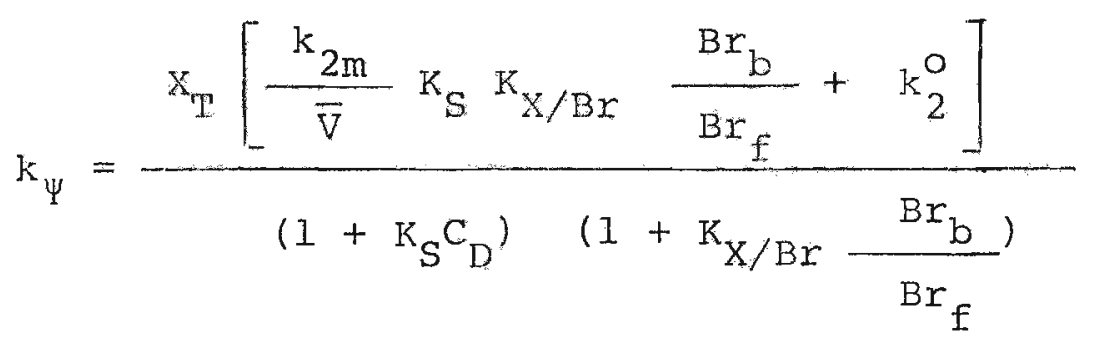

Nesta equação $K_{S}$ é a constante de distribuição do substrato neutro. O valor mais utilizado de $\mathrm{K}_{\mathrm{S}}$ para $\mathrm{DNFB}$ é $27 \mathrm{M}^{-1}$ (Yat simirski e col., 1975). Por analogia com outros derivados / como os nitroanisois $\left(\mathrm{K} \simeq 100 \mathrm{M}^{-1}\right.$ ) (Boni.1ha e col., 1979)e considerando outros valores publicados para a constante de incorporação de DNFB (Fenaler e Fendler, 1975) ê difícil ą creditar que $27 \mathrm{M}^{-1}$ seja o valor correto de $k_{S}$ para DNFB.

$\mathrm{x}_{\mathrm{T}}$ é a concentraçäo total de tiofenol adicio nado, $k_{2 m} e k_{2}^{o}\left(260 \mathrm{M}^{-1} \mathrm{~s}^{-1}\right)$ são as constantes de segunda or dem nas fases micelar e aquosa, respectivamente. $\bar{V}$ è o volu 
me de reação por mol de detergente micelizado $10,37 \mathrm{~L} / \mathrm{mol}$ para CTAB, veja 4,4). $K_{X / B r}$ é o coeficiente de seletivida de para troca tiofenöxido/brometo na superficie da micela. Este valor foi calculado a partir da constante de distribuição do tiofenóxido, $\mathrm{K}_{\mathrm{X}}\left(=3900 \mathrm{M}^{-1}\right.$, Cuccovia e col., 1978) jā que se pode demonstrax (Quina e Chaimovich, 1979) que estas constantes estão relacionados por: (ver chaimovich, 1979 para uma análise da diferença entre os dois pa râmetros).

$$
\mathrm{K}_{\mathrm{X}} \simeq \mathrm{K}_{\mathrm{X} / \mathrm{Br}} \frac{(1-\alpha)}{B r_{f}}
$$

onde $\alpha$ é o grau de ionização da micela $(=0,2 \pm 0,05$, Roms ted, 1975; Funasaki, 1978; Smith, 1979) e $\mathrm{Br}_{\mathrm{f}} \bar{e}$ a concentra ção analítica de brometo livre. o valor utilizado no câlcu 10 foi $\mathrm{K}_{\mathrm{X} / \mathrm{Br}}=15$.

Na presença de um sal não comum, neste caso a espécie $\mathrm{B}(\mathrm{OH})_{4}^{-}$derivada do tampão, que interage com a fase micelar (veja 4.4 e 5.4), as expressões apropriadas / para as concentrações analiticas de borato total $\left(B_{T}\right)$, borato ligado $\left(\mathrm{B}_{\mathrm{b}}\right)$, brometo ligado $\left(B r_{b}\right), B_{f}$ e tiofenöxido ligado $\left(\mathrm{X}_{\mathrm{b}}\right)$ são: (Quina e Chaimovich, 1979)

$$
\begin{aligned}
& B_{T}=B_{b}+B_{f} \\
& B_{b}=\frac{X_{b} B_{T}}{K_{X / B} X_{T}+x_{b}\left(1-K_{X / B}\right)}
\end{aligned}
$$




$$
\begin{gathered}
{ }_{\mathrm{Br}}=\alpha_{\mathrm{D}}+\mathrm{CMC}+\mathrm{X}_{\mathrm{b}}+\mathrm{Z}_{\mathrm{b}} \\
\mathrm{Br}_{\mathrm{b}}=(1-\alpha) \mathrm{C}_{\mathrm{D}}-\mathrm{x}_{\mathrm{b}}-\mathrm{Z}_{\mathrm{b}} \\
\mathrm{x}_{\mathrm{b}}^{3}\left(1-\mathrm{K}_{\mathrm{X} / \mathrm{B}}\right)\left(1-\mathrm{K}_{\mathrm{X} / \mathrm{B}}\right)+\mathrm{x}_{\mathrm{b}}^{2} \mid \mathrm{A}_{1}\left(1-\mathrm{K}_{\mathrm{X} / \mathrm{B}}\right)+\left(1-\mathrm{K}_{\mathrm{X} / \mathrm{Br}}\right) \\
\left(\mathrm{X}_{\mathrm{T}} \mathrm{K}_{\mathrm{X} / \mathrm{B}}+\mathrm{B}_{\mathrm{T}}\right)\left|+\mathrm{X}_{\mathrm{b}} \mathrm{X}_{\mathrm{T}}\right| \mathrm{K}_{\mathrm{X} / \mathrm{Br}}\left(\mathrm{B}_{\mathrm{T}}-(1-\alpha) \mathrm{C}_{\mathrm{D}}\left(1-\mathrm{K}_{\mathrm{X} / \mathrm{B}}\right)\right. \\
+\mathrm{K}_{\mathrm{X} / \mathrm{B}} \mathrm{A}_{1} \mid-\mathrm{K}_{\mathrm{X} / \mathrm{Br}}(1-\alpha) \mathrm{C}_{\mathrm{D}} \mathrm{K}_{\mathrm{X} / \mathrm{B}} \mathrm{X}_{\mathrm{T}}^{2}=0
\end{gathered}
$$

onde

$$
\mathrm{A}_{1}=\alpha \mathrm{C}_{\mathrm{D}}+\mathrm{CMC}+\mathrm{K}_{\mathrm{X} / \mathrm{Br}} \mathrm{X}_{\mathrm{T}}+(1-\alpha) \mathrm{C}_{\mathrm{D}} \mathrm{K}_{\mathrm{X} / \mathrm{Br}}
$$

Nesta equação usamos o coeficiente de seletividade para a troca tiofenóxido/borato definido como

$$
k_{X / B}=\frac{x_{b} B_{E}}{x_{E} B_{b}}
$$

que pode ser relacionado com os coeficientes correspondentes para a troca tiofenóxido/brometo e borato/brometo por

$$
\mathrm{K}_{\mathrm{X} / \mathrm{B}}=\mathrm{K}_{\mathrm{X} / \mathrm{Br}} / \mathrm{K}_{\mathrm{B} / \mathrm{Br}}=400 \quad \text { (veja } 4.4 \text { e 5.4) }
$$

Utilizando as equações 14 e 16-19 foram obtidas as curvas / 
Mostradas na Figura 23, Pode-se observar que utilizando-se

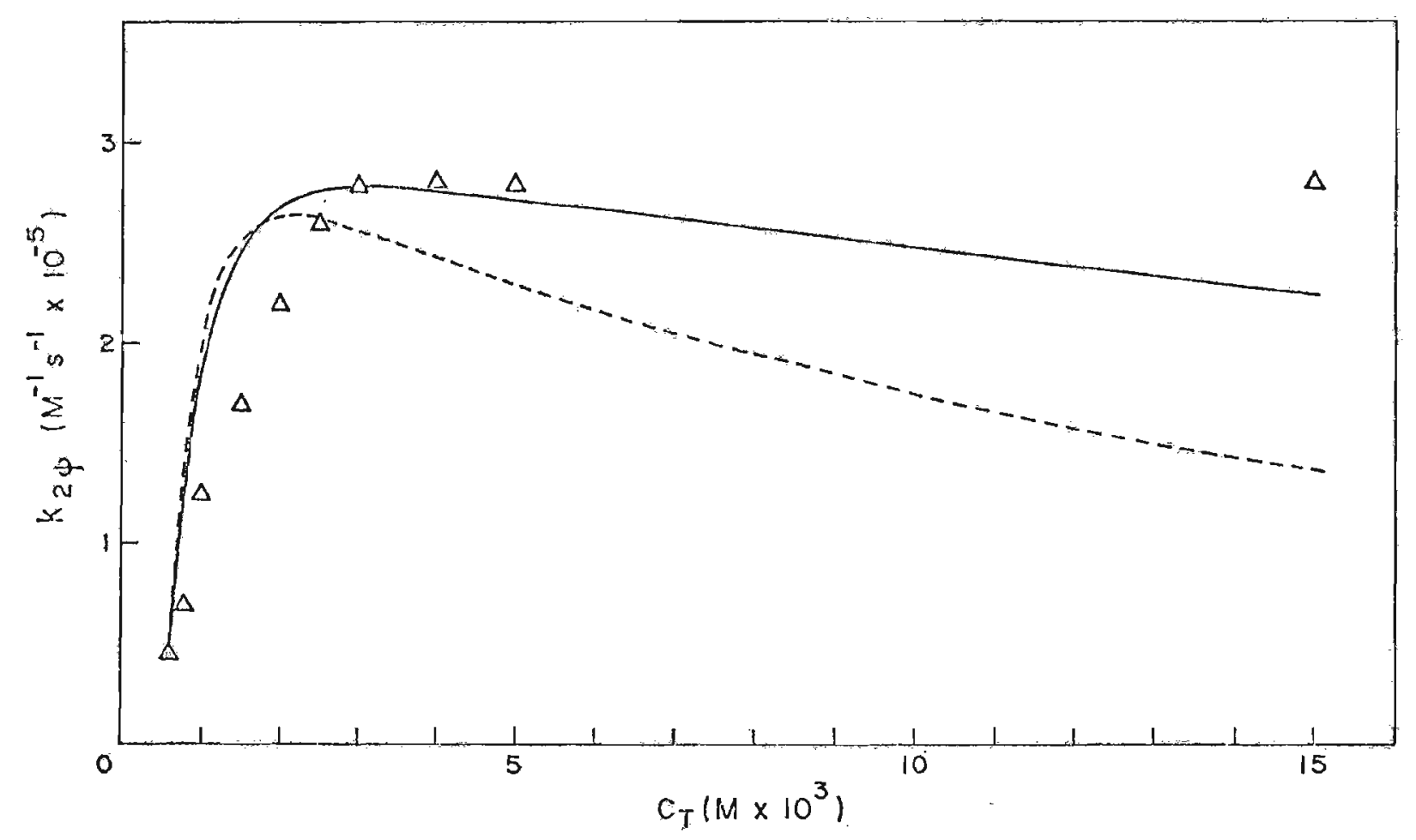

Figura 23, Cálculo do efeito de CTAB na reação de tiofenôxido com DNFB (veja o texto) ( $\Delta$ ) pontos / experimentais; parâmetros utilizados $\mathrm{CMC}=5 \times 10^{-4}$ $\mathrm{M} ; \mathrm{K}_{\mathrm{X} / \mathrm{B}}=15 ; \alpha=0,2 ; \mathrm{k}_{2}^{0}=260 \mathrm{M}^{-1} \mathrm{~s}^{-1} ; \overrightarrow{\mathrm{V}}=0,37 \mathrm{M}^{-1} ;$ $(-) \mathrm{K}_{\mathrm{S}}=27 \mathrm{M}^{-1}, \mathrm{k}_{2 \mathrm{~m}}=4420, \mathrm{~B}_{\mathrm{T}}=0,01 \mathrm{M}_{\mathrm{j}}(\cdots) \mathrm{K}_{\mathrm{S}}=100$ $\mathrm{M}^{-1} ; \mathrm{k}_{2 \mathrm{~m}}=1,300 ; \mathrm{B}_{\mathrm{T}}=0,01 \mathrm{M}$. 
- conjunto de parâmetros mais adequados (curva ) a forma da curva prediz uma diminuição de velocidade bem mais acen tuada que a observada. Deve-se notar ainda que em nenhum / dos casos simulados $k_{0}$ se aproxima de $k_{2 m}$ sugerindo que, nes te caso, a micela de CTAB aumenta a reatividade intrínseca do tiofenóxido.

E possível que, de fato, a formação de um complexo entre os substratos (na fase micelar) seja a me lhor racionalização deste efeito (veja o espectro diferencial no modelo, Parte Experimental 3.2.7.) Somente com uma análise quantitativa rigorosa poderá se afirmar se neste sistema existe uma mudança real da reatividade causada pe la interface de fase micelar do CTAB.

5.2. Reações de $S-a c i l-\beta$-mercaptoetilaminas

A "catálise" micelar provēn, frequentemente, da concentração dos reagentes na fase micelar; este efeito obviamente não existe em reações mono- e intramoleculares. Se a reação não catalizada é muito sensîvel a mudanças no solvente ou à adição de eletrólitos, as modificações na ve.locidade causadas por micelas vão refletir, diretamente, a incorporação de substrato num meio diferente da água. Assim, as moảificações na velocidade são dificilmente interpretáveis em termos de efeitos especificos das micelas na reativida 
de do substrato,

A fonte mais provāvel do efeito inibitōrio do SDS na reação de transferência intramolecular de acila de $S$ para $N$ em $\beta$-mercaptoetilaminas seria uma mudança de pK do grupo amônio terminal causada pela interação eletros tática com a superfície negativa da micela. No caso de substratos de cadeia longa, uma diminuição da sua flexibí lidade, causada tanto pela contribuição superficial como hidrofóbica, poderia conduzir a uma estabilidade adicio nal do estado inicial e, assim, a um aumento da inibição causada pela micela negativamente carregada.

A explicação mais simples para a diminuição de velocidade causada pelo SDS na reação do AMA é um aumen to do pk do amônio terminal. De fato a inibição de 100 ve zes observada para o AMA pode ser explicada por um aumento de pK por duas unidades. Deslocamentos de pK desta magnitu de tem sido observadas numa sērie de reações modificadas / por micelas (Bunton, 1973; Cordes, 1973; Fendler e Fendler, 1975). Se este efeito fosse a ûnica fonte de inibição, a velocidade de reação da forma desprotonada não seria afeta da na camada de Stern da micela. Por sua vez, isto sugeriria pouca penetração do substrato na fase micelar e esta ria de acordo com a pequena estabilização hidrofóbica espe rada para um único grupo $\mathrm{CH}_{3}$ e o valor da constante de dis tribuição do AMA em SDS. Desde que o pK do grupo amônio è 
9,1 (Martin e Heđrick, 1962) o pk aparente em micelas de SDS deve ser da ordem de 11 .

A relações altas SDS/OMA, onde o efeito inibitōrio pođe ser analizado quantitativamente, a velocidade em micelas é menor que a velocidade em água por um fator de 1,7 $x 10^{3}$. Uma mudança de $\mathrm{pk}$, como ünica fonte de inibição è im provāvel. Embora o efeito de SDS no pK de aminas alifäticas não tenha sido descrito, o deslocamento do $\mathrm{H}_{0}$ em aminas pri mārias, secundārias e terciārias ē, no māximo 1,25 unidades (Bunton e Robinson, 1970). Alēm disto, a diminuição de pK de dođecilamônio após micelização (que pođe ser considerado . o efeito reverso da incorporação do în alquilamônio numa mice la negativa) não é maior que 1,4 unidades de $\mathrm{pH}$ (Menger e Lynn, 1975). Estas considerações e o efeito de SDS na reação de AMA permitem colocar um limite de duas unidades de $\mathrm{pH}$ no deslocamento do $\mathrm{pK}$ do OMA produzido por SDS. Mesmo se considerando o efeito de SDS no pK existe um fator de, pelo menos 20 vezes, não explicado na inibição.

Este último fator pođe ser facilmente explica do assumindo-se uma diminuição de flexibilidade do substrato. Os experimentos de rmn mostram que o sinal observado para os prótons da ponte metilênica do OMA é alargada por SDS. Desde que não se observa desdobramento do sinal em nossas condições, os dados sugerem fortemente que o alargamento se deve a uma diminuição da liberdade conformacional deste segmento do 
substrato.

Os solutos possuem uma mobilidade considerá vel na fase micelar (Fendler e Fendler, 1975; Ohnishi, Cyr e Fukushima, 1970; Nakagawa e Jizimoto, 1972). e a liberda de de movimento ao longo da cadeia do detergente é restrita de forma apenas moderada; contudo, a restrição mâxima da liberdade de movimento tem sido observada perto do segmento polar da cadeia do detergente (Williams e col., 1973), e o tipo de movimento do substrato pode ser restrito de acordo com sua relação estrutural com a superfície da mice la (Shinitzky e col., 1971). Um bom exemplo desta relação entre a estrutura do substrato e a natureza do detergente é o aumento da população de um dos isômeros de N-octanoato de sarcosina ('Takahashi e col., 1976), demonstrando que in terações favoráveis podem estabilizar significativamente / uma conformação particular do substrato na interface.

Desde que as constantes de distribuição (á gua/micela) de substratos hidrofóbicos são elevados, poder-se-ia esperar que o OMA protonado interagisse favoravelmen te com SDS. De fato o alto valor de $K\left(8,2 \times 10^{4}\right)$ para OMA em SDS e o coeficicnte 250 vezes menor para AMA no mesmo detergente sugerem que a associação possui componentes hi arofóbicos bern como eletrostáticos. As interações hidrofílicas e/ou eletrostáticas facilitarão a inserção da amina na camada de stern. A(s) contribuição hidroföbica, por ou 
tro lado, favorecerá a inserção da cadeia do resíduo acila no interior da micela. Estas interações, em conjunto, favo recerão a conformação alongada do substrato (Forma 1, es quema 2). O movimento molecular de OMA em SDS será, portan to, anisotrópico, desde que a conversão na forma 2, (esque ma 2) necessāria para o ataque, serā altamente improvāvel devido em parte, à exposição da ponte metilênica ao solven te. Anisotropia rotacional de uma sonda de spin incorporada em micelas com carga positiva foi descrita recentemente ESQUEMA 2
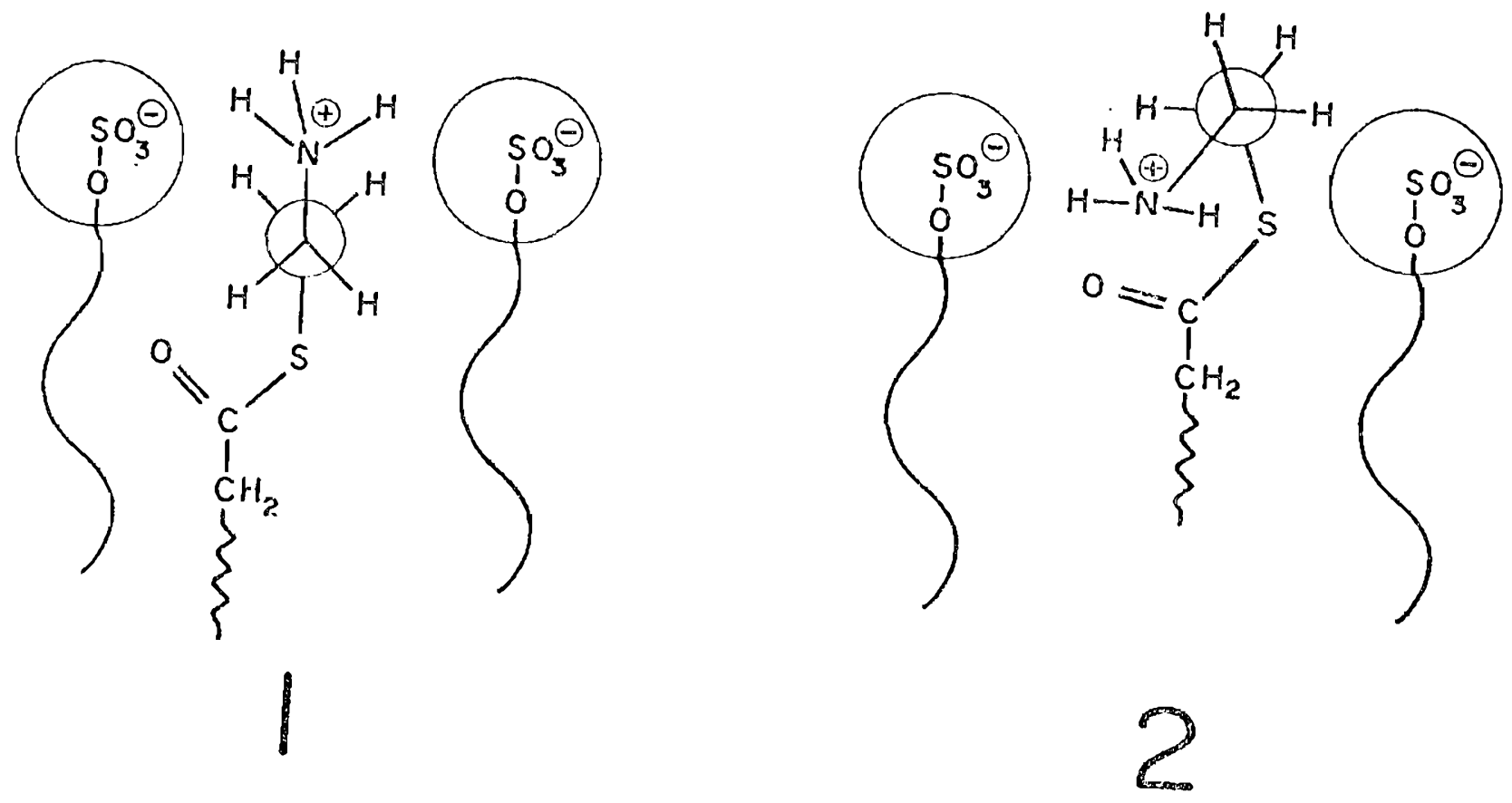
(Ernandes, Schreier e Chaimovich, 1976). Em outro sistema / inibido por SDS, propôs-se que o arranjo iônico do substra to positivo na micela negativa era necessariamente compacto a fim de explicar a estereoseletividade da reação (Sukenik, Weissman e Bergman, 1975).

A velocidade da reação de transferência intra molecular de acila de $S$ para $N$ em OMA aumenta quase cinco / vezes na presença de CTAB. A explicação mais simples deste (pequeno) efeito seria uma diminuição do pk do grupo amônio terminal aumentando assim a concentração da forma reativa. Num sistema relacionado, foi demonstrado que a micelização do cloreto de dimetildodecilamônio produz um aumento da ve locidade de troca de prótons e uma ciiminuição do pk de 1,4 unidades de $\mathrm{pH}$ (Menger e Lynn, 1975). Tomando-se este ülti mo sistema como referência esperar-se-ia um aumento de ve locidade de 30 vezes no sistema OMA/CTAB. A aceleração obtida é significativamente menor indicando a possível existência de um efeito misto (ativação-inibição) de CTAB nes te sistema.

A estabilização preferencial de uma das for mas do substrato foi, indiretamente, mostrada de maneira / extremamente elegante por Moss, Lee e Lukas (1979). Estes autores mostraram que uma micela funcional, sem atividade óp tica, pode reagir de forma estereoseletiva con LL e DL-Ncarbobenzyloxialanilprolina-p-nitrofeniléster. Embora não 
tenha sido feita uma anālise quantitativa da velocidade da reação e explicação mais provâvel desta estereoseletividade é a maior afinidade da forma LI pela micela funcional. Desde que, como os mesmos autores sugerem, a forma extendida da LI pode-se encaixar melhor na micela, o modelo pro posto para a inibição da reação de $\mathrm{S}$-acil-B-mercaptoetilaminas deve ser bastante geral.

5.3. Tiólise de NPA

A interpretação do efeito de micelas em rea ções entre nucleófilos hidrofóbicos e substratos incorpora dos em micelas foi grandemente facilitado pela anālise de vida ao grupo de Berezin (Berezin, Martinek e Yatsimirki, 1973; Martinek e col., 1977) no qual se leva em conta, ex plicitamente, a concentração dos substratos na fase mice lar. Pode ser demonstrado (Quina, 1977) que este tratamento se aplica rigorosamente (isto é, as micelas podem ser consideradas como uma pseudofase separada) quando a con centração dos substratos não é suficiente para saturar a fase e os substratos se particionam de forma independente. A anālise do efeito de CTAB na tiólise de NPA demonstra, inequivocamente, que o aumento de velocidade pode ser atribuído, exclusivamente, à concentração dos substratos na fase micelar. As constantes de segunda ordem 
calculadas para tiôlise de NPA por tiofenóxido, p-metiltio fenóxido e p-metoxitiofenóxido na fase micelar são idênticas, dentro do erro experimental, âs constantes de velocidade de segunda ordem medidas na ausência de CTAB. A constante de segunda ordem calculada para p-clorotiofenóxido è menor ainda na fase micelar que na fase aquosa. Contudo, a té neste último caso observa-se um aumento de velocidade / já que a diminuição de reatividade ê compensada pela con centração de NPA e p-clorotiofenóxido na fase micelar.

As constantes de distribuição para os ânions derivados de tiofenol aumentam na ordem

$$
\mathrm{p}-\mathrm{MeO}<\mathrm{p}-\mathrm{H}<\mathrm{p}-\mathrm{Me}<\mathrm{p}-\mathrm{Cl}
$$

Por outro lado as constantes de distribuição dos tiofenôis não dissociados são menores que as dos ânions corresponden tes e tem um valor constante de aproximadamente $1 \times 10^{3} \mathrm{M}^{-1}$. A diferença entre as constantes de distribuição das formas protonada e aniônica indicam que a associação dos tiofenó xidos com a micela possui um componente eletrostático im portante. Outrossim, a associação dos tiofenōxidos com CTAB mostra uma dependência do substituinte na posição para; e feitos de substituinte anälogos tem sido observados em outros estudos sobre incorporação de derivados aromáticos / carregados negativamente em CTAB (Larsen e Tepley, 1976 ; Lapinte e Viout, 1972). 
Associado com o efeito de substituintes em $\mathrm{K}_{\mathrm{a}}$, a micela de CTAB exerce um efeito correspondente nos pK's dos tiofenóis na ordem:

$$
\mathrm{p}-\mathrm{MeO}<\mathrm{p}-\mathrm{H}<\mathrm{p}-\mathrm{Me}<\mathrm{p}-\mathrm{Cl}
$$

Visto que a micela não produz uma alteração significativa na reatividade dos tiofenóxidos, esta mudança de pK pode ser atribuía a um aumento da solubilização dos tiofenōxi dos na fase micelar.

Os dados apresentados sugerem que a falta/ de efeitos micelares na constante de segunda ordem está re lacionada com a posição dos tiofenóxidos na micela de CTAB. A ordem da magnitude das constantes de associação dos tiofenóis e tiofenóxidos sugere que a interação principal / do(s) tiofenóxido(s) com a micela é aquela entre o anel aro mātico e o grupo tetraalquilamônio do detergente (Fendler e Fendler, 1975). Esta interação restringiria o meio ambiente do enxofre negativamente carregado à camada oe Stern. Es te meio (aquoso) e o fato de que o ataque nucleofílico não é, provavelmente, a etapa limitante da velocidade neste ca so (Hupe e Jencks, 1977) tenderiam a minimizar o efeito da interface na velocidade de reação.

Devemos enfatizar, porēm, que a falta de efeitos intrínsecos na reatividade produzidos pelo CTAB na tiólise de NPA por tiofenóxidos não pode ser considerado / 
como um efeito geral, isto ê, ausência de efeito de interfaces carregadas na reatividade de grupos SH.

\subsection{Sistenas micelares tamponados.}

Os resultados apresentados na seç̧ão 3.4. (1) demostraram que na faixa de pH investigada, a concentração / intermicelar de $\mathrm{OH}$ livre $\left(\mathrm{OH}_{\mathrm{f}}\right)$ é mantida constante pelo tam pão borato $(0,02 \mathrm{M})$ até $0,10 \mathrm{M}$ de CTAB; (2) mostram que a con centração local de ions $\mathrm{OH}$ na fase micelar $\left(\overline{\mathrm{OH}}_{\mathrm{b}}\right)$ diminui, sob estas condições, quando a concentração de detergente micelizado aumenta; (3) implicam que pode existir uma pequena interação entre o Ion borato e a fase micelar, interação es ta que é insuficiente para exceder a capacidade do tampäo e (4) assinalam vārias complicações potenciais na anälise quan titativa de reatividade em sistemas micelares tamponados. Ca da um destes pontos será analizado separadamente.

E $\mathrm{OH}_{\mathrm{f}}$ constante num sistema micelar tamponado adequadamente? A hidrólise de N-metil-cianopiridinios, ions estes que são estritamente excluidos pela fase micelar, é uma medida sensível da concentração de $\mathrm{OH}_{f}$ (Chaimovich e col., 1979). A constante de velocidade observada ( $\mathrm{k}_{\Psi}$ (MCP)) pode ser relacionada com o pH intermicelar pela equação seguinte

$$
\mathrm{k}_{\Psi}(\mathrm{MCP})=\mathrm{k}_{2}^{0} \text { antilog }\left(\mathrm{pH}-\mathrm{pk}_{\mathrm{W}}\right)
$$


Desae que $k_{\psi}$ (MCP) não varia significativamente (Fig. 13a) quando se aumenta a concentração de CTAB, devemos concluir que o pH intermicelar é mantido constante pelo tampão bo rato $0,02 \mathrm{M}$ até (pelo menos) 0,10M CTAB.

A relação de produtos $\mathrm{P} / \mathrm{A}$ é constante $(0,05$ $\pm 0,01)$ para 4-MCP a pH $9,8 \mathrm{em}$ toda a faixa de concentração de $\operatorname{ctAB}(0-0,1 M)$. A relação de produtos $\mathrm{P} / \mathrm{A}$ para 2-MCP a pH 9,5 é constante $(2,4 \pm 0,2)$ de 0 até $0,04 \mathrm{M}$ CTAB. Acima de 0,04M CTAB a relação $\mathrm{P} / \mathrm{A}$ para 2-MCP aumenta gradualmente a té alcançar um valor de 4,4 a 0,10M CTAB. Desde que P/A pä ra 4-MCP e $k_{\psi}$ (MCP) para 2-MCP säo independentes da concentração de CTAB, suspeitamos que este aumento em $\mathrm{P} / \mathrm{A}$ a CTAB alto pode refletir uma maior formação de piridona causada pela micela (Politi e col., 1978). Isto pode ser devido a entrada da cianohidrina intermediäria neutra na fase micelar após (Kosower e Patton, 1966) o ataque de ̄oH, e não a uma variação de $\mathrm{OH}_{f}$. Existe uma variação de $\overline{\mathrm{OH}}_{\mathrm{b}}$ na presença de tampão quando se varia a concentração de detergente? Para um substrato totalmente incorporado na fase micelar, a constante de velocidade para a hidrólise alcalina pode ser representado por (Quina e Chaimovich, 1979).

$$
\mathrm{k}_{\psi}=\mathrm{k}_{2 \mathrm{~m}} \overline{\mathrm{OH}}_{\mathrm{b}}
$$

onde $k_{2 m}$ è a constante de velocidade de segunda ordem para a reação de hiarólise na fase micelar. Estimando-se que a 
constante de incorporação de NPO é $1,5 \times 10^{4} \mathrm{M}^{-1}$ (vide supra), o limite de incorporação total (isto ê > 95\%) è atingido a concentração de detergente ligeiramente superiores / (perto de 3 vezes) à CMC do CTAB nestas condições $\left(5 \times 10^{-4}\right.$ M) . Assim, os dados cinēticos obtidos para hidrólise alcalina de NPO deveriam refletir, diretamente, $\overline{\mathrm{OH}}_{\mathrm{b}}$ a concen trações de CTAB maiores que $2 \times 10^{-3} \mathrm{M}$. Desde que $k_{\psi}$ (NPO) / não é constante e diminui com o aumento da concentração do detergente podemos concluir que $\overline{\mathrm{OH}}_{\mathrm{b}}$ diminui de uma forma se melhante. Este decrēscimo implica que o tampão borato 0,02M, que mantēm $\mathrm{OH}_{f}$ constante, não mantem $\overrightarrow{\mathrm{OH}}_{\mathrm{b}}$ constante quando muda a concentração de detergente.

Anālise quantitativa da hidrōlise alcalina / modificada por micelas na presença de um tampão. Temos de monstrado recentemente (Quina e Chaimovich, 1979) que, na presença de um tampão que mantēm $\mathrm{OH}_{f}$ constante, a expressão apropriada para a constante observada de pseudo-primeira or dem $\left(k_{\Psi}\right)$ para uma reação bimolecular entre um substrato não carregado (como NPA ou NPO) e um ion univalente reativo (co mo - OH) numa solução solução micelar de CTAB é:

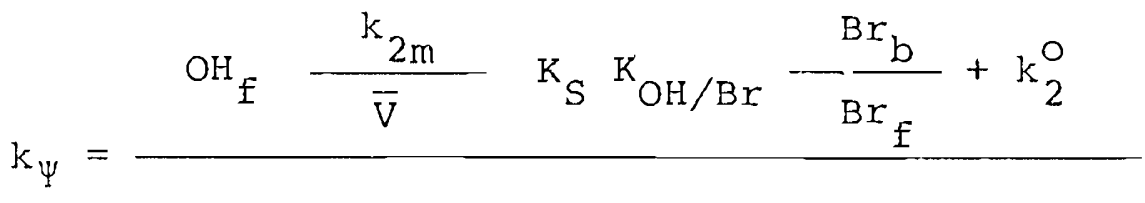

$$
\begin{aligned}
& \left(1+k_{S} C_{D}\right)
\end{aligned}
$$


Nesta equação, $K_{S}$ é a constante de distribuição do substrato neutro $\left(54 \mathrm{M}^{-1}\right.$ para NPA, Funasaki, $1979 ; \mathrm{e} 1,5 \times 10^{4} \mathrm{M}^{-1}$ para NPO) $; \mathrm{k}_{2}^{0}$ e $\mathrm{k}_{2 \mathrm{~m}}$ são as constantes de segunda ordem para a reação de hiarólise alcalina nas fases aquosa e micelar, respectivamente. $\bar{V}$ é o volume por mol de detergente micelizado na região da micela onde o ion pode se definir como "Iigado"; o valor de $\overline{\mathrm{V}}$ tem-se aproximado ao volume parcial molar do detergente $(0,37 \mathrm{~L} /$ mole para CTAB; Yatsimirki, Mar tinek e Berezin, 1971; Corkill, Goodman e Walker, 1967). / $\mathrm{K}_{\mathrm{OH} / \mathrm{Br}}$ é o coeficiente de seletividade para a troca OH/Br na superficie da micela (0,08, Chaimovich e col., 1979) e $C_{D}$ é a concentração analitica de detergente micelizado. IJa presença de um tampão ideal, isto é, um tampão que não inte rage com a fase micelar, as expressões adequadas para as concentrações analíticas de brometo ligado $\left(B r_{b}\right)$ e livre $\left(B r_{f}\right)$ e hidróxido ligado $\left(\mathrm{OH}_{b}\right)$ são (Quina e Chaimovich, 1979):

$$
\begin{aligned}
& B r_{b}=(1-a) C_{D}-O H_{b} \\
& B r_{f}=a C_{D}+C M C+O_{b} \\
& \mathrm{OH}_{\mathrm{b}}=\frac{-\mathrm{A}_{2}+\sqrt{\left(\mathrm{A}_{2}\right)^{2}+4 \mathrm{~K}_{\mathrm{OH} / \mathrm{Br}} \mathrm{OH}_{f}(I-\alpha) C_{D}}}{2}
\end{aligned}
$$

onde

$$
\mathrm{A}_{2}=a \mathrm{C}_{\mathrm{D}}+\mathrm{CMC}+\mathrm{K}_{\mathrm{OH} / \mathrm{Br}}+\mathrm{OH}_{\mathrm{f}}
$$


e $\alpha$ é o grau de ionização da micela $(=0,2 \pm 0,5$ Romsted, 1975; Funasaki, 1978; Smith, 1979).

Utilizando os valores experimentais para $K_{S}$ $\left(54 \mathrm{M}^{-1}\right.$ para NPA e $1,5 \times 10^{4} \mathrm{M}^{-1}$ para NPO), $\mathrm{K}_{\mathrm{OH} / \mathrm{Br}}(0,08), \mathrm{CMC}$ $\left(5 \times 10^{-4} \mathrm{M}\right)$ e $\mathrm{k}_{2}^{0}\left(0,05 \mathrm{~min}^{-1}\right.$ para NPA $\mathrm{pH} 9,50,0,027 \mathrm{~min}^{-1}$ para NPO a pH 9,50 e $0,048 \mathrm{~min}^{-1}$ para NPO a pH 9,80 na ausên cia de (TAB) e os valores de $\bar{V}=0,37 \mathrm{M}^{-1}$ e $\alpha=0,2$ e as equações 24-28 não se achou valor de $k_{2 m}$ que simulasse satisfato riamente os dados cinêticos de NPA ou NPO. Variação simultânea de $\alpha$ e $k_{2 m}$ resultou tambēm em simulações pouco adequadas dos dados cinéticos. A diferença entre os adados simulados e os experimentais diminui usando valores extremamente pequenos de $\alpha(<0,1)$.

De fato, a suposição da completa ausência de ligação do íon borato à fase micelar (como nos equações 24-28) pode ser por demais simplista. Assim se o ion borato se liga a fase micelar de CTAB as expressões para $B_{b^{\prime}}$ $B r_{f}$ e $\mathrm{OH}_{b}$ vem a ser

$$
\begin{aligned}
& B r_{b}=(1-\alpha) C_{D}-O H_{b}-B_{b} \\
& B r_{f}=\alpha C_{D}+C M C+O H_{b}+B_{b}
\end{aligned}
$$

$$
\begin{aligned}
& \mathrm{OH}_{\mathrm{b}}^{3}+\mathrm{OH}_{\mathrm{b}}^{2}\left(\mathrm{~A}^{2}+\mathrm{K}_{\mathrm{OH} / \mathrm{B}} \mathrm{OH}_{\mathrm{f}}+\mathrm{B}_{\mathrm{T}}\right)+\mathrm{OH}_{\mathrm{b}} \mathrm{OH}_{\mathrm{f}}\left(\mathrm{K}_{\mathrm{OH} / \mathrm{B}} \mathrm{A}_{2}+\right. \\
& \left.\mathrm{K}_{\mathrm{OH} / \mathrm{Br}}\left(\mathrm{B}_{\mathrm{T}}-(1-\alpha) \mathrm{C}_{\mathrm{D}}\right)\right)-\mathrm{K}_{\mathrm{OH} / \mathrm{Br}} \mathrm{OH}_{\mathrm{f}}^{2}(1-\alpha) \mathrm{C}_{\mathrm{D}} \mathrm{K}_{\mathrm{OH} / \mathrm{B}}=0
\end{aligned}
$$


onde $\mathrm{A}_{2}$ é definido pela eq. 28. Na equação 31 usamos o coe ficiente de troca iônica borato/hidróxido definido como

$$
\mathrm{K}_{\mathrm{OH} / \mathrm{B}}=\frac{\mathrm{OH}_{b} \mathrm{~B}_{f}}{\mathrm{OH}_{f} \mathrm{~B}_{\mathrm{b}}}=-\frac{\mathrm{OH}_{b}\left(\mathrm{~B}_{\mathrm{T}}-\mathrm{B}_{\mathrm{b}}\right)}{\mathrm{OH}_{b} \mathrm{~B}_{b}}
$$

que está relacionado com o coeficiente de seletiviade bora to-brometo por

$$
\mathrm{K}_{\mathrm{OH} / \mathrm{Br}} / \mathrm{K}_{\mathrm{OH} / \mathrm{B}}=\mathrm{K}_{\mathrm{B} / \mathrm{Br}}=\frac{\mathrm{B}_{\mathrm{b}}{ }^{\mathrm{Br}}}{\mathrm{B}_{\mathrm{f}} \mathrm{Br}_{\mathrm{b}}}
$$

onde $\mathrm{B}_{\mathrm{T}}=\mathrm{B}_{\mathrm{f}}+\mathrm{B}_{\mathrm{b}}$ é a concentração do ion $\mathrm{B}(\mathrm{OH})_{4}^{-}$no $\mathrm{pH}$ expe rimental. Duas linhas independentes de evidência experimental indicam que a troca borato/brometo é altamente desfavorável. Uma ligação substancial de borato deveria mudar o equilíbrio do tampão e, consequentemente, produzir uma varia ção de $\mathrm{OH}_{f}$ na fase aquosa intermicelar. Ainda, a adição de borato 0,02M somente diminui a CMC de C'TAB de $9 \times 10^{-4} \mathrm{M}$ até $5 \times 10^{-4} M$ (veja p.ex. o efeito de tiofenóxido na CMC de CIAB). Porēm um $\mathrm{K}_{\mathrm{B} / \mathrm{Br}}$ pequeno não implica, necessariamente, que a ligação de borato não afetará a diluição de $\overrightarrow{\mathrm{OH}}_{\mathrm{b}}$ Neste contex to os fatores chaves são a ligação desfavorável de ${ }^{-} \mathrm{OH}$ à mi cela de CTAB e a baixa concentração de $\mathrm{OH}_{f}(\mathrm{pH} 9,5-9,8)$. Como consequência, qualquex ligação do íon $\mathrm{B}(\mathrm{OH})_{4}^{-}$cuja concentração é ordens de magnitude mais alta que a de $\mathrm{OH}_{f}$, poderá exercer um efeito marcante na quantidade de ${ }^{-} \mathrm{OH}$ ligado 
à micela de CTAB especialmente a $C_{D}$ baixo.

Se a ligação de borato é altamente desfavorá vel e o equilíbrio do tampão não é perturbado significativa mente, podemos aproximar $\mathrm{B}_{\mathrm{T}}$.

$$
\mathrm{B}_{\mathrm{T}} \simeq \mathrm{B}_{\mathrm{f}}=\mathrm{BH}_{\mathrm{T}}\left|1+\operatorname{antilog}\left(\mathrm{pK}_{\mathrm{a}}-\mathrm{pH}\right)\right|^{-1}
$$

onde $\mathrm{BH}_{\mathrm{T}}$ é a concentração total de espécies iônicas do tam pão e pka é o valor da constante de dissociação do ácido bốrico $(9,22$; Kolthoff, 1959). Usando as equaçōes 24 e 29-32 e os valores dos parâmetros jà discutidos (com $\alpha=0,2$ ) foram / feitas simulações variando-se somente $k_{2 m}$ e $\mathrm{K}_{\mathrm{OH} / \mathrm{B}}$ com a restrição adicional que $\mathrm{K}_{\mathrm{OH} / \mathrm{B}}$ deveria ser idêntica em todos os casos. Os valores que forneceram melhor simulação foram / $\mathrm{k}_{2 \mathrm{~m}} / \mathrm{k}_{2}^{\circ}=0,37$ para $\mathrm{NPA}$ pH $9,50, \mathrm{k}_{2 \mathrm{~m}} / \mathrm{k}_{2}^{\circ}=0,29$ para $\mathrm{NPO}$ e $\mathrm{pH}$ 9,50 e 9,80 e $\mathrm{K}_{\mathrm{OH} / \mathrm{B}}=2,3.0 \mathrm{~K}_{\mathrm{B} / \mathrm{Br}} \simeq 0,035$ é satisfatōrio já que corresponde ao valor esperado para uma ligação de borato pouco eficiente à micela de CTAB como tinhamos previsto.

Deve-se observar que os valores de $\mathrm{k}_{2 \mathrm{~m}} / \mathrm{k}_{2}^{\mathrm{O}}$ de rivados da nossa análise não têm, necessariamente, uma signi ficação absoluta, desde que dependem do valor escolhido para $\bar{V}$. Contudo, é pouco provável que o valor de $\bar{V}$ seja muito / maior que aquele utilizado neste trabalho. Assim, os nossos valores de $\mathrm{k}_{2 \mathrm{~m}} / \mathrm{k}_{2}^{0}$ coincidem com outras indicações da litera tura (Bunton e col., 1978) na medida que indicam uma diminui ção da reatividade aparente do ${ }^{-} \mathrm{OH}$ na fase micelar do CTAB. 
Neste contexto devemos salientar, porém, que até um valor absoluto de $k_{2 m}$ (à diferença de $k_{2}^{0}$ ) será um reflexo da reạ tividade aparente na fase micelar. Destarte, $k_{2 m}$ é uma re sultante onde devem ser consideradas tanto a reatividade / absoluta do nucleófilo iônico "ligado" num elemento de volume relacionado com $\vec{V}$, como a probabilidade de encontrar - substrato incorporado na micela no mesmo elemento de vo-lume. Se a região de reação englobasse um elemento de volu me correspondente à camada de stern, isto ê a região onde se deveria encontrar a mais alta concentração de îons - $O H$ "ligados", o valor de k $2 \mathrm{~m}$ deveria refletir a reatividade / absoluta atenuada pela distribuição intramicelar do NPA ou NPo entre a região não reativa (o núcleo da micela) e a re gião reativa (a camada de Stern). Desde que NPo ê, seguramente, mais lipossolúvel que NPA, o modelo recentemente pro posto por Almgren, Grieser e Thomas (1979) sugeriria uma di ferença na distribuição intramicelar destes dois substratos na direção que favorecesse a menor reatividade aparente de NPO com $-\mathrm{OH}$ observada neste trabalho $\left(\mathrm{k}_{2 \mathrm{~m}}(\mathrm{NPO}) / \mathrm{k}_{2 \mathrm{~m}} \mathrm{NPA} \simeq 0,4\right)$. Algumas considerações sobre tampões em solução micelar.

Um dos problemas fundamentais na análise de reatividade em sistemas micelares tamponados tem sido a for ma do cálculo correto da concentração total de uma espécie iônica "tamponada" numa determinada concentração de deter - 
gente (Cordes, 1978; Funasaki, 1979). Existem hoje métodos experimentais que permitem medir as constantes de seletivi dade das trocas dos ions $\mathrm{H}^{+}$(Bunton e Wolfe, 1974) e ${ }^{-} \mathrm{OH}$ (Chaimovich e col., 1979) com os contraíons da micela na ausència de tampão. As equações utilizadas neste trabalho bem como a demonstração de que o tampão pode manter ${ }^{0} \mathrm{OH}_{f}$ constante, permitem, ao menos formalmente (Quina e Chaimovich, 1979), calcular o comportamento quantitativo de $\overline{\mathrm{OH}}_{\mathrm{b}}$ (ou, por analogia $\overline{\mathrm{H}}_{\mathrm{b}}$ ) em função da concentração de $C_{D}$ a partir do valor do coeficiente de seletividade determinado na ausência de tampão.

Todavia, deve-se enfatizar que o fato de $\mathrm{OH}_{f}$ não mudar com $C_{D}$ no sistema estudado neste trabalho, não significa que, em todos os sistemas micelares onde se adiciona um tampão, a concentração do íon tamponante intermicelar $\left(\mathrm{X}_{f}\right)$ seja uma constante quando se varia $C_{D}$. Vários / fatores podem contribuir, às vezes de forma simultânea, pa ra variações de $\mathrm{OH}_{f}$, mesmo na presença de um tampão, quan do se aumenta a concentração de detergente. Por exemplo, a pHs altos o grau de ligação de ${ }^{-} \mathrm{OH}$ na fase micelar de um detergente catiônico se faz significativo em relação à ca pacidade de um tampão. Assim, desprezando-se a ligação de espécies iônicas do tampão, pode-se estimar que aproximada mente $10^{-3} \mathrm{M}$ - $\mathrm{OH}$ Iigar-se-ão à fase micelar do CTAB a $\mathrm{pH} 11,5$ no limite de concentração alta de detergente (Quina e chai 
movich, 1979). Desta forma, ainda para um tampão "ideal", a capacidade do tampão poderia ser excedida neste, ou em valo res de pH mais altos, a menos que se utilizassem concentra.Ções relativamente altas de um sistema tampão perto do $\mathrm{pk}_{\mathrm{a}}$ e se trabalhasse na região de $C_{D}$ baixo. A troca iônica com as espécies iônicas provenientes do tampão apresenta compli cações drāsticas, tanto em termos do efeito da troca na ca pacidade do tampão quanto no perfil de diluição de $\overline{\mathrm{OH}}_{\mathrm{b}}$. ES tes efeitos podem depender não somente da natureza química como também das proporções relativas e concentração total das espécies iônicas do tampão.

De um ponto de vista conceitual, especialmen te no que se refere à anālise quantitativa, talvez o tampão mais adequado para um sistema micelar seja aquele cujas es pécies iônicas são altamente hidrofilicas, têm a mesma car ga do monômero e possuem contraíons idênticos aos do detergente. Sob estas condições a influência do tampão pode ser analizado como um efeito de sal comun (Quina e Chaimovich, 1979).

5.5. Análise de micelas utilizando sondas de spin

A. Estrutura micelar

A anisotropia do movimento rotacional de moléculas en meios tanto isotrópicos como anisotröpicos foi 
analizada em detalhe nos trabalhos de Freed e colaboradores (Freed, Bruno e Polnaszek, 1971, Goldman e col., 1972; Gold man, Bruno e Freed, 1973; Polnaszek e Freed, 1975). A complexidade de nossos sistemas fazem com que seja dificil apli car análises similares aos resultados. Contudo, Polnaszek / (1978) apresentou a base sobre a qual os tempos de correlação, calculados a partir do formalismo de estreitamento pa ra movimento isotrópico, podem ser interpretados como aniso tropia devida ao movimento molecular. Os tempos de correlação $(\tau)$ foram calculados de acordo com esse formalismo usan do as equações 12 e 13 a partir das larguras e as alturas / das linhas espectrais. Na Tabela 10 se apresentam os valores de $\tau$ para 5-SASL e 5-MeSL em soluções orgânicas e micelas / junto com os desdobramentos hiperfinos isotrópicos.

E provável que a largura de linha observada provenha de dois tipos de movimentos: aquele da sonda de spin no agregado e o da própria micela. Waggoner e colabora dores (Waggoner, Grifith e Christensen, 1967; Waggoner, / Keith e Griffith, 1968) foram os primeiros a aplicar a técnica de marcação de spin ao estudo de moléculas associadas com micelas. Estes autores calcularam $\tau$ para uma sonda de spin em dodecano $\left(1,6 \times 10^{-10} \mathrm{seg}\right)$,ägua $\left(1,8 \times 10^{-10} \mathrm{seg}\right) \mathrm{e}$ numa micela $\left(1,1 \times 10^{-8} \mathrm{seg}\right)$ utilizando a equação de stokes-Einstein. A partir de medidas de e $s$ os $\tau$ calculados pa ra uma sonda em dodecano, āgua e SDS são $9,1 \times 10^{-11}, 7 \mathrm{x}$ 
$10^{-11}$ e $6 \times 10^{-10} \mathrm{seg}$. Observa-se uma grande discrepância entre os valores de $\tau$ para a sonda na micela e o $\tau$ calcula do, Pode-se concluir então que, neste caso, a forma da Iinha é determinada, sobretudo, pelo prōprio movimento mo lecular da sonda. Contudo o tamanho duma micela é tal que se poderia esperar que o seu movimento afetasse, em algum grau, o espectro observado.

Recentemente, stockton e col. (1976) calcularam o tempo de correlação rotacional de vesículas de uma única bicamada composta de lipídeos. O valor obtido por rmn de deutério $\left(5,8 \times 10^{-7} \mathrm{seg}\right)$ é bastante semelhante ao obtido utilizando-se a equação de Stokes-Einstein $(9,4 \mathrm{x}$ $\left.10^{-7} \mathrm{seg}\right)$. Os cálculos de $\tau$ para micelas são mais comple xos, em parte devido as dificuldades na determinação do raio hidrodinâmico da micela. Ainda observou-se que o mode lo de difusão Stokes-Einstein pode não ser adequado para sistemas onde os solutos interagem fortemente com o solven te (Edward, 1970) e nas micelas os grupos polares estão bem mais expostos ao solvente que os grupos polares de uma ve sicula de fosfolipídio (Tanford, 1974). Deve-se lembrar ain da que o tempo de correlação rotacional será determinado pela microviscosidade e que este parâmetro é dificil de de finir numa micela. Deste modo definimos um "tempo de corre lação efetivo" e analizamos os nossos dados assumindo que este se deve, essencialmente, ao componente do próprio mo 
vimento da sonda dentro da micela. Na Tabela 10 apresentam-se os valores calculados de $\tau$ bem como o $\Delta \tau=\tau_{1}-\tau_{2}$. A quantidade $\quad \Delta \tau$ está associada à anisotropia do movimento da sonda (Polnaszek, 1978). Os valores de $\tau_{1}, \tau_{2}$ e $\Delta \tau$ são bem maiores nas micelas do que nos solventes orgânicos uti lizados como referência, sendo tambēm maiores para 5-SASL que para 5-MeSL. Nas micelas esta diferença pode ser devida à carga da parte polar do 5-SASL que favoreceria a sua interação com o meio aquoso. Além disto è de se esperar / uma interação eletrostātica adicional quando 5-SASL é uti lizado como sonda em micelas de CTAB que possuem uma carga oposta.

Contudo, a diferença nos valores de $\tau$ calculados para as sondas em micelas de SDS e CTAB poderiam / ser atribuidas a diferenças nos movimentos rotacionais das micelas. Assumindo-se uma conformação trans para as molécú las do detergente e usando-se a equação de stokes-Einstein, o valor de $\tau$ (CTAB) $\sim 2 \tau$ (SDS) coincidindo com os resultados da Tabela 1 . Os tempos de correlação rotacional das mi celas teriam um efeito nos espectros se as sondas estivessem ordenadas ao nível microscópico. A rotação das micelas, então, tenderia a compensar estatisticamente os desdobramen tos anisotrópicos hiperfinos $\left(a_{11}\right.$ e $\left.a_{1}\right)$ esperados para as sondas ordenadas e obter-se-ia um espectro de três linhas. Neste caso o valor calculado de $\tau$ seria tambēm uma função 
do tempo de correlação rotacional da micela.

Os valores de $a_{n}$ obtidos para 5 - SASL em mice las são menores que os da mesma sonda em água indicando assim que o segmento contendo o nitróxido se encontra num ambiente menos polar. Os valores de $a_{n}$ em micelas são interme diārios entre aqueles obtidos em āgua e em solventes não po lares. Este ültimo dado sugere que os grupos metilênicos / perto da porção polar do detergente se encontram hidratadus (veja Introdução, Chaimovich, 1979) .

o valor de $a_{n}$ é sempre menor em CTAB que em SDS sugerindo que a micela de SDS é mais "mole" e, consequen temente, mais hidratada.

B. Efeito de tiofenóxido na micela de CTA3.

A adição de tiofenóxido afeta a CMC do CTAB, os tempos de correlação calculados para sondas e os valores de $a_{n}$ para 5-MeSL. A diminuição e o aumento subsequente de $\tau$ para o experimento em que se aumentou tiofenóxido a con centração constante de CTAB foram interpretados em termos / de uma competição entre o ânion e o 5-SASL na interação ele trostática com os grupos carregados do detergente. Tiofenóxido deslocaria o 5-SASL e este deslocamento conduziria a uma diminuição de $\tau$. o aumento da concentração de tiofenóxido levaria a uma neutralização parcial da carga dos gru 
pos alquiltrimetilamônio, diminuiria a repulsão, produzindo um empacotamento maior da micela e um aumento consequente de $\tau$.

A diminuição de $a_{n}$ decorrente do aumento de tiofenóxido indica que o segmento paramagnético está sentin do um ambiente menos polar. Isto poderia se dever seja a um movimento da sonda até um sitio menos polar ou a uma diminui ção da polaridade do sítio. Esta última hipótese poderia a contecer por desidratação de micela após ligação do substra to. Este fenômeno foi considerado um evento importante em catálise micelar desde que causaria um aumento da reativida de de substratos nucleofilicos (Fendler e Patterson, 1971; Larsen, Magid e Payton, 1973; Chaimovich e col., 1975; Mar tinek e col., 1975). Diversos compostos, quando adicionados em alta concentração a micelas de CTAB mudam a estrutura da fase (Fendler e Patterson, 1971; Larsen, Magid e Payton,1973; Hyde e Steverson, 1969; Lindblom, Lindman e Mandell, 1973). observando-se a relaxação de ${ }^{81} \mathrm{Br}$ por ressonância nuclear / magnētica, concluiu-se que a solubilização de compostos co mo benzeno, hexanol e N,N-dimetilanilina provavelmente en volve a remoção de água da estrutura micelar (Lindblom, Lind man e Mandel, 1973). 
C. Agregação de detergentes abaixo da CMC.

Os espectros obtidos com diversas sondas em SDS abaixo da CMC indicavam agregação pré-micelar. A quanti ficação desta agregação foi feita aumentando a concentração da sonda (5-MeSL) em solução micelar de SDS até se obter espectros comparáveis com os obtidos abaixo da CMC. Os resultados indicaram que as porcentagens de agregação abaixo da CMC são $5,3\left(6,5 \times 10^{-3} \mathrm{M}\right), 9,6\left(7 \times 10^{-3} \mathrm{M}\right), 19,2(7,5 \mathrm{x}$ $\left.10^{-3} M\right)$ e $24\left(8 \times 10^{-3} M\right)$.

Uma anālise termodinâmica das forças envolvi das na formação de micelas indica que a CMC, e o nümero de agregação, só podem ser afetadas quando o soluto é adiciona do em uma quantidade suficiente para alterar o balanço en tre as contribuições hidrofóbicas e hidrofilicas relacionadas com a formação das micelas (Tanford, 1974). Duma inspec ção da literatura pode-se concluir que a quantidade de reagente necessāria para alterar a CMC e o número de agregação è, em geral, alta (Fendler e Patterson, 1971; Larsen, Magid e Payton, 1973; Hyde e Stevenson, 1969; Lindblom,Lindman e Mandel1, 1973; Hutchinson, Inaba, Bailey 1955; Parfitt e Wood, 1969; Kalyanasundaram, Gratzel e Thomas, 1975). A natureza anfifilica das sondas utilizadas sugere, tambëm, que - balanço hidrofỉlico-hidrofóbico do sistema não deveria ser perturbado. Deve ser notado, alēm disso, que a relação son- 
da/detergente foi sempre baixa $(<1: 100)$ e que as sondas uti lizadas tem estruturas bem diferentes entre si e deveriam in teragir de formas desiguais com os agregados de detergentes. o conjunto destes argumentos indica que é pouco provável que as sondas usadas fossem a fonte (e não a medida) da agrega ção de SDS observado abaixo da CMC.

D. Distribuição não homogènea de um soluto hiarofóbico em sô lução micelar.

Restrições termodinâmicas demandam que, no equi líbrio, o sistema utilizado deveria consistir de micelas con tendo, en média, uma sonda por micela (sonda/detergente - 1 : 100 , número de agregação perto de 100).

o espectro de e s r de soluções de CTAB-CSL / recentemente preparadas mostram a existência de agregados on de a relação sonda/detergente é bem diferente. O processo de redistribuição é lento, depende de tempo e temperatura, mas ê, aparentemente independente da concentração inicial de CTAB / (acima da CMC), da concentração de CSL ou do tamanho dos agre gados iniciais.

A escala de tempo em que se processa a troca/ de monômeros ou a dissociação de micelas ê da ordem de mili-/ ou microsegundos (Fendler e Fendler, 1975; Lang e col., 1975; Aniansson e col., 1976). Em isooctano (onde um composto solū 
vel em āgua ê "completamente" insolúvell a troca de àgua en tre agregados de detergente é mais rápida que o tempo de mistura (1 a 2 mseg.) (Eicke, Sheperd e Steinemann, 1976). Quando as micelas contém uma molécula de substrato que possui uma solubilidade mensurável em água, o tempo de perma nência do substrato é da ordem do tempo de relaxação da micela (Fendler e Fendler, 1975; Eriksson e,Gilberg, 1966). / Compostos mais hidrofóbicos, por outro lado, apresentam uma velocidade de troca lenta entre a āgua e a fase micelar (Eriksson e Gilberg, 1966; Dorrance e Hunter, 1972,1974).

A meia vida para a redistribuição do CSL é da ordem de horas e a independência da concentração de de tergente (acima da CMC) sugere que a velocidade de chegada ao equilíbrio depende, somente, da colisão entre agregados (contendo CSL) em monômeros do detergente.

Os nossos estudos da distribuição não homogê nea de CSL em CTAB, bem como estudos de distribuição em ou tros sistemas (Dorrance e Hunter, 1973; Infelta, Gratzel e Thomas, 1974) são relevantes na descrição de propriedades / dināmicas de sistemas micelares, catālise micelar e proprie dades solubilizantes de agregados micelares. Vários modelos de solubilização foram propostos (Tachiya, 1971) e o nosso sistema é, em princípio similar ao proposto por Dorrance e Hunter (1974). O modelo é válido somente para estes solu tos extremamente hidrofóbicos que difundem na solução somen 
te quando associados à detergentes.

A distribuição, no equilíbrio, no sistema CSL-CT'AB, é alcançado após uma sequência de etapas que po de ser descrita no sistema aqui apresentado. A descrição detalhada é complexa e exige mais dados do que dispomos atualmente.

O espectro do CSL nos dois tipos extremos de agregados tem valores de $g$ bem diferentes. Foi des crito que o valor de $g$ de nitróxidos, bem como a constan te de acoplamento hiperfino, varia com a mudança de pola ridade do meio (Brière, Lemaire e Rassat, 1965). O valor de $g$ mais alto na situção inicial sugere que o ambiente/ da maioria das moléculas de CSL é pouco polar. O valor mais baixo de g observado no espectro de CSL em micelas/ sugere que a sonda está orientada com $\mathrm{O}$ segmento $\mathrm{N}-\mathrm{O}$ per to da interface, de forma semelhante à observada em cris tais líquidos (Seelig, 1970) e bicamadas de fosfolipi dios (Schreier-Muccillo, Marsh e Smith, 1976). 
6. CONCLUSÕES

As micelas, da mesma forma que as enzimas, mo dificam a velocidade de reações químicas como "demônios en trópicos" já que a perda de entropia associada a concentração de reagentes num volume pequeno da solução, a fase micelar,é compensada pelo decréscimo de energia livre associado à trans ferência do substrato da fase aquosa à fase micelar. Neste / trabalho demonstrou-se, de forma inequívoca, que a tiólise de ésteres é acelerada pela adição de micelas muito embora a reatividade dos tiofenóxidos nas fases micelar e aquosa possa ser idêntica. Neste caso, portanto, toda a aceleração é devi da à concentração dos reagentes na fase micelar. Por outro la do, a simples concentração de reagentes não é suficiente pạ ra explicar a aceleração da reação de dinitrofluorobenzeno / com tiofenóxido. Neste ültimo caso, um cálculo preliminar in dica que a reatividade do ânion na fase micelar deve ser, pe lo menos, dez vezes superior à reatividade na fase aciuosa. A formação de um complexo entre os substratos, complexo este estabilizado pela fase micelar, parece, de momento, ser a explicação mais razoável para a aceleração "extra" na reação do tiofenóxido com dinitrofluorobenzeno. A modificação da vê locidade de uma reação quỉmica em fase micelar pode, ainda, estar associada a mudanças do grau de dissociação de grupos ionizāveis do substrato. Assim, tanto a aceleração da reação 
de transferência intramolecular de $S$ para $N$ em S-octanoil- $\beta$-mercaptoetilamina (OMA) causada por CTAB como a inibição da mesma reação em s-acetil-mercaptoetilamina causada por dodecilsulfato do sódio (SDS) podem ser atribuidas a uma mudança de $\mathrm{pk}$ do grupo amônio terminal na fase micelar. Outro tipo de efeito causado pela introdução de um substrato na fase micelar pode ser a seleção de uma conformação particular do substrato que resulte, ao mesmo tempo, numa interação māxima com a fase e, em consequência, num efeito cinético na reação na qual o substrato participa. De fato, a inibição da reação intramolecular de transferência de acila em OMA na fase micelar de SDS pode ser explicada em base a os resultados estruturais obtidos por ressonância nuclear magnētica, por uma seleção da configuração não reativa do substrato. Esta seleção que, necessariamente, resulta numa anisotropia de movimento a nível mo lecular, tambēm foi observada para sondas de spin em mice las de CTAB.

A existência de uma interface carregada de termina uma distribuição iônica entre as fases micelar e aquosa que depende do pH, da natureza e concentração do tampão e outros sais presentes e do tamanho da fase micelar. Neste trabalho demonstrou-se, diretamente, que ainda sob condições em que o pH intermicelar se mantem constante, a concentração de ${ }^{-} \mathrm{OH}$ ligados à interface varia com a 
concentração de detergente. Este resultado (1) mostra a apli cabilidade da teoria de troca seletiva de íons em sistemas / tamponados (Quina e Chaimovich, J. Phys. Chem., 83, 1844,1979); (2) indica condições de trabalho para se analisar reações em fase micelar na presença de tampão; (3) contribui para a com preensão do significado de "pH" em interfaces e, portanto, a bre a perpectiva de se poder analisar este problema em outros sistemas mais complexos como vesiculas e membranas.

A utilização de sondas se spin permite analisar parâmetros estruturais e dinâmicos em sistemas micelares. A localização de sondas de spin em micelas pode ser descrita, a partir dos resultados apresentados, por um modelo onde a penetração de âgua alcança os primeiros carbonos da cadeia do detergente. E possivel que a hidratação nesta região mude quando um substrato iônico é incorporado a fase micelar. A agregação premicelar em SDS foi demonstrada inequivocamente utilizando-se sondas de spin de estrutura molecular diferentes. Os dados obtidos ao se estudar as variações espectrais de sondas de spin insolúveis em ãgua em solução de CTAB sü gerem, fortemente, que o mecanismo de redistribuição estatís tica (lenta) da sonda envolve a colisão de monômeros do de tergente com agregados contendo o substrato insolüvel. 


\section{RESUMO}

A adição de brometo de $N$-hexadecil-N, N,N-tri metilamônio (CTAB) produz um aumento da velocidade das rea ções de 2,4-dinitrofluorobenzeno (DNFB) com fenóxido (230 vezes) e tiofenóxido (1100 vezes). O efeito de CTAB na rea ção de DNFB com tiofenōxido foi analisada quantitativamente, de forma preliminar, (Quina e Chaimovich, J, Phys. Chem., 83, 1844, 1979) podendo-se concluir que a aceleração produzida por CTAB não pode ser atribuía exclusivamente à concentração de substratos na micela.

A tiólise de acetato de p-nitrofenila (NPA) por tiofenóis é também acelerada pela adição de CTAB. Demonstrou-se que a reatividade dos tiofenóis nas fases micelar e aquosa é comparável e que o aumento da velocidade po de ser explicado em base a concentração dos reagentes na fa se micelar.

A velocidade de transferência intramolecular de acila de $S$ para $N$ em $S$-acetil- $\beta$-mercaptoetilamina (AMA) e S-octanoil-B-mercaptoetilamina (OMA) foi estudada na pre sença de CTAB e dodecilsulfato de sódio (SDS). Observou-se uma aceleração da velocidade de reação com OMA na presença de CTAB e uma inibição com SDS que é da ordem de 100 vezes para AMA e mais de mil vezes para OMA. Estudos de ressonân cia nuclear magnética demonstraram uma imobilização da pon 
te metilênica do OMA nos complexos de SDS-OMA. O efeito de detergentes na reação foram explicados em termos de uma va riação do pk do grupo amônio terminal do substrato e um mo vimento anisotrōpico do substrato mais hidrofóbico (OMA) na micela de SDS.

o estudo de reatividade em solução micelar foi complementado com uma investigação da relação entre o pH do meio aquoso na presença de tampão e a concentração / de de N-metil-4-e, N-metil-2-cianopiridínios não sofrem alte ração quando se adiciona CTAB na presença de tampão borato a pH 9,6 ou 9,8. Estes dados e a completa exclusão dos $\mathrm{N}$ Metilcianopiridínios da fase micelar demonstram inequivoca mente que, nestas condições, o pH intermicelar não varia quando se adiciona CTAB. Por outro lado a hidrólise alcali na de octanoato de p-nitrofenila, um substrato que particio na favoravelmente na fase micelar, diminui quando a concen tração de detergente excede a necessāria para alcançar a incorporação total do substrato. Estudou--se tambēm a hidró lise de NPA em função da concentração de CTAB na presença de tampão. Os dados de hidrôlise foram analizados quantita tivamente de acordo com a teoria proposta por Quina e chai movich (op. cit) e os dados experimentais podem ser reproduzidos quantitativamente supondo uma ligação fraca do tam pão à micela. 
Neste trabalho se analisa o uso de ressonân cia eletrónica paramagnética para o estudo de agregados de detergentes. Utilizando-se diversas sondas de spin determi na-se a concentração micelar crítica, verifica-se o efeito de tiofenóxido na estrutura micelar de micelas de CTAB, de monstra-se a existência de agregação premicelar em SDS e se estabelecem critêrios para estudar o fenômeno de redistribuição de substratos insolûveis em āgua em soluções de detergentes. Estes resultados são analisados em termos da relevância para se entender formação de micelas, acelera ção de reações em fase micelar e mecanismos de solubilização em fase micelar. 
7.2 . SUMMARY

The reactions of 2,4 -dinitroflorobenzene (DiJFB) with phenoxide and thiophenoxide ions are accelerated by the addition of $\mathrm{N}$-hexadecyl-iv, $\mathrm{N}, \mathrm{N}$-trimethylammonium bromide (CTAB) by factors of 230 and 1100, respectively. The effect of CTAB on the reaction of DNFB with thiophenoxide ion was analyzed quantitatively (Quina \& Chaimovich, J. Phys. Chem., 83, 1844, 1979) demonstrating that the rate enhancement can not be attributed, exclusively, to substrate concentration in the micellar phase. The thiolysis of p-nitrophenylacetate by thiophenoxides is accelerated (50 fold) by the addition of CTAB. The quantitative analysis of the effect of CTAB on thiolysis demonstrated that the reactivity of thiophenoxides in the aqueous and micellar phases is comparable and that the rate enhancement can be explained entirely on the basis of concentration of the substrates in the micellar phase. The effect of detergents on the intramolecular ( $S$ to $N$ ) acyl transfer was studied using $s$-acetyl- $\beta$-mercaptoethylanine (AMA) and S-octanoyl-B-mercaptoethylanine (OMA). The addition of CTAB produces a moderate rate enhancement in the rate of acyl transfer in OMA. The addition of sodium dodecyl sulfate (SDS) produces a rate decrease of 100 fold for AiA and 1000 fold in OMA. Nuclear magnetic resonance studies of OMA-SDS complexes were interpreted in terms of inmobilization of the 
methylenic bridge of OMA in the complex (es). The overall effect of detergents in the $\mathrm{s}$ to $\mathrm{N}$ acyl transfer in mercaptoethylanines were explained in terms of variation of the $\mathrm{pK}$ of the terminal ammonium group and anisotropy of the molecular motions of the hydrophobic substrate in the SDS micelle,

The studies of reactivity in micellar solutions were complemented with an investigation of the relationship between the $\mathrm{pH}$ in the aqueous intermicellar phase in the presence of buffer and the ${ }^{-} \mathrm{OH}$ concentration in the micellar phase. The rate of alkaline hydrolysis of $\mathrm{N}$-methyl-4- and $\mathrm{N}$-methyl-2-cyanopyridinium ions is not altered by the addition of CTAB in the presence of borate $(0,02 \mathrm{M})$ buffer pH 9.6 or 9.8. These data, and the complete exclussion of the N-methyl-cyanopiridinium ions from the CTAB micellar phase demonstrates unequivocally, that under these conditions the intermicellar $\mathrm{pH}$ does not vary with increasing CTAB. The rate of alkaline hydrolysis of p-nitrophenyl octanoate, a substrate that is totally incorporated in the micellar phase of СТАВ, diminishes with increasing detergent concentration in the presence of buffer. The hydrolysis of NPA was also studied as a function of $|C T A B|$ in the presence of buffer. The experimental data for the alkaline hydrolysis of esters in the presence of buffered micellar CTAB was analysed quantitatively using the selective ion exchange aproach 
proposed by Quina \& Chaimovich (ref. cit,). Using various spin probes (1) premicellar aggregation, (2) the effect of substrates on micellar structure, (3) the critical micelle concentration of detergents ans (4) redistribution of water insoluble substrates in detergent solutions were analysed in terms of micelle formation mechanism, rate enhancements in micellar solutions and solubilization mechanisms by detergents. 
8. REFERENCIAS

1. Almgren, M., Grieser, F. \& Thomas, J.K. (1979). J. Am. Chem. Soc., $\underset{\sim}{101}, 279$.

2. Annianson, E.A.G., Wall, S.N., Almgren, M. , Hoffman, H., Kielmann, I., Ulbricht, W., Zana, R., Lang, J. \& Ton are, C. (1976). J. Phys. Chem., $\underset{\sim}{80}, 905$.

3. Atherton, N.M. \& Strach, S. (1972). J. Chem. Soc. Faraday II. $\underset{\sim}{68}, 374$.

4. Barnett, R.F. \& Jencks, W.P. (1969). J. Am. Chem. Soc., $\underset{\sim}{9}, 2358$.

5. Behme, M.T.A., Fullington, J.G., Noel, R. \& Cordes, E.H. (1965). J. Am. Chem.Soc., 87, 266.

6. Berezin, J.V., Martinek, K., Yatsimirski, A.K. (1973). Russ. Chem. Revs. (English Transl.) $\underset{\sim}{4 \underset{\sim}{2}, 487 .}$

7. Bohme, H. \& Schran, H. (1949). Chem. Ber., 82, 453.

8. Bonilha, J.B.S., Chaimovich, H., Toscano, V. \& Quina,F.H. (1979). J. Phys. Chem., $\underset{\sim}{83}, 00$.

9. Brière, R., Lemaire, H. e Rassat, A. (1965). Bull. Soc. Chim. Fr., 3273.

10. Brotherus, J. \& Tormala, P. (1973). Kolloid Z.Z. Polym., $2 \underset{\sim}{2}, 774$. 
11. Bruice, T.C., Katzhendler, J. \& Fedor, L.R. (1968).

J. Am. Chem. Soc., $\underset{\sim}{90}, 1333$.

12. Buist, G.J., Bunton, C.A., Robinson, L., Sepúlveda, L. \& Stam, M. (1970). J. Am. Chem. Soc., 92, 4072.

13. Bunnett, J.F. (1958). Quart. Rev. (London), 12, 1.

14. Bunnett, J.F. \& Merrit, W.D. (1957). J. Am. Chem. Soc., 78, 5967 .

15. Bunton, C.A. (1973). Progr. Solid state Chem., 8, 239.

16. Bunton, C.A. (1976), in "Applications of Biomedical Systems in Chemistry". Part II. J.B. Jones. Ed. J. Wiley \& Sons. New York, N.Y.

17. Bunton, C.A., Carrasco, N., Huang, S.K., Paik, C.H. \& Romsted, L.S. (1978). J. Am. Chern. Soc., 100, 5420.

18. Bunton, C.A., Fendler, E.J., Sepúlveda, L. \& Yang, K.U. $(1967)$. J. Am. Chem. Soc., 89, 1221.

19. Bunton, C.A., Kamego, A. \& Minch, M. (1972). J. Org. Chem. , $\underset{\sim}{2}, 1388$.

20. Bunton, C.A., Minch, M.J., Hidalgo, J. \& Sepúlveda, L. (1973). J. Am. Chem. Soc., 9 $\underset{\sim}{5}, 3262$.

21. Bunton, C.A. \& Minch, M.J. (1974). J. Phys. Chem., 78, 1490.

22. Bunton, C.A., Rivera, F. \& Sepúlveda, L. (1978). J. org. Chem., 43, 1166. 
23. Bunton, C.A. \& Robinson, L. (1968). J. Am. Chem. Soc., 90,5972 .

24. Bunton, C.A. \& Robinson, L. (1969). J. Org. Chem., 34, 780 .

25. Bunton, C.A. \& Robinson, I. (1970). J. Am. Chem. Soc., $92,356$.

26. Bunton, C.A. \& Robinson, L. (1970). J. Phys. Chem., $7 \underset{\sim}{\text {, }}$ 1062 .

27. Bunton, C.A., Robinson, L. \& Sepúlveda, I. (1969). J. Am. Chem. Soc., $\underset{\sim}{91}, 4813$.

28. Bunton, C.A., Romsted, L.S. \& Savelli, G. (1979). J.Am. Chem. Soc., 101, 1253.

29. Bunton, C.A. \& Wolfe,B. (1973). J.Am. Chem. Soc., 95, 3742 .

30. Bunton, C.A. \& wolfe, B. (1974). J. Am. Chem, Soc., 96 67747.

31. Byers, L.D. (1977). J. Am. Chem. Soc., 99 9, 4146.

32. Cannon, B., Polnaszek, C.F., Butler, K.W., Eriksson, L.E.G. \& Smith, I.C.P. (1975). Arch. Biochem. Biophys., 167,505 .

33. Chaimovich G., H. (1979) Tese de Doutoramento, Institu to de Química, USP. 
34. Chaimovich, H., Blanco, A., Chayet, L., Costa, L.M., Monteiro, P.M., Bunton, C.A. e Paik, C. (1975). Te trahedron, $\underset{\sim}{3} \underset{\sim}{1}, 1139$.

35. Chaimovich, H., Politi, M.J., Bonilha, J.B.S. \& Quina, F.H. (1979). J. Phys. Chem., 83, 1851.

36. Chevion, M., Katzhendler, J. \& Sarel, S. (1972). Israel J. Chem. , $\underset{\sim}{10}, 975$.

37. Chuchani, G. \& Frohlich, A.J. (1971). J. Chem. Soc., 13,1417 .

38. Connors, K.A. \& Bender, M.L. (1961). J. Org. Chem., 26, 2498.

39. Cordes, E.H. ed (1973). "Reaction Kinetics in Micelles" Plenum Press, New York.

40. Cordes, E.H. (1978). Pure. Appl. Chem., 50, 617 .

41. Cordes, E.H. \& Dunlap, R.B. (1969). Acts. Chem. Res., 2,329 .

42. Cordes, E.H. \& Gitler, C. (1973). Progr. Bioorg. Chem., 2,1 .

43. Corkill, J.M., Goodman, J.F.\& Walker, T. (1967). Trans. Faraday Soc., $\underset{\sim}{63}, 768$.

44. Cuccovia, I.M., Schroter, E.H., Baptista, R.C. \& Chaimo vich, H. (1977). J. Org. Chem., $\underset{\sim}{42}, 3400$. 
45. Cuccovia, I.M., Schroter, E.H., Monteiro, P.M. \& Chaimo vich, H. (1978). J. Org. Chem., $\underset{\sim}{4} \underset{\sim}{2}, 2248$.

46. Danehy, P. \& Noel, C.J. (1960). J. Am. Chem. Soc., 82, 2511 .

47. Danielsson, I. \& Stenius, P. (1971). J. Colloid. Interf. Sci., 37,264 .

48. Demas, J.N. \& Addington, J.(1976). J. Am. Chem. Soc., 98,5800 .

49. Dorrance, R.C. \& Hunter, T.F. (1972). J. Chem. Soc. Faraday I. $\underset{\sim}{68}, 1312$.

50. Dorrance, R.C. \& Hunter, T.F. (1974). J. Chem. Soc. Fa raday $I, \underset{\sim}{70}, 1572$.

51. Eagland, D. \& Franks, F. (1965). Trans. Faraday Soc., $\underset{\sim}{6} \underset{\sim}{\sim}, 2468$.

52. Edward, J.T. (1970). J. Chem. Educ., $\underset{\sim}{47}, 261$.

53. Ei.cke, H., Sheperd, J.C.W. \& Steineman, A, (1976). J. Coll. Interf. Sci., $\underset{\sim}{56}, 168$.

54. Ellman,G.L. (1959). Arch. Biochem. Biophys, , 82, 70 .

55. Elworthy, P.H., Florence, A.T. \& Mac Farlane, C.B. (1968). "Solubilization by Surface Active Agents and Its Applications in Chemistry and the Biological Sciences". Chapman and Hall, London. 
56. Ernandes, J.R., Chaimovich, H. \& Schreier, S. (1977). Chem. Phys. Lipids $\underset{\sim}{18}, 304$.

57. Ernandes, J.R., Schreier, S. \& Chaimovich, H. (1976). Chem. Phys, Lipids, $\underset{\sim}{16}, 19$.

58. Eriksson, J.C. \& Gillberg, G. (1966). Acta Chem. Scand., 20,2019 .

59. Fendler, J.H. \& Fendler, E.J. (1975). "Catalysis in Micellar and Macromolecular systems". Academic Press, New York.

60. Fendler, E.J., Fendler, J.H. \& Liechti, R.R. (1970). J. Org. Chem., $\underset{\sim}{3} \underset{\sim}{5}, 1658$.

61. Fendler, J.H. \& Patterson, L.K. (1971). J. Phys. Chem., 75. 3907 .

62. Fontell, K. (1971). Kolloid Z.Z. Polym., $\underset{\sim}{24} \underset{\sim}{4}, 253$.

63. Fontell, K. (1971). Kolloid Z.Z. Polym., 24 4 , 246.

64. Foye, W.O., Duvall, R.N. \& Mickles, J. (1962). J. Pharm. Sci., $\underset{\sim}{51}, 168$.

65. Fox, K.K. (1971). Trans. Faraday Soc., $\underset{\sim}{\text { 7 }, ~} 2802$.

66. Freed, J.H. (1972). Ann. Rev. Phys. Chem., 23, 265.

67. Freed, J.H., Bruno, G.V. \& Polnaszek,C.F. (1971). J. Phys. Chem., 7 $\underset{\sim}{6}, 3385$. 
68. Freed, J.H. \& Fraenkel, G.K. (1963). J. Chem. Phys., $39,326$.

69. Friedman, M. (1973). "The Chemistry and Biochemistry of the Sulfhydryl Group in Aminoacids, Peptides and Proteins". Perganon Press, New York, N.Y. Cap. 12.

70. Funasaki, N. (1978). J. Coll. Interf. Sci., 64, 641.

71. Funasaki, N. (1979). J. Phys. Chem., 83, 237.

72. Gitler, C. \& Ochoa-Solano, A. (1968). J. Am. Chem. Soc., 90, 5004 .

73. Goldman, S.A., Bruno, G.V. \& Freed, J.H. (1973). J.Chem. Phys., $\underset{\sim}{59}, 3071$.

74. Goldman, S.A., Bruno, G.V., Polnaszek, C.F. \& Freed,J.H. $(1972)$. J. Chem. Phys., $\underset{\sim}{56}, 716$.

75. Gustavsson, H. \& Lindman, B. (1975). J. Am. Chem, Soc., 97. 3923 .

76. Hauser, M. \& Klein, U. (1972). Z, Phys, Chem, Neue Folges, $\underset{\sim}{78}, 32$.

77. Heitman, P. (1978). European J. Biochem. 5, 305.

78. Herries, D. G., Bishop. W. \& Richards, F.M. (1964). J. Phys. Chem., $\underset{\sim}{6} \underset{\sim}{8} 1842$.

79. Hiskey, C.F. \& Downey, T.A. (1954). J. Phys. Chem., $\underset{\sim}{5}$, 835 . 
80. Hupe, D.J. \& Jencks, W.P. (1977). J. Am. Chem. Soc., $\underline{9}, 451$.

81. Husain, S.S. \& Lowe, G. (1970)-Biochem. J., 117, 341.

82. Hutchinson, E., Inaba, A. \& Bailey, L.G. (I955). Z. Phys. Chem. (Frankfurt), 5, 344.

83. Hyde, A.J. \& Stevenson, D.M. (1969). Kolloid Z.z. Polym., 232,797 .

84. Infelta, P.P., Gratzel, M. \& Thomas, J.K. (1974). J.Phys. Chem., 78, 190 .

85. Jencks, W.P. (1969). "Catalysis in Chemistry and Enzymology". Me Graw $\rightarrow$ Hill Inc.

86. Jencks, W.P. (1975). Adv. in Enzymol., 43 $3,219$.

87. Jocelyn, P.C. (1972). "Biochemistry of the SH Group", Academic Press, New York, N.Y. Cap, 6 .

88. Kalyanasundaram, K., Gratzel, M. \& Thomas, J.K, (1975). J. Am. Chem. Soc., 97, 3915.

89. Kivelson, D. (1960). J, Chem. Phys, , 30, 1094.

90. Kolthoff, I.H. (1959). "Treatise on Analytical Chemistry". Interscience Encyclopedia, Inc. New York, N.Y.

91. Kosower, E.M. \& Patton, J.W. (1966). Tetrahedron, 22 2 , 2081 . 
92. Kreevoy, M.M., Harper, E.T., Duvall, R.E., Wilgus, H.S. \& Ditsch, L.T. (1960). J. Am. Chem. Soc., 8무 4899.

93. Lang, J., Tondre, C., Zana, R., Bauer, R., Hoffman, H. \& Ulbricht, W. (1975). J. Phys. Chem., 79 9276.

94. Lapinte, C. \& Viout, P. (1972). Tetrahedron Lett., 4221.

95. Larsen, J.W., Magid, L.J. \& Payton, V. (1973). Tetrahedron Lett., 2663.

96. Larsen, J.W. \& Tepley, L.B. (1976). J. Org. Chem., 4I, 2968.

97. Lewis, S.D., Johnson, F.A. \& Shafer, J.A. (1976). Biochemistry, $\underset{\sim}{2}, 5009$.

98. Lindblom, G., Lindman, B. \& Mandell, L. (1973). J. Coll. Interf. Sci., $\underset{\sim}{42}, 400$.

99. Lindman, B. \& Brun, B. (1973). J. Coll. Interf. Sci., $\underline{42}, 388$.

100. Lindman, B., Kamenka, N. \& Brun, B. (1974). C.R. Acad. Sci. Ser. C., 278, 393.

101. Martin, R.B. \& Hedrick, R.I. (1962). J. Am. Chem, Soc., $84,106$.

102. Martin, R.B., Hedrick, R.I. \& Parcell, A. (1964). J. Org. Chem. , $\underset{\sim}{29}, 3197$.

103. Martin, R.B., Lowey, S., Elson, E.L. \& Edsall, J.T. (1959). J. Am. Chem. Soc., $\underset{\sim}{\text { I }}, 5089$. 
104. Martin, R.B. \& Parcell, A. (1961). J. Am. Chem. Soc., 83,4830 .

105. Martinek, K., Osipov, A.P., Yatsimirski, A.K. \& Berezin, I.V. (1975). Tetrahedron, 31, 709 .

106. Menger, F.M., Donohue, J.A. \& Williams, J.R. (1973). J. Am. Chem. Soc., $925,286$.

107. Menger, F.M. \& Lynn, J.L. (1975). J. Am. Chem. Soc., 97,948 .

108. Metrione, R.M., Johnston, R.B. \& Seng, R. (1967). Arch. Biochem. Biophys., $\underset{\sim}{2} \underset{\sim}{2}, 137$.

109. Meyer, G. (1972). Tetrahedron Lett. 4581.

110. Miller, J. (1968). "Aromatic Nucleophilic Substitution". Elsevier, New York.

111. Mittal, K.L. ed. (1977). "Micellization, Solubilization and Microemulsions". Vol. 1 \& 2. Plenum, Press, New York.

112. Moss, R.A., Lee, Y-S \& Lukas, T.J. (1979). J. Am. Chem. SOC., $\underset{\sim}{101}, 2499$.

113. Mukerjee, P., Mysels, K.J. \& Dulin, C.I. (1958). J. Phys. Chem. , 62, 1390 .

114. Nakagawa, T. \& Jizimoto, H. (1972). Kolloid Z.z. Polym, 250,594 . 
115. Niehaus, W.G. (1974). Bioorg. Chem., 3, 302 ,

116. Noda, L.H., Kuby, S.A. \& Lardy, H.A. (1953). J. Am. Chem. Soc., $\underset{\sim}{7}, 913$.

117. Oakes, J. (1971). Nature (London) $\underset{\sim}{23} \underset{\sim}{2}, 38$.

118. Ohnishi, S., Cyr, T.J.R. \& Fukushima, H. (1970) . Bull. Chem. Soc. Jpn., $43,673$.

119. Parfitt, G.D. \& Wood, A. (1969). Kolloid Z.Z. Polym., 229,55 ,

120. Pascal, I. \& Tarbell, D.S. (1957). J. Am. Chem. Soc., $\underset{\sim}{79}, 6015$.

121. Politi. M., Cuccovia, I.M., Chaimovich, H., Almeida, M. L.C., Bonilha, J.B.S. \& Quina, F.H. (1978). Tetrahedron Lett., 115.

122. Polnaszek, C.F. (1978). Quart. Rev. Biophys. submetido

123. Polnaszek, C.F. \& Freed, J.H. (1975). J. Phys. Chem., 79,2283 .

124. Quina, F.H. (1977). Tese de Livre Docência, Instituto de Quimica, Universidade de são Paulo.

125. Quina, F.H. \& Chaimovich, H, (1979). J. Phys, Chem, , 83,1844 .

126. Quina, F.H., Politi, M.J., Cuccovia, I.M., Baumgarten, E., Martins-Francheti, S. \& Chaimovich, H. (1979). submetido à publicação. 
127. Romsted, L.R. (1975). PhD Thesis.Dept. Chem. Indiana University. Bloomington Indiana.

128. Romsted, L.R. \& Cordes, E.H. (1968). J. Am. Chem. Soc.,

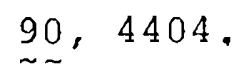

129. Ross, S.D. (1963). Progr. Phys. Org. Chem., 1, 31.

130. Schales, O. \& Schales, S.S. (1941). J. Biol. Chem., 140,879 .

131. Schreier, S., Ernandes, J.R., Cuccovia, I. \& Chaimovich, H. (1978). J. Mag. Resn., 30, 283.

132. Schreier-Muccillo, S., Marsh, D. \& Smith, I.C.P. (1976) Arch. Biochem. Biophys., 172, 1.

133. Seelig, J. (1970). J. Am. Chem. Soc, , 92 2, 3881

134. Shinitzky, M. Dianoux, A.C., Gitler, C. \& Weber, G. (1971). Biochemistry, 10, 2106.

135. Shinkai, S. \& Kunitake, T, (1976). Bul1. Chem. Soc. Jpn. , $\underset{\sim}{4}, 3219$.

136. Smith, D.H. (1979). J. Coll, Interf, Sci,, 68, 70.

137.Sparlin, S., Hinze, W. \& Armstrong, D.W. (1977). Analytical Lett., $\underset{\sim}{10}, 997$.

138. Stockton, G.W., Polnaszek, C.F., Tulloch, A.P., Hasan, F. \& Smith, I.C.P. (1976). Biochemistry, 125, 954. 
139. Sukenik, C.N., Weissman, B-A. \& Berman, R.G. (1975). J. Am. Chem. Soc., $\underset{\sim}{97}, 445$.

140. Tachiya, M. (1975). Chem. Phys. Lett., $\underset{\sim}{3}, 289$.

141. Tagaki, W., Amada, T., Yamashita, J. \& Yano, J. (1972). Chem. Comm. 1131.

142. Takahashi, H., Nakayama, Y., Hori, H., Kihara, K., Okabayashi, H. \& Okuyama, M. (1976). J. Coll. Interf. Sci., $\underset{\sim}{54}, 102$.

143. Tanford, C. (1974). J. Phys. Chem., 78, 2469.

144. Tong, L.K.J. \& Glesman, M.C. (1957). J. Am. Chem, Soc., 79, 4305 .

145. Waggoner, A.S., Griffith, O.H. \& Christensen, C.R.(1967). Proc. Nat. Acad. Sci. USA, $\underset{\sim}{57}, 1198$.

146. Waggoner, A.S., Kieth, A.D., \& Griffith, O.H. (1968). J. Phys. Chem., 72, 4129.

147. Wieland, T. \& Bokelman, F. (1952). Ann. Chem, , 576 20.

148. Wieland, T. \& Horning, H. (1956). Ann. Chem., $\underset{\sim}{600} \underset{\sim}{ }, 12$.

149. Williams, E., Sears, B., Allerhand, A. \& Cordes, E.H. (1973). J. Am. Chem. Soc., 925, 4871.

150. Williams, R.J., Philips, J.N. \& Mysels, K.J. (1955). Trans. Faraday Soc., $\underset{\sim}{51}, 728$. 
151. Yatsimirski, A.K., Martinek, K. \& Berezin, I.V. (1971). Tetrahedron, 27, 2855.

152. Yatsimirski, A.P., Osipov, A.P., Martinek, K. \& Berezin, I.V. (1975). Kolloid Zhurn (Russ) $\underset{\sim}{37}, 526$. 